Portland State University

PDXScholar

4-30-2021

\title{
Exploring the Relationships Between Community Experiences and Well-Being among Youth Experiencing Homelessness
}

Katricia Stewart

Portland State University

Follow this and additional works at: https://pdxscholar.library.pdx.edu/open_access_etds

Part of the Psychology Commons

Let us know how access to this document benefits you.

Recommended Citation

Stewart, Katricia, "Exploring the Relationships Between Community Experiences and Well-Being among Youth Experiencing Homelessness" (2021). Dissertations and Theses. Paper 5689.

https://doi.org/10.15760/etd.7562

This Dissertation is brought to you for free and open access. It has been accepted for inclusion in Dissertations and Theses by an authorized administrator of PDXScholar. Please contact us if we can make this document more accessible: pdxscholar@pdx.edu. 
Exploring the Relationships Between Community Experiences and Well-Being among Youth Experiencing Homelessness

by

Katricia Stewart

A dissertation submitted in partial fulfillment of the requirements for the degree of

Doctor of Philosophy

in

Applied Psychology

\begin{abstract}
Dissertation Committee:
Greg Townley, Chair

Eric Mankowski

Karlyn Adams-Wiggins

Maura Kelly
\end{abstract}

Portland State University

2021 
C 2021 Katricia Stewart 


\begin{abstract}
The current dissertation presents two published empirical studies and one new study informed by the findings and recommendations of the first two. The first study investigated how intrapersonal factors (self-esteem, psychological distress, and optimism) and social-contextual factors (social support, sense of community, and empowerment) relate to the psychological well-being of 100 youth experiencing homelessness. The results indicated that all six variables were significantly related to well-being, but the intrapersonal factors had a stronger association with psychological well-being than the social-contextual factors. The second manuscript is a qualitative study investigating what community means to youth experiencing homelessness, what communities they are a part of, and how these communities contribute to their well-being. This study found that 1) youth generally define community in ways that align with current theory on sense of community, 2) youth view community as important, and 3) their experiences within community settings promote their overall well-being in a variety of ways. However, the findings also suggest that community is not always a positive experience for these youth. The third manuscript is a qualitative study undertaking a more detailed and contextualized exploration of community supports and well-being among youth experiencing homelessness. This study centered the perspectives and lived experiences of youth and engaged them in reflection on how their community supports and well-being might impact their short- and long-term goals. Further, this study explored how the COVID-19 pandemic has impacted well-being and community supports among youth.
\end{abstract}


Findings from the final study have the potential to inform future research aimed at supporting the well-being and needs of youth experiencing homelessness. 


\section{Acknowledgements}

This dissertation research could not have been possible without the numerous mentors, teachers, collaborators, participants, and loved ones who supported both the work itself and me as a student, scholar, researcher, and human.

First, I would like to thank Dr. Greg Townley, who served as my dissertation committee chair, graduate school mentor, and friend. Your continual guidance, feedback, collaboration, and support equated to the best mentorship I have thus far witnessed or experienced. I could not have successfully progressed through graduate school or conducted the research in this dissertation without your support.

I would also like to acknowledge my dissertation committee: Dr. Eric Mankowski, Dr. Karlyn Adams-Wiggins, and Dr. Maura Kelly. Your guidance has proven invaluable to both my education and this research, and I am deeply grateful for the perspectives and expertise you have brought to the table. Thank you for serving on my dissertation committee.

I am further deeply grateful to p:ear for their collaboration and support of this research, and for their ongoing efforts to support and empower the youth in our community. Thank you to all of the youth at p:ear who chose to participate in this research. I hope that your contributions will make a positive difference in the lives of future youth.

To my friends, family, loved ones, and family-of-choice: thank you for believing in me and encouraging me to follow my heart and my intuition. Thank you for your patience and understanding as I navigated this chapter of life, and thank you for always 
supporting my dreams. All of our intersecting paths, conversations, and collaborations led me here, and I am eternally grateful for the beautiful ways all of you inspire me to do this work. I would not be here without you. 
Table of Contents

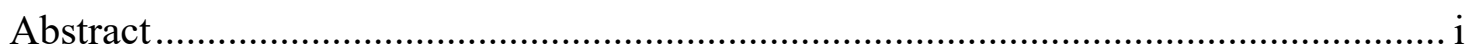

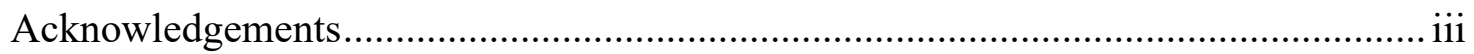

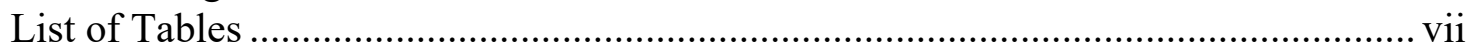

List of Figures ............................................................................................ vii

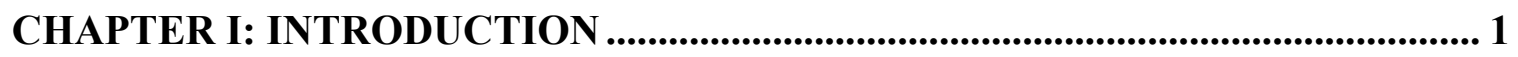

Youth Homelessness ................................................................................... 1

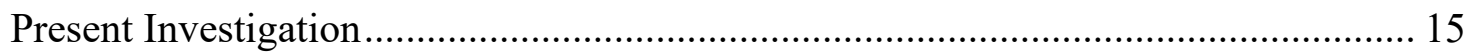

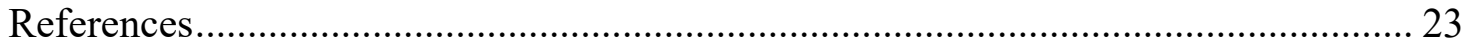

CHAPTER II: INTRAPERSONAL AND SOCIAL-CONTEXTUAL FACTORS RELATED TO PSYCHOLOGICAL WELL-BEING AMONG YOUTH EXPERIENCING HOMELESSNESS ...................................................................... 37

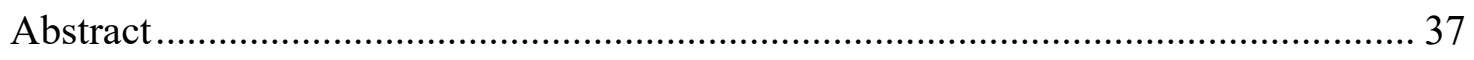

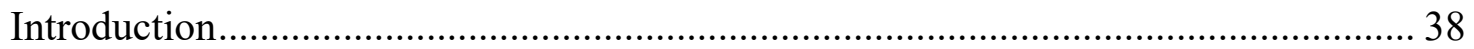

Study Purpose, Research Questions, and Hypotheses .............................................. 45

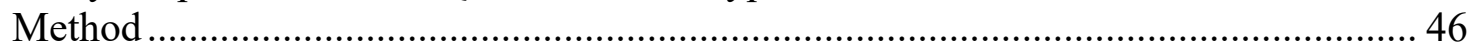

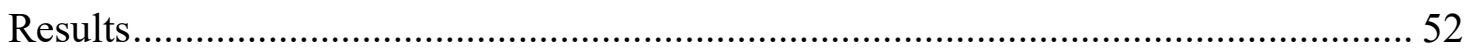

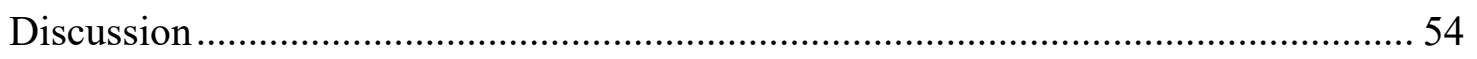

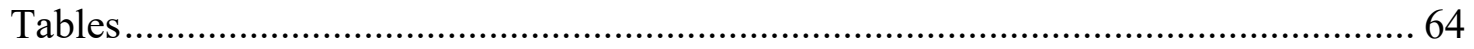

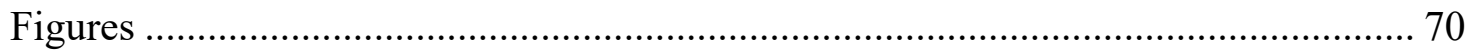

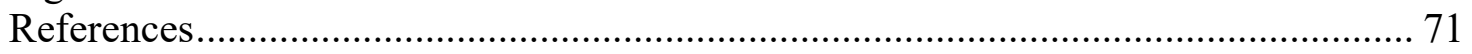

CHAPTER III: COMMUNITY AND WELL-BEING: A QUALITATIVE STUDY OF HOW YOUTH EXPERIENCING HOMELESSNESS DEFINE COMMUNITY AND ITS RELATIONS TO THEIR WELL-BEING ............................................. 87

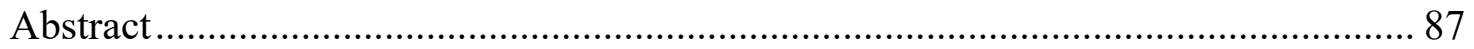

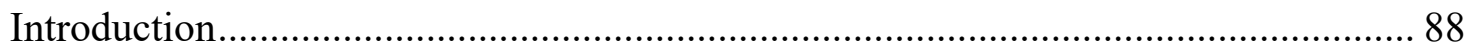

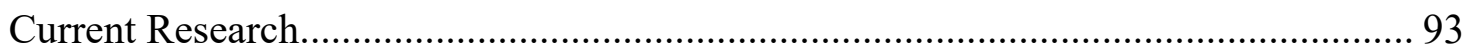

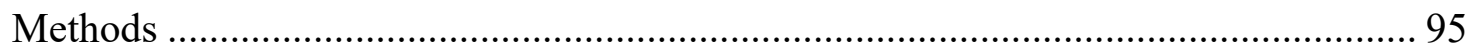

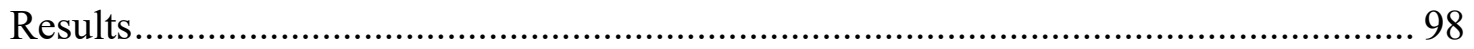

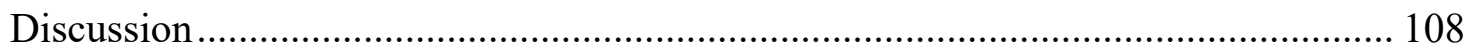

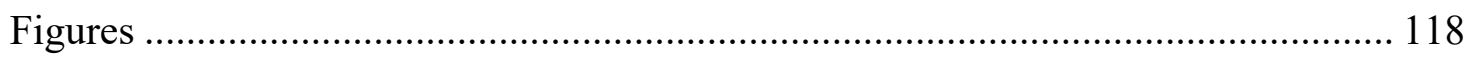

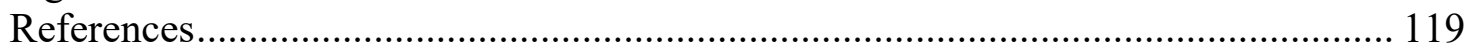

CHAPTER IV: A QUALITATIVE EXPLORATION OF COMMUNITY

SUPPORTS, WELL-BEING, GOALS, AND THE COVID-19 PANDEMIC

AMONG YOUTH EXPERIENCING HOMELESSNESS. .................................. 126

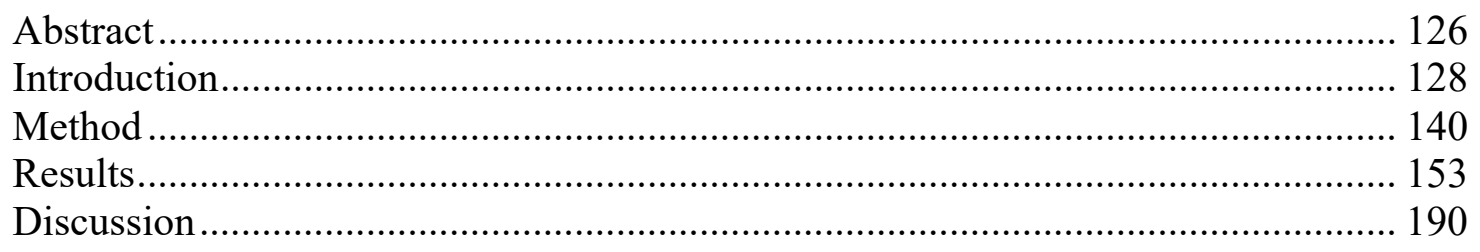


Supplemental Material for Chapter IV: Semi-Structured Interview Questions..... 215

References..

CHAPTER V: CONCLUSION................................................................................ 226

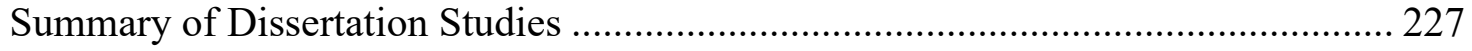

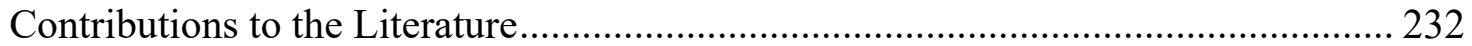

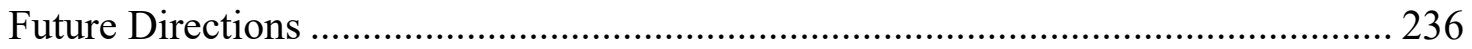

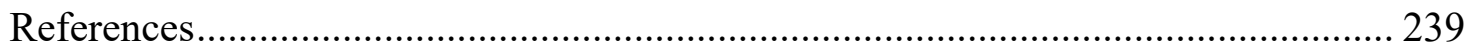




\section{List of Tables}

Chapter 2 Tables

Table 1. Demographic Percentages. .64

Table 2. Correlation Matrix of Variables.

Table 3. Linear Regression of Intrapersonal Variables Predicting

Psychological Well-Being. .66

Table 4. Linear Regression of Social-Contextual Variables Predicting

Psychological Well-Being....

Table 5. Hierarchical Linear Regression of Intrapersonal and Social-Contextual

Variables Predicting Psychological Well-Being ................................................68

Table 6. Thematic Categories for the Open-Ended Well-being Question ..........................69

Chapter 4 Tables

Table 1. How youth defined well-being..... 155

Table 2. How community experiences \& social support impact well-being.....................164

Table 3. Impact of community supports on goals.......................................................175

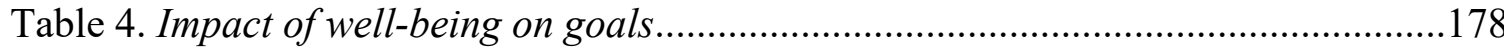

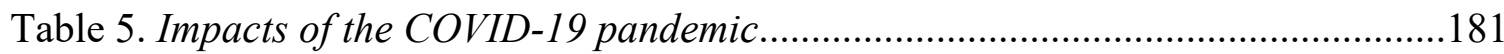


WELL-BEING AMONG YOUTH EXPERIENCING HOMELESSNESS

List of Figures

Chapter 2 Figures

Figure 1. Hypothesized associations between psychological well-being and intrapersonal and social-contextual factors..................................................70

Chapter 3 Figures

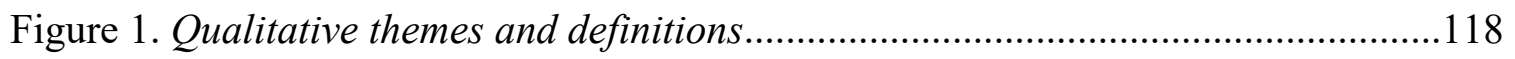




\section{Chapter I: Introduction}

\section{Youth Homelessness}

Youth experiencing homelessness are unaccompanied adolescents and young adults ages 12 to 24 who do not have stable residences, but instead live on the street, in shelters, in abandoned homes, or in other precarious living situations (Kidd \& Davidson, 2009). Every year in the United States, roughly 700,000 adolescents and 3.5 million young adults experience homelessness (Morton, Dworsky, and Samuels, 2017; Morton et al., 2018; Samuels et al., 2019). This equates to at least 1 in 30 adolescent minors (ages 13-17), and 1 in 10 young adults (ages 18-25) experiencing some form of homelessness. These numbers reflect what is primarily reported as "explicit" homelessness (i.e., living on the streets or in shelters), but can also include unstable living situations such as being doubled up (e.g., too many occupants for the dwelling) or staying with friends (Morton, Dworsky, and Samuels, 2017; Morton, Samuels, Dworsky, and Patel, 2018; Samuels, Cerven, Curry, Robinson, and Patel, 2019). For the purposes of the current research, the term "youth" refers to those under the age of 25 (both adolescents and young adults) experiencing homelessness, as this is the term most commonly used by researchers, service providers, and advocacy groups to describe this age group of individuals experiencing homelessness (Kidd \& Davidson, 2009).

Youth who face societal disadvantages and hold marginalized identities experience disproportionately high rates of homelessness. In particular, Native American, Alaskan Native, Black, and Latinx youth, as well as LGBTQ youth, are far more likely to experience homelessness than White youth and/or those who identify as cisgender and 
heterosexual. For example, African American youth have an $83 \%$ increased risk of homelessness as compared to youth of other races, even when controlling for factors such as income and education, while Hispanic youth have a 33\% higher risk homelessness than other ethnic groups (Morton, Dworsky, \& Samuels, 2017). Further, some research suggests that LGBTQ youth have a $120 \%$ increased risk of homelessness as compared to heterosexual and cisgender youth (Morton, Dworsky, \& Samuels, 2017). Other studies have found that LGBTQ youth are 4 to $13 \%$ more likely to experience homelessness than heterosexual youth, and some surveys have reported that as high as $40 \%$ of service-using youth identify as LGBTQ (Durso \& Gates, 2012). However, it is important to note that many of these statistics only include point-in-time reports of explicit homelessness and that homelessness is likely under reported among youth (Morton, Dworsky, \& Samuels, 2017), and thus the actual risks and likelihood of homelessness among certain populations may be much higher.

Related to the above at-risk groups, young people who do not have a high school diploma and those with histories of child welfare and/or juvenile or criminal justice systems involvement are at a much greater risk of experiencing homelessness (Morton, Dworsky, \& Samuels, 2017; Morton et al., 2018; Samuels et al., 2019). Notably, racial and ethnic minorities are also disproportionately represented within the child welfare and criminal justice systems (e.g., Rosich, 2007; Wildeman \& Emanuel, 2014).

\section{Causes of Youth Homelessness}

The most common reason that youth cite as the cause of their homelessness is familial breakdown or instability (Hyde, 2005; Mallet, Rosenthal, \& Keyes, 2005; Reeg, 
2003; Samuels et al., 2019; Zufferey, 2017). Familial breakdown can include the behaviors of parents, economic problems, and residential instability (Reeg, 2003; van Wormer, 2003).

One way in which familial breakdown can lead to youth homelessness is through early familial homelessness and involvement with foster care. Recent research indicates that homeless youth's housing instability often begins much earlier than their first experience of unaccompanied homelessness, and that youth link earlier familial homelessness and entrance into foster care as the beginning of their homelessness trajectory (Samuels et al., 2019). Familial homeless and instability—often due to economic hardships (National Coalition for the Homeless, 2009; U.S. Conference of Mayors, 2012) — can lead to youth entering foster care (e.g., Samuels et al., 2019); and youth who then "age out" of foster care are at increased risk of homelessness (Hyde, 2005; Fowler, Toro \& Miles, 2009; Samuels et al., 2019; Tyler \& Melander, 2010). Some research suggests that aging out of foster care was a direct cause of homelessness for $23 \%$ of youth, and for another $24 \%$ of youth the initial experience of being removed from their homes of origin was a critical factor in their current experience of homelessness (Samuels et al., 2019).

While familial breakdown may contribute to youth homelessness through experiences of familial homelessness and/or foster care, other components of familial breakdown are also large contributors to youth homelessness. For many youth, familial breakdown revolves around conflict within the family, including unsafe or volatile home environments that eventually lead to youth being rejected or kicked out by their families 
or choosing to leave for their own safety and/or well-being (Samuels et al., 2019). While this type of familial breakdown can lead to homelessness via engagement with foster care, conflict and unsafe home environments can also be a direct pathway into youth homelessness (Coates \& McKenzie-Mohr, 2010; Reeg, 2003; Samuels et al., 2019; van Wormer, 2003).

For example, familial breakdown is commonly tied to high rates of trauma and abuse prior to youth's experience of homelessness, which often leads to youth choosing to leave home in order to escape these dangerous environments (Coates \& McKenzieMohr, 2010; Ferguson, 2009; Haber \& Toro, 2009; Reeg, 2003; Tyler, Cauce \& Whitbeck, 2004; US DHHS, 2009; Zerger, Strehlow \& Gundlapalli, 2008). This is reflected in youth's reports of adverse childhood experiences (ACEs): in some samples of youth experiencing homelessness, most of the youth reported experiencing one or more ACEs prior to homelessness, and nearly half report four or more ACEs prior to homelessness (Kozloff et al., 2016). These findings provide evidence that childhood victimization is predictive of young adult homelessness (van den Bree et al., 2009). Among LGBTQ youth, the familial breakdown and conflict they face makes them particularly vulnerable to experiencing homelessness (Fowler, Toro \& Miles, 2009; Ray, 2006). Their narratives chronicle abuse and being forced to leave home after revealing their sexual orientation and/or gender identity to their families (Kidd \& Kral, 2002). This research suggests that the abuse and trauma that can accompany familial breakdown among youth is likely a major precursor to their subsequent homelessness. 
While youth often experience trauma and abuse prior to homelessness, some research has pointed to a bidirectional relationship between trauma and/or abuse and youth homelessness: youth may leave home to avoid abuse, but unfortunately may encounter further abuse and trauma while homeless (Coates \& McKenzie-Mohr, 2010). The violence and trauma that youth can experience while homeless puts them at a greater risk of psychological consequences than their housed counterparts, such as higher rates of anxiety and depressive symptoms, anger, and irritability (Coates \& McKenzie-Mohr, 2010). Combined with unstable or dangerous living situations, limited emotional and financial resources, engagement in substance abuse and high-risk activity, and irregular sleeping and eating patterns, these factors contribute to poorer physical and mental health among homeless youth as compared to housed youth (Johnson et al., 1996; Robertson \& Toro, 1999; Salomonsen-Sautel et al., 2008; Wrate \& McLoughlin, 1997).

\section{Implications of Homelessness in Youth}

Once homeless, youth face many barriers to transitioning back into housing, such as financial barriers to accessing healthcare (Christiani, Hudson, Nyamathi, Mutere, \& Sweat, 2008) and difficulties accessing free or affordable housing and education (National Health Care for the Homeless Council, 2008). Homelessness among youth can also lead to long-term financial instability (Cauce et al., 2000; Ferguson et al., 2010; National Health Care for the Homeless Council, 2008; US Census Bureau, 2009) that may put youth at risk of other consequences, such as adult homelessness (Johnson \& Chamberlain, 2008). 
A variety of challenges that youth may face while they are homeless can also contribute to impaired cognitive and academic functioning among this population (e.g., National Health Care for the Homeless Council, 2004; Parks, Stevens, \& Spence, 2007; Rafferty, Shinn, \& Weitzman, 2004). These factors can exacerbate youth's barriers to affordable education, employment, and housing. For example, the multitude of stressful events experienced by homeless youth are associated with learning difficulties (Bryk, Sebrig, Allensworth, Luppesca, \& Easton, 2010), and thus with lower levels of academic achievement. Other factors related to homelessness such as high rates of missed school days and frequently transferring between schools (Buckner, Bassuk, \& Weinreb, 2001) can also contribute to low academic achievement. Low levels of academic achievement can, in turn, make it more difficult for youth to obtain employment, access housing, and transition out of homelessness (Buckner, Bassuk, \& Weinreb, 2001; Obradovic et al., 2009; Rafferty, Shinn, \& Weitzman, 2004).

Furthermore, adolescence and young adulthood are a sensitive time period for socioemotional development (e.g., Dumontheil, 2016; Fuhrmann, Knoll, \& Blakemore, 2015). In the context of homelessness, instability, and exposure to related trauma, this developmental stage can become a vulnerability that puts youth at risk of long-term consequences to their mental and emotional development (Gaetz et al., 2013; Johnson \& Chamberlain, 2008).

Indeed, a recent review of the literature found that youth experiencing homelessness typically have worse mental and physical health outcomes than their housed counterparts (Eddin et al., 2012); and the detrimental physical and mental health 
effects of homelessness have been consistently noted in research literature over the last four decades (American Psychiatric Association, 1987; Busen \& Engebretson, 2008; Cochran et al., 2002; Desai et al., 2003; Kamienicki, 2001; O’Connell, 2004; Parks, Stevens, \& Spence, 2007; Robertson \& Toro, 1999; Salomonsen-Sautel et al., 2008; Slesnick \& Prestopnik, 2005; Yu et al., 2008). While it can be difficult to determine whether the mental health status of a person experiencing homelessness is caused by a pre-existing mental disorder, the demands of homelessness, chronic stress, substance abuse, or a combination of these factors (Haldenbury, Berman, \& Forchuk, 2007), a review of the current literature on the health of youth experiencing homelessness (Kulik et al., 2011) suggests a strong argument for the direct mental health consequences of homelessness. These consequences often include post-traumatic stress disorder, elevated rates of depression and psychiatric disorders, mood disorders, and substance use (e.g., Kidd, 2004; Kidd \& Kral, 2002; Rotheram-Borus et al., 2003; Roy, Boudreau, \& Biovin, 2009; Tolomiczenko, Goering, \& Durbin, 2001).

For example, multiple studies have demonstrated that 48 to $98 \%$ of homeless youth meet the criteria for a psychiatric disorder (e.g., Hodgson, Shelton, van den Bree, et al., 2013). Specifically, a recent study by Kozloff and colleagues (2016) delineated the rates of different mental illnesses among homeless youth, including major depressive episodes (51\%); manic or hypomanic episodes (21\%); PTSD (35\%); psychotic disorder (29\%); substance use disorder (74\%); and moderate or higher suicidality (41\%). Furthermore, over $40 \%$ of these youth reported two or more psychiatric hospitalizations within the previous five years (Kozloff et al., 2016). 
All of the above factors, barriers, and consequences can make escaping homelessness particularly difficult for youth. Unfortunately, the longer that youth experience homelessness, the harder it can be to regain housing and stability (Morton, Dworsky, \& Samuels, 2019). Indeed, youth homelessness is the most common pathway into adult homelessness, which points to the difficulty of escaping homelessness as a young person and suggests the importance of early intervention with at-risk youth or those currently experiencing homelessness (Chamberlain \& Johnson, 2013). Although the above risk factors can contribute to a vicious cycle of homelessness and drastically impact the welfare of this population, research has demonstrated characteristics of resilience and certain protective factors among this population that may bolster youth's chances of achieving positive outcomes in the face of adversity.

\section{Well-Being and Associated Factors among Youth Experiencing Homelessness}

Because of the high levels of marginalization, mental health distress, and hardships faced by many youth who experience homelessness, lower levels of well-being might be expected among members of this population. Surprisingly, one of the few studies comparing the well-being of homeless youth to housed youth found that many unhoused youth report their well-being to be similar to that of their housed peers (Taylor et al., 2004). However, previous research with youth experiencing homelessness has been highly varied in how researchers chose to measure well-being - often opting for a combination of measures that may suggest well-being, but that do not directly and holistically capture the construct (Barczyk, Thompson, \& Rew, 2014; Usborne, Lyndon, \& Taylor, 2009). The few studies that have utilized established measures of well-being in 
research with homeless youth have reported varied levels of well-being among this population (Taylor et al., 2004; Townley, Pearson, Lehrwyn, Prophet, \& Trauernicht, 2016).

Due to these inconsistencies, further examination of well-being among this population is warranted. More specifically, further research is needed that more accurately captures how youth understand their own well-being and the factors that support their well-being in their day-to-day lives. The following section will review theories of well-being that are relevant to the current investigation, along with a discussion of two constructs that may be particularly important to the well-being of youth experiencing homelessness.

Well-Being. The empirical literature on well-being is vast, and various theoretical frameworks and definitions of well-being have been proposed over the decades. Current understandings of well-being fall into two primary categories: (a) hedonic, or emotional, well-being, and (b) eudaimonic, or psychological, well-being (Deci \& Ryan, 2008).

Hedonic well-being focuses individuals' subjective appraisals of their lives and is typically concerned with both affective appraisals (the relative presence of positive emotions and absence of negative emotions) as well as cognitive appraisals (the degree to which a person positively views different aspects of their lives) (Deci \& Ryan, 2008; Diener, 1984; Keyes, 2009). Hedonic well-being is primarily focused on individuals' satisfaction with life and subjective levels of happiness (Deci \& Ryan, 2008; Diener, 1984). 
Eudaimonic well-being, alternatively, goes beyond happiness-as-well-being and is focused on optimal human functioning (Ryff, 1989; Ryff \& Keyes, 1995). It includes psychological well-being (Ryff \& Keyes, 1995), which assesses a person's general degree of social-psychological wellness (Deci \& Ryan, 2008), as well as social wellbeing (Keyes, 1998, 2002), which assesses a person's degree of functioning in society. Recently, more encompassing frameworks of well-being have been developed that include emotional, psychological, and social components of well-being (Keyes, Fredrickson, \& Park, 2012).

Research on well-being among youth experiencing homelessness. Despite the numerous mental and physical health challenges that youth who experience homelessness may face, some research suggests that they report levels of subjective well-being that are comparable to that of housed young adults (Taylor, Lydon, Bougie, \& Johannesen, 2004; Usborne et al., 2009). These levels of well-being among homeless youth could be due to a number of factors, such as their strong social networks and sense of personal autonomy (Taylor, Lydon, Bougie, \& Johannesen, 2004; Usborne et al., 2009), or the ways in which they draw on their own resilience and personal strengths while homeless (Bender, Thompson, McManus, Lantry, \& Flynn, 2007; Usbome et al., 2009).

Across this research, several factors have stood out as being important to the wellbeing of youth experiencing homelessness, including social support, optimism, and selfesteem. For example, optimism has also been associated with a greater sense of wellbeing among youth experiencing homelessness (Barczyk, Thompson, \& Rew, 2014; Stewart \& Townley, 2019). Optimism and positive expectations for the future can be 
critical components of coping with negative life events (Sawyer, Pfeiffer, \& Spence, 2009; Tusaie, Puskar, \& Sereika, 2007), particularly for youth experiencing homelessness, who emphasize positivity and hopes for the future as key to their survival while homeless (Bender et al., 2007; Kidd, 2003; Usborne et al., 2009).

Self-esteem has also demonstrated strong associations with well-being among members of this population. Homeless youth with higher levels of self-esteem also have greater psychological well-being (Stewart \& Townley, 2019), whereas those with lower levels of self-esteem are at greater risk of succumbing to the emotional distress associated with loneliness and feeling trapped (Kidd \& Shahar, 2008), depression, suicidal ideation, and suicide attempts (Baumeister, Campbell, Krueger, \& Vohs, 2003; Cleverly \& Kidd, 2011; Mann, Hosman, Schaalma, \& deVries, 2004). Indeed, when controlling for other factors, self-esteem has been found to be the strongest predictor of psychological wellbeing among youth experiencing homelessness (Stewart \& Townley, 2019).

While optimism and self-esteem may be important to the well-being of youth experiencing homelessness, these are intrapersonal factors that put the impetus for resilience solely on the individual. However, social-ecological models (e.g., Oishi \& Graham, 2010; Sarason, 1972) and research focused on well-being (e.g., Costa, McCrae, \& Zonderman, 1987; Keyes, 1998; Ryff \& Keyes, 1995) suggest that much of an individual's well-being is influenced by their relationships and interactions with others. In relation to youth experiencing homelessness, factors such as social support and sense of community have emerged as important interpersonal-level correlates of well-being 
among this population (e.g., Stewart \& Townley, 2019; Stewart \& Townley, 2020a;

Townley et al., 2016).

Social support and sense of community. Social support is the "the perception or experience that one is cared for, esteemed, and part of a mutually supportive social network" (Taylor, 2011, p. 189). Social support can include various forms of formal and informal support, such as emotional, informational, tangible, and companionship support (e.g., Wills \& Margaret, 1991). Two of the strongest predictors of well-being among various populations include the number and strength of an individual's social connections (Cohen \& Wills, 1985; Dolan et al., 2008; Helliwell \& Putnam, 2004; Pichler, 2006), while the social support received from these connections can also enhance well-being (Cohen \& Wills, 1985; Jetten, Haslam, Haslam, Dingle, \& Jones, 2014).

Sense of community is defined as "the sense that one [is] part of a readily available, mutually supportive network of relationships" (Sarason, 1974, p. 1). This includes feelings of belonging and mattering to the group, as well as a sense that one's needs will be met through their membership in the group (McMillan \& Chavis, 1986). The primary theoretical framework that much of the empirical sense of community literature is based on includes four components: membership, influence, integration and fulfillment of needs, and shared emotional connection (McMillan \& Chavis, 1986). Sense of community has previously been associated with increased psychological well-being (Pretty et al., 1996; Prezza et al., 2001), perceptions of belonging and community connectedness (Sonn \& Fisher, 1996), and community participation (e.g., Talo, Mannarini, \& Rochira, 2014). Community participation is further associated with 
strengthened social bonds and sense of belonging with the community, as well as increased well-being (Wandersman \& Florin, 2000).

\section{Research on Social Support and Sense of Community among Youth}

Experiencing Homelessness. Social support and sense of community may be particularly important to the well-being of youth experiencing homelessness (Barczyk, Thompson, \& Rew, 2014; Stewart \& Townley, 2019; Stewart \& Townley, 2020a; Townley et al., 2016). Quantitative studies have suggested positive correlations between well-being, social support, and sense of community among this population (e.g., Stewart \& Townley, 2019). This may be because youth experiencing homelessness tend to rely on one another more than on service providers or other supportive adults (Karabanow, 2006; Taylor et al., 2004). These close peer relationships can protect youth against feelings of vulnerability and insecurity (Taylor et al., 2004) as well as loneliness and alienation, while also acting as a source of emotional support (Bender et al., 2007). Indeed, some research indicates that the size and makeup of youth's social networks is a driving factor in why they report unexpectedly high levels of well-being while homeless (Taylor et al., 2004; Usborne, Lydon, \& Taylor, 2009). Considering that placing trust in close friendships is a buffer against feelings of insecurity and vulnerability (Taylor et al., 2004), peer support networks have the potential to bolster the mental-emotional well-being and resilience of homeless youth.

Recent qualitative research also supports the overall positive relationship between community supports and well-being among youth experiencing homelessness, but also found that the relationship between these phenomena is not always positive for youth 
(Stewart \& Townley, 2019). This emerging research suggests areas for further investigation in order to better understand how the community experiences of youth may impact their well-being, in what circumstances it is beneficial, and how these experiences impact youth's outcomes.

\section{The Need for More Research}

While previous research on the well-being of youth experiencing homelessness has pointed to important directions for future research and opportunities for intervention, much of this research operates under the assumption that youth understand, define, and relate to these constructs and phenomena in the same ways that the mainstream populations whom these measures were standardized on do. More research is needed to examine how youth understand and define well-being for themselves, and what factors they identify as contributing most strongly to their well-being while homeless.

A deeper and more nuanced understanding of the well-being of youth experiencing homelessness can inform practitioners, researchers, policy makers, and communities about critical ways of supporting youth as they navigate the impacts of homelessness on their lives. While research has suggested significantly positive associations of social support and sense of community with well-being among this population, these studies have primarily examined these factors at a broader, quantitative level. In-depth, qualitative research focused on how these factors relate to youth's wellbeing can help researchers and practitioners develop effective, empirically supported prevention and intervention programs that can positively benefit youth's short- and longterm outcomes (Altena, Brilleslijper-Kater, \& Wolf, 2010). 


\section{Present Investigation}

Much research has focused on the well-being (and related factors) of youth experiencing homelessness. However, this area of research is primarily quantitative and exploratory. Further, it is not clear whether this research is relevant to and applicable to service centers and practitioners who work with this population daily. While crosssectional, correlational, quantitative research can point to broad trends, it is often very difficult to directly apply these findings to the daily operations of organizations that serve these youth and strive to support their well-being and long-term outcomes. Further, much research supports the conclusion that certain factors are positively related to well-being among both the general population and also youth experiencing homelessness. However, this area of research is currently lacking a level of depth and specificity that would allow researchers and practitioners to understand how to apply these findings to address the homelessness crisis facing many communities. Engaging qualitative methods to further explore these phenomena can help researchers and practitioners better understand the lived experiences of homeless youth and the specific contextually based needs they have for social support, sense of community, and well-being.

The following section will briefly review two published manuscripts the topics of well-being and community supports. Findings from these two studies inform the need for further qualitative research to explore these phenomena within specific social-ecological contexts in order to acquire a deeper understanding of how they operate, as well as how they can be harnessed to improve individual and collective well-being. A third study presents a more detailed qualitative exploration of the relationships between well-being, 
community supports, and positive outcomes among youth experiencing homelessness. The findings from this research have the potential to directly benefit organizations serving homeless youth and also inform future research focused on application of findings and development of contextually relevant interventions.

\section{Chapter II Overview: Intrapersonal and Social-Contextual Factors Related to Psychological Well-Being among Youth Experiencing Homelessness}

Study One is a published manuscript in the Journal of Community Psychology that examined how six different factors related to psychological well-being among homeless youth. Specifically, three intrapersonal factors (optimism, self-esteem, and mental health) and three social-contextual factors (sense of community, social support, and empowerment) were examined in relation to psychological well-being among youth experiencing homelessness. A quantitative survey was administered to 100 youth engaged with a local homelessness service center. It was hypothesized that all factors would be significantly and positively related to well-being, but that the intrapersonal factors would have a stronger relationship to the well-being of youth than the socialcontextual factors.

Correlational analyses confirmed that all six factors were significantly related to well-being, such that youth with greater levels of optimism, self-esteem, sense of community, social support, and empowerment, and lower levels of psychiatric distress, had greater levels of psychological well-being. In the hierarchical regression analyses, only self-esteem and psychological distress remained significant predictors of psychological well-being, with self-esteem having the strongest correlations and 
accounting for more of the variance in psychological well-being than any other factor included in the analyses. These findings suggest that the relationships of these factors to the well-being of youth experiencing homelessness is less straightforward than previous research may suggest, particularly when multiple factors are taken into consideration at one time.

More research is needed to fully understand youth's well-being and the external factors that support them while homeless. In particular, an emphasis on interpersonal factors such as sense of community and social support can help researchers turn the focus away from individual factors within youth (e.g., self-esteem) and toward factors that interventions and service centers might be more readily able to address. This could include programs that foster positive community experiences among youth and interventions that increase their social support.

\section{Chapter III Overview: Community and well-being: A qualitative study of how youth experiencing homelessness define community and its relations to their well- being}

Study Two is published in the Journal of Community Psychology and reports the qualitative component of a mixed method study examining well-being and community experiences among youth experiencing homelessness. Specifically, the qualitative component consisted of brief semi-structured interviews with 24 youth experiencing homelessness, and asked youth the following questions:

1. What does the word 'community' mean to you? 
2. Is the idea of 'community' important to you? Do you like participating in communities or would you rather stay more to yourself?

3. What types of communities do you belong to?

4. What things in your life have made your day-to-day living better or harder for you?

The analysis that contributed to this manuscript focused on youth's responses to what community means and how it is important to them. Analysis then consisted of connecting youth's descriptions of community to their comments on what makes their day-to-day living easier or more difficult. The purpose of this was to explore why community might be important to youth and how it relates to their day-to-day well-being.

Results of this study demonstrated that youth experiencing homelessness define community in terms of: (1) commonality, (2) membership-acceptance, (3) social support, and (4) collaboration. These themes reflected the four dimensions of the primary theoretical framework for sense of community (McMillan \& Chavis, 1986) and demonstrated the ways in which youth draw upon their communities and community experiences for support while homeless. However, the results also provided counterexamples to this overarching narrative, suggesting that community is not always a positive experience for these youth. For example, some youth described certain aspects of community, such as negative or pessimistic orientations toward life, as potentially detrimental to their own well-being. Overall, the study suggested the need for further research that more explicitly engages youth in describing their experiences of community 
and social support and how those experiences relate to their current well-being as well as their short- and long-term outcomes.

\section{Chapter IV Overview: A qualitative exploration of community supports, well-being, goals, and the COVID-19 pandemic among youth experiencing homelessness.}

Based on the findings and recommendations of the first two studies, the third paper presents a qualitative exploration of the relationship between well-being and community supports among youth experiencing homelessness. Specifically, Study One and other prior research suggests that sense of community and social support are positively related to well-being among members of this population, but the mechanisms behind this association, how it manifests in daily life for youth, and the impacts of these phenomena on youth's outcomes is still unclear. Study Two suggested overarching ways in which youth understand and relate to community, as well as how these experiences may connect to their well-being. However, more research is needed to understand the contextual basis of when community is important to the well-being and outcomes of youth, the myriad communities that youth are a part of, and the potential benefits some youth find in disengaging from community.

Finally, prior research suggests that youth may define and understand their community experiences and well-being both similarly to and differently than how current quantitative measures operationally define these constructs. More research is needed that emphasizes the voices of youth as experts of their own experiences. This can allow researchers and practitioners to acquire a more accurate understanding of how community experiences and well-being manifest in the daily lives of youth, and thus can 
inform how they might better support youth in meeting their needs and achieving their goals.

Study Three engaged youth experiencing homelessness in semi-structured interviews to further explore the topics of well-being and community experiences, focusing on how youth define and understand these phenomena in the contexts of their own lives, what they perceive as the relationships between these factors and how they operate in their daily lives, and how they understand these factors as being related to their short- and long-term goals. Further, given the context of the COVID-19 pandemic, these interviews asked youth about how the pandemic has impacted their well-being, community experiences and social supports, and goal pursuits.

Findings from this study indicate that youth's definitions of well-being clustered into the following themes: physical well-being, mental well-being, attitude toward self, social well-being, and self-actualization. Further, youth overwhelmingly described positive impacts of community experiences and social supports on their well-being, explaining that these community experiences and social supports benefited their wellbeing through emotional or mental health support; tangible support; and self-actualization support. However, some youth also described disengagement from community experiences, which supports findings from prior research (e.g., Stewart \& Townley, 2020).

Further, participants described how both their community and social supports, as well as their well-being, impact their goal pursuits. First, they explained that the tangible and emotional support they receive from their social and community connections helps 
them to work toward their goals. Second, participants described the influence well-being can have on their mindset and emotional state, which impacts their capacity for striving towards their goals.

Finally, participants described how the COVID-19 pandemic impacted their wellbeing and community supports in a primarily negative way, and thus also inhibited their ability to strive towards their goals. Within these discussions, however, youth demonstrated high levels of resilience and adaptation, which has been demonstrated in prior research with this population (e.g., Kidd \& Davidson, 2007).

\section{Summary}

The current dissertation presents two published studies and one new study that qualitatively examines the relationships between community supports and well-being among youth experiencing homelessness and how the interactions between community experiences and well-being might impact the short- and long-term goals of these youth. Results from Study One suggest that factors such as sense of community and social support are related to the well-being of youth experiencing homelessness. Findings from Study Two suggest that these factors are indeed important to youth but reveal that more in-depth research is needed to understand how these phenomena manifest in the lives of youth experiencing homelessness. Further, numerous researchers in the field of community psychology have called for more qualitative research on sense of community and well-being (e.g., Chavis \& Pretty, 1999; Townley et al., 2011) in order to provide rich, culturally anchored understandings of how these phenomena manifest in specific contexts. The third study expanded on the findings and recommendations of the two 
published papers and responded to this call by qualitatively examining the relationship between community experiences and well-being, and how this relationship impacts the outcomes of youth experiencing homelessness. The third study also incorporated discussions around how the COVID-19 pandemic impacted the community experiences and social supports, well-being, and goal pursuits of youth experiencing homelessness.

Collectively, this body of work demonstrates that community experiences and social supports impact the well-being and goal striving of youth experiencing homelessness and explores some of the ways in which these impacts occur. This body of work also illuminates how disruptions to community experiences and social supports can negatively impact members of this population, providing foundational justification for more robust systems that support the well-being of youth experiencing homelessness. 


\section{References}

Altena, A. M., Brilleslijper-Kater, S. N., \& Wolf, J. L. M. (2010). Effective interventions for homeless youth: a systematic review. American Journal of Preventive Medicine, $3,637-645$.

American Psychiatric Association. (1987). Diagnostic statistical manual of mental disorders, 3rd ed, Revised. APA, Washington.

Baron, S. W. (1999). Street youths and substance use - the role of background, street lifestyle, and economic factors. Youth and Society, 31, 3-26.

Barczyk, A. N., Thompson, S. J., \& Rew, L. (2014). The impact of psychosocial factors on subjective well-being among homeless young adults. Health and Social Work, $39(3), 172-180$.

Baumeister, R. F., Campbell, J. D., Krueger, J. I., \& Vohs, K. D. (2003). Does high selfesteem cause better performance, interpersonal success, happiness, or healthier lifestyles? Psychological Science in the Public Interest, 4(1), 1-44.

Bender, K., Thompson, S. J., Mcmanus, H., Lantry, J., \& Flynn, P. M. (2007). Capacity for survival: Exploring strengths of homeless street youth. Child Youth Care Forum, $36(1), 25-42$.

Boivin, J. F., Roy, E., Haley, N., \& Galbaud du, F. G. (2005). The health of street youth: A Canadian perspective. Canadian Journal of Public Health, 5(96), 432-437.

Bryk, A., Sebrig, P. B., Allensworth, E., Luppesca, S., \& Easton, J. Q. (2010). Organizing schools for improvement: Lessons from Chicago. Chicago, IL: University of Chicago Press. 
Buckner, J. C., Bassuk, E. L., \& Weinreb, L. F. (2001). Predictors of academic achievement among homeless and low-income housed children. Journal of School Psychology, 39, 45-69.

Busen, N. H. \& Engebretson, J. C. (2008). Facilitating risk reduction among homeless and street-involved youth. Journal of the American Association of Nurse Practitioners, 20, 567-575.

Cauce, A. M., Paradise, M., Ginzler, J. A., Embry, L., Morgan, C. J., \& Lohr, Y., et al. (2000) The characteristics and mental health of homeless adolescents: Age and gender differences. Journal of Emotional and Behavioral Disorders, 8, 230-239.

Chamberlain, C., \& G. Johnson. 2013. Pathways into adult homelessness. Journal of Sociology, 49(1), 60-77.

Cicognani, E., Albanesi, C., \& Zani, B. (2008). The impact of residential context on adolescents' subjective well-being. Journal of Community \& Applied Social Psychology, 18, 558-575. https://doi.org/10.1002/casp.972

Cleverley, K., \& Kidd, S. A. (2011). Resilience and suicidality among homeless youth. Journal of Adolescence, 34(5), 1049-1054.

Coates, J. \& McKenzie-Mohr, S. (2010). Out of the frying pan, into the fire: Trauma in the lives of homeless youth prior to and during homelessness. Journal of Sociology and Social Welfare, 37, 65-96.

Cochran, B. N., Stewart, A. J., Ginzler, J. A., \& Cauce, A. M. (2002). Challenges faced by homeless sexual minorities: Comparison of gay, lesbian, bisexual, and 
transgender homeless adolescents with their heterosexual counterparts. American Journal of Public Health, 92, 773-777.

Cohen, S., \& Wills, T. A. (1985). Stress, social support, and the buffering hypothesis. Psychological Bulletin, 98(2), 310-357.

Costa, P. T., McCrae, R. R., \& Zonderman, A. B. (1987). Environmental and dispositional influences on well-being: Longitudinal follow-up of an American national sample. British Journal of Psychology, 78, 299-306.

Deci, E. L., \& Ryan, R. M. (2008). Hedonia, eudaimonia, and well-being: An introduction. Journal of Happiness Studies, 9, 1-11.

Desai, R. A., Liu-Mares, W., Dausey, D. J., \& Rosenheck, R. A. (2003). Suicidal ideation and suicide attempts in a sample of homeless people with mental illness. The Journal of Nervous and Mental Disease, 191, 365-371.

Diener, E. (1984). Subjective well-being. Psychological Bulletin, 95, 542-575.

Diener, E. (2009). Assessing Well-Being: The Collected Works of Ed Diener. Dordrecht Heidelberg London New York: Springer.

Diener, E., Emmons, R. A., Larsen, R. J., \& Griffin, S. (1985). The satisfaction with life scale. Journal of Personality Assessment, 49, 71-75.

Dolan, P., Peasgood, T., \& White, M. (2008). Do we really know what makes us happy? A review of the economic literature on the factors associated with subjective wellbeing. Journal of Economic Psychology, 29, 94-122.

Dumontheil, I. (2016). Adolescent brain development. Current Opinion in Behavioral Sciences, 10, 39-44. doi: https://doi.org/10.1016/j.cobeha.2016.04.012. 
Durso, L. E., \& Gates, G. J. (2012). Serving our youth: Findings from a national survey of services providers working with lesbian, gay, bisexual, and transgender youth who are homeless or at risk of becoming homeless. Retrieved from http://williamsinstitute.law.ucla. edu/wp-content/uploads/Durso-Gates-LGBTHomeless-Youth-Survey-July-2012.pdf

Edidin, J. P., Ganim, Z., Hunter, S. J., \& Karnik, N. S. (2012). The mental and physical health of homeless youth: A literature review. Child Psychiatry and Human Development, 43(3), 354-375.

Ferguson, K. M. (2009). Exploring family environment characteristics and multiple abuse experiences among homeless youth. Journal of Interpersonal Violence, 24, 18751891.

Felitti, V. J., Anda, R. F., Nordenberg, D., Wiliamson, D. F., Spitz, A. M., Edwards, V., .. . Marks, J. S. (1998). Relationship of childhood abuse and household dysfunction to many of the leading causes of deaths in adults: The Adverse Childhood Experiences (ACE) Study. American Journal of Preventive Medicine, 14(4), 245-258.

Fowler, P. J., Toro, P. A., \& Miles, B. W. (2009). Pathways to and from homelessness and associated psycho-social outcomes among adolescents leaving the foster care system. American Journal of Public Health, 99, 1453-1458.

Fuhrmann, D., Knoll, L. J., \& Blakemore, S. J. (2015). Adolescence as a Sensitive Period of Brain Development. Trends in Cognitive Sciences, 19(10): 558-566. 
Gaetz, S., O’Grady, B., Buccieri, K., Karabanow, J., \& Marsolais, A. (2013). Youth Homelessness in Canada: Implications for Policy and Practice. Toronto: Canadian Homelessness Research Network Press.

Haber, M.G., \& Toro, P.A. (2009). Parent-adolescent violence and later behavioral health problems among homeless and housed youth. American Journal of Orthopsychiatry, $79,305-318$.

Haldenbury, A.M., Berman, H., \& Forchuk, C. (2007). Homelessness and health in adolescents. Qualitative Health Research, 17, 1232-1244.

Haley, N., Roy, E., Leclerc, P., Boudreau, J.F. \& Boivin, J.F. (2004). HIV risk profile of male street youth involved in survival sex. Sexually Transmitted Infections, 80, 526530.

Helliwell, J. F., \& Putnam, R. (2004). The social context of well-being. Philosophical Transactions of the Royal Society of London. Series B, Biological sciences, 359, $1435-1446$.

Hyde, J. (2005). From home to the street: understanding young people's transitions into homelessness. Journal of Adolescence, 28, 171-183.

Jetten, J., Haslam, C., Haslam, S. A., Dingle, G., \& Jones, J. M. (2014). How groups affect our health and well-being: The path from theory to policy. Social Issues and Policy Review, 8, 103-130.

Johnson, T. P., Aschkenasy, J. R., Herbers, M. R., \& Gillenwater, S. A. (1996). Selfreported risk factors for AIDS among homeless youth. AIDS Education and Prevention, 8(4),308-322. 
Johnson, G., \& Chamberlain, C. (2008). "From youth to adult homelessness," Australian Journal of Social Issues, 43(4), 563-582.

Karabanow, J. (2004). Being young and homeless: Understanding how youth enter and exit street life. New York: Peter Lang.

Kamieniecki, G. W. (2001). Prevalence of psychological distress and psychiatric disorders among homeless youth in Australia: A comparative review. Australian and New Zealand Journal of Psychiatry, 35, 352-358.

Kerr, T., Oleson, M., \& Wood, E. (2004). Harm-reduction activism: A case study of an unsanctioned user-run safe injection site. Canadian HIV/AIDS Policy and Law Review, 9, 13-19.

Keyes, C. (1998). Social Well-Being. Social Psychology Quarterly, 61(2), 121-140.

Keyes, C. (2002). The mental health continuum: From languishing to flourishing in life. Journal of Health and Social Behavior, 43(2), 207-222.

Keyes, C. L. M., Fredrickson, B., \& Park, N. (2012). Positive psychology and the quality of life. In K. C. Land, A. C. Michalos, \& J. Sirgy (Eds.), Handbook of social indicators and quality of life studies (pp. 99-112). New York, NY: Springer.

Kidd, S. A. (2004). "The walls were closing in, and we were trapped" - A qualitative analysis of street youth suicide. Youth and Society, 36, 30-55.

Kidd, S. A. (2003). Street youth: coping and intervention. Child and Adolescent Social Work Journal, 235-261.

Kidd, S. A., \& Davidson, L. (2007). "You have to adapt because you have no other choice": The stories of strength and resilience of 208 homeless youth in New York 
City and Toronto. Journal of Community Psychology, 35(2), 219-238. https://doi.org/10.1002/jcop.20144

Kidd, S. A., \& Davidson, L. (2009). Homeless youth: The need to link research and policy. Finding home: Policy options for addressing homelessness in Canada, 1-9.

Kidd, S. A., \& Kral, M. J. (2002). Suicide and prostitution among street youth: A qualitative analysis. Journal of Adolescence, 37, 411-430.

Kidd, S., \& Shahar, G. (2008). Resilience in homeless youth: the key role of self-esteem. The American Journal of Orthopsychiatry, 78(2), 163-172.

Kozloff, N., Stergiopoulos, V., Adair, C. E., Cheung, A. H., Misir, V., Townley, G., ... \& Goering, P. (2016). The Unique Needs of Homeless Youths with Mental Illness: Baseline Findings from a Housing First Trial. Psychiatric Services, 67(10), 10831090.

Kulik, D. M., Gaetz, S., Crowe, C., et al. (2011). Homeless youth's overwhelming health burden: a review of the literature. Pediatrics and Child Health, 16, 43-47.

Leslie, M. B., Stein, J. A., \& Rotheram-Borus, M. J. (2002). Sex-specific predictors of suicidality among runaway youth. Journal of Clinical Child and Adolescent Psychology, 31, 27-40

Mallett, S., Rosenthal, D., \& Keys, D. (2005). Young people, drug use and family conflict: Pathways into homelessness. Journal of Adolescence, 28, 185-199.

Mann, N., Hosman, C. M. H., Schaalma, H. P., \& deVries, N. K. (2004). Self-esteem in a broad-spectrum approach for mental health promotion. Health Education Research, $19,357-372$. 
McMillan, D. W., \& Chavis, D. M. (1986). Sense of community: A definition and theory. Journal of Community Psychology, 14, 6-23.

Morton, M. H., Dworsky, A., \& Samuels, G. M. (2017). Missed opportunities: Youth homelessness in America. National estimates. Chicago, IL: Chapin Hall at the University of Chicago. Retrieved from voicesofyouthcount.org

Morton, M. H., Samuels, G. M., Dworsky, A., \& Patel, S. (2018). Missed Opportunities: LGBTQ Youth Homelessness in America. Chicago, IL: Chapin Hall at the University of Chicago. Retrieved from voicesofyouthcount.org

National Coalition for the Homeless. (2009). Education of homeless children and youth. Retrieved from: http://www.nationalhomeless.org/factsheets/education.html\#footnotes.

National Health Care for the Homeless Council. (2004). Homeless young adults ages 1824: Examining service delivery adaptation. Author, Nashville.

O'Connell, J. J. (2004) Dying in the shadows: the challenge of providing health care for homeless people. Canadian Medical Association Journal, 170, 1251-1252.

Oishi, S., \& Graham, J. (2010). Social ecology: Lost and found in psychological science. Perspectives on Psychological Science, 5(4), 356-377.

Palepu, A., Tyndall, M. W., Leon, H., et al. (2001). Hospital utilization and costs in a cohort of injection drug users. Canadian Medical Association Journal, 165, 415420. 
Parks, R. W., Stevens, R. J., \& Spence, S. A. (2007). A systematic review of cognition in homeless children and adolescents. Journal of the Royal Society of Medicine, 100, 46-50.

Pichler, F. (2006). Subjective quality of life of young Europeans: Feeling happy but who knows why? Social Indicators Research, 75, 419-444.

Rafferty, Y., Shinn, M., \& Weitzman, B. C. (2004). Academic achievement among formerly homeless adolescents and their continuously housed peers. Journal of School Psychology, 42, 179-199.

Ray, N. (2006). Lesbian, gay, bisexual and transgender youth: an epidemic of homelessness. National Gay and Lesbian Task Force Policy Institute and the National Coalition for the Homeless, New York.

Reeg, B. (2003). The Runaway and Homeless Youth Act and disconnected youth. In: Levin-Epstein, J. \& Greenberg, M.H. (eds). Leave no youth behind: opportunities for congress to reach disconnected youth. Center for Law and Social Policy, Washington, DC.

Rew, L., Taylor-Seehafer, M., \& Fitzgerald, M. L. (2001). Sexual abuse, alcohol and other drug use, and suicidal behaviors in homeless adolescents. Issues in Comprehensive Pediatric Nursing, 24, 225-240.

Robertson, M. J., \& Toro, P. A. (1999). Homeless youth: research, intervention, and policy. In: Fosburg, L.B. \& Dennis, D.L. (eds). Practical lessons: the 1998 national symposium on homeless research, urban development, and the U.S. Department of Health and Human Services. Washington. 
Rosich, K. J. (2007). Race, Ethnicity, and the Criminal Justice System. Washington, DC: American Sociological Association. (Available at http://asanet.org.)

Rotheram-Borus, M. J., Song, J., Gwadz, M., Lee, M., Van, R. R., \& Koopman, C. (2003). Reductions in HIV risk among runaway youth. Prevention Science, 4, 173187.

Roy, E., Boudreau, J. F., \& Boivin, J. F. (2009). Hepatitis C virus incidence among young street-involved IDUs in relation to injection experience. Drug and Alcohol Dependence, 102, 158-161.

Ryff, C. D. (1989). Happiness is everything, or is it? Explorations on the meaning of psychological well-being. Journal of Personality and Social Psychology, 57, 10691081.

Ryff, C. D., \& Keyes, C. L. M. (1995). The structure of psychological well-being revisited. Journal of Personality and Social Psychology, 69(4), 719-727.

Salomonsen-Sautel, S., Van Leeuwen, J. M., Gilroy, C., Boyle, S., Malberg, D., \& Hopfer, C. (2008). Correlates of substance use among homeless youths in eight cities. American Journal on Addictions, 17, 224-234.

Samuels, G. M., Cerven, C., Curry, S., Robinson, S. R., \& Patel, S. (2019). Missed Opportunities: Youth Pathways Through Homelessness. Chicago, IL: Chapin Hall at the University of Chicago. Retrieved from voicesofyouthcount.org Sarason, S. B. (1972). The creation of settings and the future societies. San Francisco: Jossey-Bass. 
Sarason, S. B. (1974). The Psychological Sense of Community: Prospects for a Community Psychology. San Francisco: Jossey-Bass.

Sawyer, M. G., Pfeiffer, S., \& Spence, S. H. (2009). Life events, coping and depressive symptoms among young adolescents: A one-year prospective study. Journal of Affective Disorders, 117, 48-54.

Slesnick, N., Dashora, P., Letcher, A., Erdem, G., \& Serovich, J. (2009). A review of services and interventions for runaway and homeless youth: Moving forward. Children and Youth Services Review, 31(7), 732-742.

Sonn, C. C., \& Fisher, A. T. (1996). Aspirations to community: Community responses to rejection. Journal of Community Psychology, 24(4), 417-430.

Stewart, K., \& Townley, G. (2019). Intrapersonal and social-contextual factors related to psychological well-being among youth experiencing homelessness. Journal of Community Psychology, 47(4), 772-789.

Stewart, K., \& Townley, G. (2020). Community and well-being: A qualitative study of how youth experiencing homelessness define community and its relations to their well-being. Journal of Community Psychology, 48(3), 994-1009.

Talo, C., Mannarini, T., \& Rochira, A. (2014). Sense of community and community participation: A meta-analytic review. Social Indicators Research, 117, 1-28.

Taylor, S. E. (2011). Social support: A review. In The Oxford handbook of health psychology. Edited by H. S. Friedman, 189-214. Oxford: Oxford Univ. Press 
Taylor, D. M., Lydon, J. E., Bougie, É., \& Johannsen, K. (2004). “Street Kids”: Towards an Understanding of their Motivational Context. Canadian Journal of Behavioural Science, 36(1), 1-16.

Tolomiczenko, G. S., Goering, P. N., \& Durbin, J. F. (2001). Educating the public about mental illness and homelessness: A cautionary note. Canadian Journal of Psychiatry, 46, 253-257.

Townley, G., Pearson, L., Lehrwyn, J. M., Prophet, N. T., \& Trauernicht, M. (2016). Utilizing participatory mapping and GIS to examine the activity spaces of homeless youth. American Journal of Community Psychology, 57, 404-414.

Tyler, K., Cauce, A. M., \& Whitbeck, L. B. (2004). Family risk factors and prevalence of dissociative symptoms among homeless and runaway youth. Child Abuse and Neglect, 28, 355-366.

Tyler, K. A. \& Melander, L. A. (2010). Foster care placement, poor parenting, and negative outcomes among homeless young adults. Journal of Child and Family Studies, 19, 787-794.

Tusaie, K., Puskar, K., \& Sereika, S. M. (2007). A predictive and moderating model of psychosocial resilience in adolescents. Journal of Nursing Scholarship, 39(1), 5460.

U.S. Census Bureau. (2009). Family status and household relationship of people 15 years and over, by marital status, age, and sex: 2009. Retrieved 22 September 2010, from http://www.census.gov/population/www/socdemo/hh-fam/cps2009.html 
U.S. Conference of Mayors. (2012). Hunger and Homelessness Survey: A status report on hunger and homelessness in America's cities. A 25-city survey. Washington, DC.

U.S. Department of Health and Human Services. (2009). Report to congress on the runaway and homeless youth programs of the family and youth services bureau for fiscal years 2008 and 2009. Retrieved 22 August 2011, from http://www.acf.hhs.gov/programs/fysb/content/docs/508-fysb-congress-0809.pdf

Usborne, E., Lydon, J. E., \& Taylor, D. M. (2009). Goals and social relationships: Windows into the motivation and well-being of "Street Kids." Journal of Applied Social Psychology, 39(5), 1057-1082.

van den Bree, M.B., Shelton, K., Bonner, A., et al. (2009). A longitudinal populationbased study of factors in adolescence predicting homelessness in young adulthood. Journal of Adolescent Health, 45, 571-578.

Van Wormer, R. (2003). Homeless youth seeking assistance: A research-based study from Duluth, Minnesota. Child and Youth Care Forum, 32, 89-103.

Wandersman, A., \& Florin, P. (2000). Citizen participation and community organizations. In J. Rappaport \& E. Seidman (Eds.), Handbook of Community Psychology (pp. 247-272). New York: Plenum.

Wildeman, C., \& Emanuel, N. (2014). Cumulative risks of foster care placement by age 18 for U.S. children, 2000-2011. PLoS ONE, 9(3): e92785.

Wills, T. A. (1991). Social support and interpersonal relationships. In C. Margaret (ed.) Review of Personality and Social Psychology, Vol. 12. Prosocial behavior. Thousand Oaks, CA (265-289). 
Wrate, R., \& McLoughlin, P. (1997). Feeling bad: the troubled lives and health of single young homeless people in Edinburgh. Edinburgh: Lothian Health Authority.

Yu, M., North, C. S., LaVesser, P. D., Osborne, V. A., \& Spitznagel, E. L. (2008). A comparison study of psychiatric and behavior disorders and cognitive ability among homeless and housed children. Community Mental Health Journal, 44,1-10.

Zerger, S., Strehlow, A. J., \& Gundlapalli, A. V. (2008). Homeless young adults and behavioral health. American Behavioral Scientist, 51, 824-841.

Zufferey, C. (2017). Homelessness and social work: An intersectional approach. New York, NY: Routledge. 
Chapter II: Intrapersonal and social-contextual factors related to psychological well-being among youth experiencing homelessness

Stewart, K., \& Townley, G. (2019). Intrapersonal and social-contextual factors related to psychological well-being among youth experiencing homelessness. Journal of Community Psychology, 47(4), 772-789.

\begin{abstract}
Homeless youth are adolescents and young adults who do not have stable dwellings, but instead live on the streets, in shelters, or in other unstable situations. While researchers have begun examining well-being among this population, little is known about components of well-being that are relevant to homeless youth, or which factors predict differences in well-being. This study examined psychological well-being and its associations with demographic characteristics, intrapersonal factors (mental health, optimism, self-esteem), and social-contextual factors (social support, sense of community, empowerment) among 100 youth experiencing homelessness. The intrapersonal and social-contextual variables were all associated with well-being at the bivariate level. In the full regression model, only self-esteem and psychological distress remained significant. Thematic analysis revealed 11 factors impacting well-being, including Self Care and Personal Outlook. Findings inform future research and program development at homeless service centers.
\end{abstract}

Keywords: Homeless youth, well-being, psychological well-being, sense of community, homelessness, self-esteem, social support 


\section{Introduction}

Homeless youth are unaccompanied youth and young adults (aged 12-24 years)

who do not have stable dwellings but instead live on the streets, in shelters or abandoned buildings, or in other unstable situations (Kidd \& Davidson, 2009). Each year, approximately 550,000 unaccompanied, single youth and young adults experience a homelessness episode of longer than one week (National Alliance to End Homelessness, 2014). The social context influencing youth homelessness often centers around familial breakdown or disruptive family relationships, including behaviors of parents, economic problems, and residential instability (Reeg, 2003; van Wormer, 2003). Compared with their housed counterparts, homeless youth report experiencing high rates of trauma and abuse both before and during homelessness (Coates \& McKenzie-Mohr, 2010; Haber \& Toro, 2009), putting them at a greater risk of psychological consequences (Coates \& McKenzie-Mohr, 2010). Youth who identify as gay, lesbian, and transgender are 4\%$13 \%$ more likely to experience homelessness than heterosexual youth, and some surveys report that as high as $40 \%$ of service-using youth identify as lesbian, gay, bisexual, transgender, questioning, or queer (Durso \& Gates, 2012).

Although mental illness can and sometimes does precede homelessness, the detrimental effects of homelessness on mental health are consistently noted in research (e.g., Castellow, Kloos, \& Townley, 2015), contributing to an 11-fold increase in mortality rates among homeless youth compared with housed youth, accounted for primarily by suicide and drug overdose (Roy et al., 2004). Further, $48 \%-98 \%$ of homeless youth meet the criteria for a psychiatric disorder (Hodgson, Shelton, van den 
Bree, \& Los, 2013), a rate alarmingly high compared to peers of the same age group (Kessler et al., 2005), whereas lifetime rates of depressive disorders, posttraumatic stress disorder, and alcohol and drug abuse are many times higher among homeless youth than housed youth (Whitbeck, Hoyt, Johnson, \& Chen, 2007).

Youth experiencing homelessness also have numerous financial, structural, and personal barriers to accessing mental and emotional support (Christiani, Hudson, Nyamathi, Mutere, \& Sweat, 2008; Hudson et al., 2010; Reid, Berman, \& Forchuk, 2005), with up to $50 \%$ reporting a perceived unmet need for health care in the past 6 months (Kozloff et al., 2016). Homeless youth are also more likely to work in lower paying jobs without benefits or health insurance and have difficulties accessing affordable housing and education (National Health Care for the Homeless Council, 2008).

Despite the adversities and struggles faced by many homeless youth, some research suggests that youth are able to capitalize on both internal and external resources to survive on the streets (Cleverley \& Kidd, 2011; Kidd \& Carroll, 2007), which may be a key component to maintaining well-being while homeless. However, previous studies examining the well-being of homeless youth have been inconsistent, using a combination of measures that may suggest well-being but that do not directly and holistically capture the construct (e.g., measures focusing on psychological symptom distress rather than positive psychological functioning) and are potentially lacking relevance to the values and experiences of homeless youth (Barczyk, Thompson, \& Rew, 2014; Taylor, Lyndon, Bougie, \& Johannsen, 2004; Usborne, Lyndon, \& Taylor, 2009). 
The present study aims to develop a deeper and more specific understanding of the intrapersonal and social- contextual factors that may predict greater levels of psychological well-being among some members of this population. Examining the nature of well-being among homeless youth can point to internal and external sources of support that may enhance youth's chances of experiencing positive outcomes despite the adversities they face.

\section{Intrapersonal factors related to well-being}

Well-being research has spread into multiple disciplines, and research has demonstrated its associations with a myriad of outcomes, traits, and experiences. However, there are specific intrapersonal factors associated with well-being that are important to consider within the context of youth homelessness, including mental health, optimism, and self-esteem.

Mental health. The World Health Organization (2014) defines mental health as "a state of well-being in which every individual realizes his or her own potential, can cope with the normal stresses of life, can work productively and fruitfully, and is able to contribute to her or his community". It has also been described as a state in which individuals are both free of psychopathology and are flourishing (Keyes, 2002). However, mental illness and well-being have been construed as independent dimensions with their own continua (e.g., mental illness to mental health, languishing to flourishing; Huppert \& Cooper, 2014; Keyes, 2002; Weich et al., 2011). Although individuals suffering from psychiatric distress typically have lower levels of well-being than those without mental illness (Diener \& Seligman, 2004; Suslow, Roestela, Ohrmanna, \& 
Arolta, 2003), levels of well-being can vary among those with mental illness, with differences being predicted by both internal and external factors, such as coping style, finances, social relations, and healthcare (Lehman, 1983; Meyer, 2001). Given the higher-than-average rates of mental illness among homeless youth, it is particularly important to understand the relationship between mental health distress and psychological well-being within this population.

Optimism. Optimism is defined as a generalized tendency to expect positive outcomes even in the face of obstacles (Scheier \& Carver, 1985), and it has been shown to predict numerous components of well-being (e.g., Diener, Oishi, \& Lucas, 2003; Eid \& Diener, 2004). Optimistic individuals tend to use problem-focused coping strategies and more effective forms of emotion regulation, both of which can contribute to better overall well-being when experiencing adversity or intense stressors (Taylor \& Armor, 1996). Youth with greater self-regulation tend to have fewer symptoms of anxiety and depression when faced with adversities (Dishion \& Connell, 2006), whereas youth with a more negative orientation toward life tend to have lower levels of well-being (White \& Jones, 1996; White, Wampler, \& Winn, 1998).

Among homeless youth, research suggests that optimism has a positive effect on their lives (Bender, Thompson, McManus, Lantry, \& Flynn, 2007; Usborne, Lydon, \& Taylor, 2009), with youth viewing a positive attitude as a key to survival on the streets (Bender et al., 2007). In qualitative interviews, homeless youth have emphasized the importance of seeing adversity as an opportunity for growth, as well as the need to look toward a positive future and remember that their situation is temporary (Kidd, 2003). 
Self-esteem. Self-esteem is defined as the value one places on the self (Rosenberg, 1965). High self-esteem not only has been found to be strongly associated with well-being among a variety of heterogeneous samples and populations (e.g., Diener \& Diener, 1995; Lin, 2015; Rosenberg, Schooler, Schoenbach, \& Rosenberg, 1995), but it has also been recognized as a distinct construct that has not received sufficient attention in the well-being literature (Paradise \& Kerns, 2002). Self-esteem has also been related to numerous positive psychological outcomes, such as psychological adjustment, prosocial behavior, and positive affect (Joiner, 1995; Leary \& MacDonald, 2003; Watson, Suls, \& Haig, 2002).

Conversely, homeless youth with low self-esteem are at risk of succumbing to the emotional distress associated with loneliness and feeling trapped, which puts them at a greater risk of negative health outcomes (Kidd \& Shahar, 2008). For example, one study found that self-esteem accounted for $16 \%$ of the variance in suicidal ideation among homeless youth (Cleverley \& Kidd, 2011), and other studies also have connected low self-esteem with depression, suicidal ideation, and suicide attempts (Baumeister, Campbell, Krueger, \& Vohs, 2003; Mann, Hosman, Schaalma, \& deVries, 2004).

\section{Social-contextual factors related to well-being}

Along with intrapersonal factors, social-contextual factors may positively affect psychological well-being among youth experiencing homelessness. Although researchers have only recently begun to pay close attention to the social-contextual experiences of homeless youth, preliminary research suggests the positive role of sense of community, social support, and empowerment as they relate to well-being. 
Sense of community. Defined by Sarason (1974) as "the sense that one was part of a readily available, mutually supportive network of relationships" (p. 1), sense of community has a well-established role in influencing community connectedness and well-being across the lifespan (e.g., Chipuer, Bramston, \& Pretty, 2003; Davidson \& Cotter 1991; Pretty, Conroy, Dugay, Fowler, \& Williams, 1996; Prezza \& Costantini, 1998). Conversely, a lower sense of belonging has been related to higher levels of personal distress and having experienced a greater number of negative life events (Gracia \& Herrero, 2004). Although the direction of this relationship is not fully understood, it is likely a bidirectional relationship in the case of youth homelessness.

Homelessness typically entails a loss of housing and a disaffiliation from mainstream society and conventional social structures (Zlotnick, Robertson, \& Lahiff, 1999). The longer an individual spends homeless, the greater the chance that they will identify with the culture of street life and the negative social roles ascribed to them by society (Farrington \& Robinson, 1999; Grigsby, Baumann, Gregorich, \& Roberts-Gray, 1990; Snow \& Anderson, 1987). This disaffiliation may contribute to a lower sense of belonging and identification with housed society, which has the potential to negatively affect youth's well-being and complicate their efforts to transition out of homelessness.

Social support. The number and strength of an individual's social connections are two of the strongest predictors of well-being among various populations (Cohen \& Wills, 1985; Dolan, Peasgood, \& White, 2008; Helliwell \& Putnam, 2004; Pichler, 2006). Research suggests that effective social support through social connectedness may enhance well-being (Cohen \& Wills, 1985; Jetten, Haslam, Haslam, Dingle, \& Jones, 
2014). Among individuals experiencing homelessness, positive social relationships have been found to contribute to well-being (Biswas-Diener \& Diener, 2006), with recent research suggesting that gains in social support can benefit well-being among individuals using homeless services and housing programs (Johnstone, Jetten, Dingle, Parsell, \& Walter, 2016).

Although homeless youth experience persistent challenges related to social exclusion and disaffiliation from conventional social structures, they often develop peer social networks that contribute to a sense of companionship and help them adapt to the complexities of street life (Bender et al., 2007). Although housed youth receive the wellbeing benefits of social support in the form of family members (Morgan et al., 2011), homeless youth typically depend on one another rather than family members, service providers, or authority figures (Karabanow, 2006; Taylor, Lydon, Bougie, \& Johannesen, 2004). These networks of "street friends" are similar to the nuclear family and fill those missing roles, helping youth to combat feelings of loneliness and alienation while providing emotional support and assistance (Bender et al., 2007).

Empowerment. Empowerment pertains to the ability of individuals and communities that have been marginalized by society to regain control over their own lives (Rappaport, 1987), and it has been related to both sense of community and wellbeing among youth and vulnerable populations (Friis-Hansen \& Duveskog, 2012). Further, active participation among youth in community organizations has been associated with psychological empowerment (Flanagan, 2004; Mazzoni, Cicognani, Albanesi, \& Zani, 2014; Youniss \& Yates, 1999; Zimmerman \& Rappaport, 1988), 
whereas youth who are supported by adults in community decision making are more likely to demonstrate greater confidence and agency, increased community connections, and a greater sense of empowerment (Krauss et al., 2014).

In one of the few published studies to examine empowerment among homeless youth, Ferguson, Kim, and McCoy (2011) suggested that greater ownership of service programs and involvement in agency decision making may increase their sense of community, enhance their motivation to participate actively in agency programming, and encourage them to improve their lives. Given the positive associations between empowerment and well-being reported in studies of other vulnerable populations (e.g., Friss-Hansen \& Duveskog, 2012), it is likely that empowerment can also positively affect well-being for homeless youth, helping them influence the settings in which they participate and eventually transition out of homelessness.

\section{Study Purpose, Research Questions, and Hypotheses}

The experiences of well-being are varied both among homeless youth and between homeless and housed youth. This study aims to increase our understanding of well-being among youth experiencing homelessness by examining associations of both intrapersonal and social-contextual factors with psychological well-being. Understanding the well-being of homeless youth can inform the services and supports offered to them as they work toward transitioning out of homelessness, as well as the development of interventions aimed at enhancing well-being among homeless youth.

To address the aims of this study, we first examined the relationship between psychological well-being and demographic characteristics of homeless youth, including 
race, age, gender, and sexual orientation. Few studies have examined the relationship between demographic characteristics and psychological well-being among homeless youth. Therefore, rather than testing specific a priori hypotheses, the demographic analyses were exploratory and served the dual purpose of (a) contributing to the limited research literature and (b) determining whether any demographic variables needed to be controlled for in subsequent analyses.

Next, we examined the association between two categories of explanatory variables (intrapersonal and social contextual factors) and psychological well-being. Based on previous research among homeless youth and other populations, we hypothesized that intrapersonal factors would explain a significant portion of variability in psychological well-being. Specifically, higher levels of self-esteem and optimism and lower levels of psychiatric distress would be related to greater well-being. Second, we hypothesized that social-contextual factors would also explain a significant portion of variability in psychological well-being. Specifically, higher levels of sense of community, empowerment, and social support would be associated with greater wellbeing. Third, we hypothesized that the intrapersonal factors would account for more variance in well-being than the social-contextual factors because they are more proximal to an individual's overall level of psychological functioning and wellness.

\section{Method}

\section{Participants}

Participants in this study were 100 youth using homeless services in a Pacific Northwest city of the United States. Participants were recruited via in-person invitation 
and informational flyers at a nonprofit mentoring center that provides drop-in services to homeless youth (meals as well as educational, art, and recreational activities). The first author worked with staff at the organization to recruit potential participants. Staff were fully briefed on the study before the distribution of flyers so that they were equipped to answer questions from potential participants.

To be included in the study, participants had to be between 18 and 25 years of age and currently using services at the nonprofit community center from which data were collected. Youth were able to participate on a first-come, first-served basis. Although there were likely youth who opted not to volunteer for participation, information concerning the response rate was not captured given the variable nature of youth attendance at the community center. The extent to which youth had been receiving mentoring services before data collection was not known, though there was likely a variety of prior mentorship engagement (e.g., for some youth it was the first day at that service center, whereas others had been engaged for at least one year).

Demographics and participant characteristics. In this sample $(N=100), 68 \%$ of participants identified as male, $67 \%$ as heterosexual, and $52 \%$ as White (see Table 1 ). Ages ranged from 18 to 25 years, with the mean age being 21.42 (standard deviation $[S D]=2.09)$. The age at which youth became homeless ranged from 1 to 23 years, with a mean of $16.53(S D=2.09)$. Participants reported an average of $4.63(S D=11.27)$ lifetime episodes of homelessness; and the current length of homelessness ranged from 1 week to 12 years $($ mean $[M]=20.63$ months, $S D=27.93)$. 
Participants were asked how they became homeless this most recent time, and the most common reasons were being kicked out of their previous homes $(n=36)$ or choosing to leave $(n=29)$. Youth also cited personal issues (e.g., drug relapse and pregnancy; $n=14)$, financial difficulties $(n=11)$, and difficulty finding housing $(n=4)$. Numerous participants $(n=39)$ mentioned familial factors as part of the reason they became homeless. For example, youth cited abuse from family members, an unhealthy living environment, and differences in beliefs or morals as their reasons for either being kicked out of or choosing to leave their homes. None of these homelessness experience variables were significantly correlated with the psychological well-being outcome variable and thus were not included in the primary analyses.

\section{Measures}

Psychological well-being. We used the 18-item Psychological Well-Being Scale (Ryff \& Keyes, 1995) to measure psychological well-being. The scale assesses the six primary components of the construct (Ryff, 1989; 1995): autonomy, environmental mastery, personal growth, positive relations with others, purpose in life, and selfacceptance (e.g., "I gave up trying to make big improvements or changes in my life a long time ago" and "I have confidence in my opinions, even if they are contrary to the general consensus"). Participants rated the items on a 6-point Likert scale ranging from 1 (strongly disagree) to 6 (strongly agree). This measure has been used in previous studies of homeless youth (e.g., Townley, Pearson, Lehrwyn, Prophet, \& Trauernicht, 2016) and demonstrated sufficient internal consistency in the current study $(\alpha=0.76)$. 
Mental health. We used the Kessler-6 Scale to measure mental health. The scale assesses the severity of psychological distress and was designed to estimate the proportion of serious mental illness within the general population (Kessler et al., 2002). The six items ask participants how often they felt nervous, hopeless, restless, depressed, worthless, or that everything was an effort over the past 30 days. Participants rated the items on a 5-point Likert scale ranging from 1 (all of the time) to 5 (none of the time). The Kessler- 6 has established reliability and validity and has been used within a variety of populations both in the United States and internationally (Kessler et al., 2002). The internal consistency for this scale in the current study was adequate $(\alpha=0.78)$.

Optimism. We used the Life Orientation Test-Revised (LOTR; Scheier, Carver, \& Bridges, 1994) to measure optimism. The Life Orientation Test was originally developed to assess individual differences in generalized optimism versus pessimism ("In uncertain times, I usually expect the best"). The LOTR is a six-item measure, and participants rated each item on a 5-point Likert scale ranging from 1 (strongly agree) to 5 (strongly disagree). The LOTR has demonstrated good reliability and validity in a variety of studies with multiple populations (for a review, see Carver, Scheier, \& Segerstrom, 2010) and had adequate internal consistency in this sample $(\alpha=0.76)$.

Self-esteem. We used the 10-item Rosenberg Self-Esteem Scale (Rosenberg, $1965)$ to measure self-esteem. The scale measures global self-worth by assessing both positive and negative feelings about the self ("I feel that I am a person of worth, at least on an equal plane with others"). Participants rated the items on a 4-point Likert scale ranging from 1 (strongly agree) to 4 (strongly disagree). More recent studies have 
confirmed the reliability and validity of this scale (e.g., Gray-Little, Williams, \& Hancock, 1997), and the scale demonstrated good internal consistency in the current study $(\alpha=0.85)$

Sense of community. We used the 24-item Sense of Community Index-2 (SCI-2; Chavis, Lee, \& Acosta, 2008) to assess the perceptions of sense of community. Participants responded to 24 items assessing perceptions of community membership, influence, fulfillment of needs, and shared emotional connection ("I get important needs of mine met because I am part of this community" and "being a member of this community is part of my identity"). Participants rated the items on a 4-point Likert scale ranging from 1 (not at all) to 4 (completely). Participants were given a general instruction to answer questions in relation to the areas where they spend the most time. Multiple studies across different cultures and types of communities have used this measure and demonstrated its validity and reliability (Chavis et al., 2008). The scale demonstrated a high level of internal consistency in this sample $(\alpha=0.91)$.

Social support. Although social support has been measured in a variety of ways in the literature, we measured youth's social support networks by asking how many (a) family members, (b) friends, and (c) other adults the participant can turn to for sup-ort. In addition to reporting the total number of supports in each category, participants were also asked to rate their satisfaction with the relationship on a 5-point Likert scale ranging from 1 (very dissatisfied) to 5 (very satisfied).

Total Social Support scores for each participant were obtained by first creating a product between network size and satisfaction for each category (i.e., family members, 
friends, other adults), and second by summing the product scores across the three support categories to yield a weighted social support score (i.e., a measure of the total number of supports weighted by the satisfaction the participant has with each type of support). This scaling was employed to capture the importance of both the quantity and the quality of support networks and is consistent with other social support measures used in homelessness research (e.g., The Social Network Inventory; Bates \& Toro, 1999).

Although this variable was positively skewed and peaked, a logarithmic transformation did not substantially alter the results, and the skewness and kurtosis values were within an acceptable range according to less stringent guidelines $(|S|<3,|k|<10$; Kline, 2011). All other variables were normally distributed and fell within a more conservative range for skewness and kurtosis (e.g., $|s|<1,|k|<3$; see Table 2).

Empowerment. We used the 17-item Sociopolitical Control Scale for Youth (Peterson, Peterson, Agre, Christens, \& Mort, 2011) to measure empowerment. The scale assesses leadership competence (e.g., "I can usually organize people to get things done") and policy control (e.g., "youth like me have the ability to participate effectively in community activities and decision making"). Participants rated the items on a 5-point Likert scale ranging from 1 (strongly agree) to 5 (strongly disagree). This scale has been used with multiple youth populations in the United States and internationally (Peterson et al., 2011) and demonstrated good internal consistency in the current study $(\alpha=0.83)$.

\section{Design and Procedures}

Approval for the study was granted by the university's institutional review board in April 2017. Data were collected in a one-on-one interview format. Participants 
responded verbally to survey measures administered by a researcher, who then recorded their responses electronically using iPads. The first author worked with two research assistants to recruit participants and conduct interviews. Inclusion criteria were being within the specified age range and accessing services at the data collection site during the times that interviews were conducted. Interviews took an average of 30 minutes to complete and were conducted in a semiprivate common area to ensure privacy and minimal distractions.

Before the interview, youth were asked to read and sign an informed consent document specifying that participation was entirely voluntary and would not affect receipt of services. All survey item responses were kept entirely confidential. All youth received a copy of the informed consent, and the first author and/or research assistants answered any questions that they had before, during, and following their involvement. Youth received $\$ 10$ cash for completing the survey.

\section{Results}

Data were analyzed using IBM SPSS (version 24). Continuous composite scores of individual variables were computed for all scales, and demographic variables were categorized into binary variables (e.g., male/ non-male1). Table 2 presents descriptive statistics, and Table 3 presents a correlation matrix of all study variables. All independent variables had moderate (i.e., $0.3 \leq|r|<0.7$ ) to strong (i.e., $|r|>=0.7$ ) significant correlations with psychological well-being. 


\section{Demographic Characteristics and Well-Being}

We conducted Pearson correlation and independent samples $t$ tests to examine associations between participant demographics and psychological well-being. Age was not significantly associated with psychological well-being $(r=-.05, p=.65)$. There were no significant differences in psychological well-being between White participants $(M=$ 4.46, $S D=0.66)$, and non-White participants $(M=4.32, S D=0.63), t(98)=1.08, p=.28$, and between participants who identified as heterosexual $(M=4.42, S D=0.61)$ and those who did not identify as heterosexual $(M=4.35, S D=0.72), t(98)=1.08, p=.59$.

However, psychological well-being was significantly greater among male participants $(M$ $=4.49, S D=0.59)$ than participants identifying as female, transgender, or nonbinary $(M$ $=4.20, S D=0.72), t(98)=2.15, p<.05$. Based on these findings, gender was entered as a covariate in the subsequent regression analyses, whereas the other demographic variables were not.

\section{Bivariate correlations between intrapersonal, social-contextual, and well-being variables}

Correlational analyses indicated that all six intrapersonal and social-contextual factors were significantly related to psychological well-being in the expected direction. Optimism $(r=.52, p<.001)$, self-esteem $(r=.72, p<.001)$, social support $(r=.30, p<$ $.01)$, sense of community $(r=.23, p<.05)$, and empowerment $(r=.47, p<.001)$ were all positively correlated with psychological well-being, whereas psychological distress was negatively correlated with psychological well-being $(r=-.59, p<.001$; see Table 3). 


\section{Assessing the relative influence of intrapersonal and social-contextual factors}

A hierarchical linear regression was conducted to examine whether intrapersonal or social-contextual factors accounted for more variance in psychological well-being. Explanatory variables were added in blocks, and the resulting change in R-squared values as well as the beta-weights for each individual variable were assessed. The full hierarchical model was significant, accounting for $57 \%$ of the variance in psychological well-being, $F(7,92)=17.99, p<.001$ (see Table4).

In block 1 , gender accounted for $4.5 \%$ of the variance in the model and was significantly negatively related to psychological well-being $(\beta=-.21, p<.05)$, indicating that males experienced significantly greater psychological well-being that nonmale-identified participants. The inclusion of intrapersonal variables in block 2 accounted for an additional $52 \%$ of the variance $(p<.001)$.

Self-esteem was significantly positively related to well-being $(\beta=.65, p<.001)$, whereas psychological distress was significantly negatively related to psychological wellbeing $(\beta=-.27, p<.05)$. Optimism was not significantly associated with well-being $(\beta$ $=-.11, p=.31)$. The addition of the social-contextual variables in block 3 did not account for a significant amount of additional variance $(\Delta R 2=.02, p=.31)$. In the full model, self-esteem $(\beta=.56, p<.001)$ and psychological distress $(\beta=-.26, p<.05)$ were the only significant predictors of psychological well-being.

\section{Discussion}

Research with youth experiencing homelessness has typically focused on their challenges, setbacks, and negative outcomes as opposed to their strengths and positive 
outcomes-their resilience in the face of adversity. This study's exploration of psychological well-being among homeless youth can add to the emerging strengths-based research literature and help to illuminate several factors that may affect the well-being of homeless youth.

\section{Study Findings and Implications}

Demographics and participant characteristics. Although this study did not find psychological well-being to be related to age, sexual orientation, or racial background among homeless youth, male-identified individuals reported greater psychological wellbeing than participants who identified as female, transgender, nonbinary, and gender fluid. In addition to males possibly underreporting negative characteristics and overreporting positive characteristics (e.g., psychological well-being), these differences are likely also due to the marginalization often faced by those who step outside of the gender binary norms (e.g., Cochran, Stewart, Ginzler, \& Cauce, 2002). Further, female, transgender, and genderqueer youth who experience homelessness may face certain stressors or dangers that those who are male do not face (e.g., managing feminine hygiene, threats of sexual violence or assault). Results suggest the importance of services that are focused on supporting individuals with gender-related needs.

Intrapersonal correlates of psychological well-being. Each of the intrapersonal variables was significantly associated with psychological well-being at the bivariate level. Specifically, greater levels of optimism and self-esteem were associated with higher scores on psychological well-being, with self-esteem being the strongest correlate of all study variables. Because greater optimism and lower pessimism have been linked to 
better psychological well-being outcomes after facing adversity (e.g., Taylor \& Armor, 1996), future studies should examine whether and how optimism might benefit the wellbeing of homeless youth.

Moreover, previous research has discussed the crucial protective role that selfesteem may have for the resilience of homeless youth, reporting that homeless youth emphasize a reliance on the self to remain resilient (e.g., Kidd \& Shahar, 2008). Youth's ability to depend on their own self-resources may be directly related to their self-esteem, such that those who have lower self-esteem may experience a heightened vulnerability to negative psychological health outcomes (Kidd \& Shahar, 2008). Thus, self-esteem may promote self-reliance and autonomy among homeless youth, which in turn could boost their psychological well-being. Considering that homeless youth tend to have lower selfesteem than nonhomeless youth (Maccio \& Schuler, 2011), programs that promote the development of healthy self-esteem among this population may be particularly crucial to supporting their well-being.

Psychological distress was also significantly associated with psychological wellbeing, with lower psychological distress predicting greater psychological well-being. Considering the moderate size of this association, it is possible that youth may experience minor levels of psychological distress while still having above-average levels of psychological well-being, supporting the notion that psychological health is a distinct construct from psychological well-being (Provencher \& Keyes, 2011). Further research is needed to understand the nuances of this relationship and how to promote mentalemotional health of youth experiencing homelessness. 
Social-contextual correlates of well-being. Empowerment, sense of community, and social support were all positively associated with psychological well-being, such that higher scores on each of these social-contextual variables were associated with greater levels of psychological well-being. Empowerment may encourage homeless youth to take initiative in developing autonomy and gaining mastery over their environments, particularly for youth who display a sense of agency in leaving abusive homes or dangerous circumstances for the sake of their own health and safety. These youth may view homelessness as a situation that they are in control of and that supports their autonomy and thus may feel empowered in their experiences of homelessness.

Further, empowerment could contribute to a sense of purpose and meaning if youth see themselves as being able to make positive changes in their communities, and if service programs support youth to take control of their lives, set goals, and work toward positive changes. Indeed, recent research demonstrates that youth benefit from having “increased voice, choice, and responsibility in developing programs that better respond to" their own needs (Ferguson et al., 2011) (p. 15).

Social support was also significantly associated with psychological well-being. Social support provided by service center programs may aid youth in developing autonomy and mastery while fostering personal growth. Further, these supports may provide youth with opportunities to develop positive social relationships, whether with the service center staff or with other youth who visit the service centers. Developing peer friendships is acutely important to youth and emerging adults as they begin to break away from their families and establish autonomy (e.g., Arnett, 2004). These social relationships 
may be particularly important to the well-being of youth experiencing homelessness because these friendships may be their primary sources of support and protection on the streets (e.g., Oliver \& Cheff, 2014), particularly if they are disconnected from their families. Aside from peer networks, supportive adults in the community may also be important to the well-being of homeless youth, such as by reducing the risk of substance use (Ferguson \& Xie, 2012).

Although sense of community was significantly correlated with psychological well-being, it had the weakest correlation of all intrapersonal and social-contextual variables. Although much research demonstrates the importance of supportive social networks to the well-being of youth, as well as factors associated with the well-being of youth (e.g., Whitbeck, 2009), sense of community may not be equally important to all youth experiencing homelessness or may depend upon their particular circumstances. For example, Rice, Milburn, Rotheram-Borus, Mallett, and Rosenthal (2005) describe the role of peer networks in influencing some homeless youth to engage in problem behaviors, such as substance abuse.

Further, disaffiliation from conventional social structures and identification with street life culture can make transitioning out of homelessness more difficult because research has demonstrated positive associations between adaptation to street life and the length of time spent homeless (Piliavin, Sosin, Westerfelt, \& Matsueda, 1993). And because experiences on the street can exacerbate already existing psychiatric symptoms or result in new symptoms (Whitbeck, 2009), a strong sense of community with other homeless youth may be detrimental to well-being. With these findings in mind, a lower 
sense of community may actually be adaptive if overidentification with other homeless youth puts individuals in danger or exposes them to influences that may interfere with their efforts to transition out of homelessness.

As we discuss in more detail in the Limitations section, additional research is needed to better understand and measure the nuanced relationship between sense of community and psychological well-being among homeless youth, particularly because the strength of affiliation with various communities likely affects the well-being of homeless youth differentially at various stages of homelessness.

Hierarchical regression predicting psychological well-being. Examined collectively, the intrapersonal variables remained significantly associated with psychological well-being, whereas the social-contextual variables did not. Because psychological well-being is an inherently intrapersonal construct, it would be theoretically expected to have a stronger relationship with the intrapersonal variables than the social-contextual variables. From a measurement perspective, it is also likely that there are more similarities in the content of items between the intrapersonal variables and psychological well-being, which could inflate the size of their associations. Future studies should incorporate measures of well-being and its hypothesized correlates that are more conceptually distinct or include multiple respondents (e.g., service staff, peers) and types of measurement (e.g., observational data or secondary analysis of service use data).

\section{Limitations}

Several limitations should be addressed and considered in future research. First, generalizability in this study is limited by (a) the relatively small sample size and (b) the 
fact that data were collected from youth who are engaged in service use. Findings may not generalize to homeless youth who are not currently using services or those who elected not to participate in the study. Furthermore, based on discussions between our university's institutional review board and the partnering community center pertaining to informed consent and guardians not being present to sign consent, youth younger than age 18 years could not be interviewed. Therefore, this study may not generalize to youth who are minors. Moreover, data were collected during the summer months. The experiences of homeless youth from winter to summer may vary, and future research should consider seasonal challenges when studying the well-being of homeless youth.

A second major limitation is that correlational, cross-sectional analyses cannot determine causality, and thus caution should be taken when interpreting findings. It is quite possible that other factors that were not directly measured in this study exist and interact in complex ways to explain differences in psychological well-being. It is also possible that the directionality between well-being and the intrapersonal and socialcontextual predictors may be reversed. For example, youth who have higher levels of well-being may be more likely to seek out opportunities for cultivating social support and sense of community. Longitudinal studies are needed to further understand the direction of effects between variables and their potential interactions.

A third limitation is the possibility for response bias because of the self-reported nature of the data. For example, participants may have felt pressured to manage their selfpresentation and thus may have under- or overreported negative or positive experiences. Although efforts were made to ensure that participants knew that responses would be 
confidential, it is possible that participants were concerned that answering openly and honestly could affect their receipt of services. All efforts were taken to minimize these concerns and to provide resources in the event that any of the questions become distressing.

Finally, the lack of clarity concerning the communities youth were reporting a sense of connectedness to in the sense of community measure is a major limitation of this study. Participants were asked to answer the sense of community questions thinking about the parts of their community where they spend the most time. Thus, although some youth likely thought about the broader geographic community when responding, many youth answered the questions in relation to the homeless youth community or to areas where they spend time with other youth experiencing homelessness (e.g., homeless youth service centers). This inconsistency makes interpretation of findings quite difficult. Future research should consider how to capture the sense of community construct more clearly and consistently and how to best distinguish the importance of youth's localitybased communities from their relational communities, particularly in light of their tendency to view other friends experiencing homelessness as "family."

\section{Directions for future research}

The findings and limitations of this study inform numerous future directions for research. First, replication research is needed to determine whether similar findings are observed among samples of youth experiencing homelessness in different locations, with youth who are not engaged in service centers and with youth from other diverse backgrounds, that may not be reflected here. 
Future studies should also focus on additional risk and protective factors that expand upon the current investigation. In particular, characteristics of personal strength and resilience, which have been found to be associated with well-being, have also been cited by homeless youth as being important to their survival on the streets. Some of these potential protective factors include goal orientation (Kidd \& Shahar, 2008; Usborne et al., 2009), spirituality (Bender et al., 2007; Kidd, 2003), and nonconformity (Bender et al., 2007; Kidd, 2003; Lindsay, Kurtz, Jarvis, Williams, \& Nackerud, 2000). Longitudinal research is also needed to examine causal relationships among the factors examined in this study as well as other factors not included in the current research.

Future research should also incorporate more participatory approaches, such as asking youth about their perspectives of what is important to measure for their wellbeing, which could inform new measures that more accurately reflect their developmental stage and the components of well-being that they prioritize. This research could also ask youth about the ways in which service centers might best meet their needs for physical, emotional, and mental well-being and what barriers might prevent them from accessing such services, as suggested in a review conducted by Thompson, Bender, Windsor, Cook, and Williams (2010). Such participatory research could mirror the framework developed in recent participatory approaches to youth engagement (i.e., Iwasaki, Springett, Dashora, McLaughlin, \& McHugh, 2014) or create setting-specific frameworks using similar participatory approaches. 


\section{Conclusion}

The results of this study expand our understandings of psychological well-being among youth experiencing homelessness. Individual-level factors (e.g., self-esteem, psychological distress, and self-care) appear to be particularly important to well-being, but the influence of social-contextual factors (e.g., social support and empowerment) must also be considered. The findings of this study can inform prevention, health promotion, and interventions for homeless youth as well as assist service centers in developing programs that capitalize on the strengths and values of youth while recognizing the unique challenges and needs of this population. 
Tables

Table 1.

Demographic Percentages

\begin{tabular}{lc}
\hline Gender & Percent \\
\hline Male & 68 \\
Female & 26 \\
Transgender & 3 \\
Non-binary & 2 \\
Gender fluid & 1 \\
\hline Sexual Orientation & Percent \\
\hline Heterosexual & 67 \\
Bisexual & 18 \\
Gay & 3 \\
Other & 12 \\
\hline Racial Background & Percent \\
\hline White & 52 \\
Black & 15 \\
Latino & 6 \\
Native Hawaiian or & \\
other Pacific & 16 \\
Islander & 1 \\
Asian & \\
Multiracial & \\
Other & 16 \\
\hline
\end{tabular}




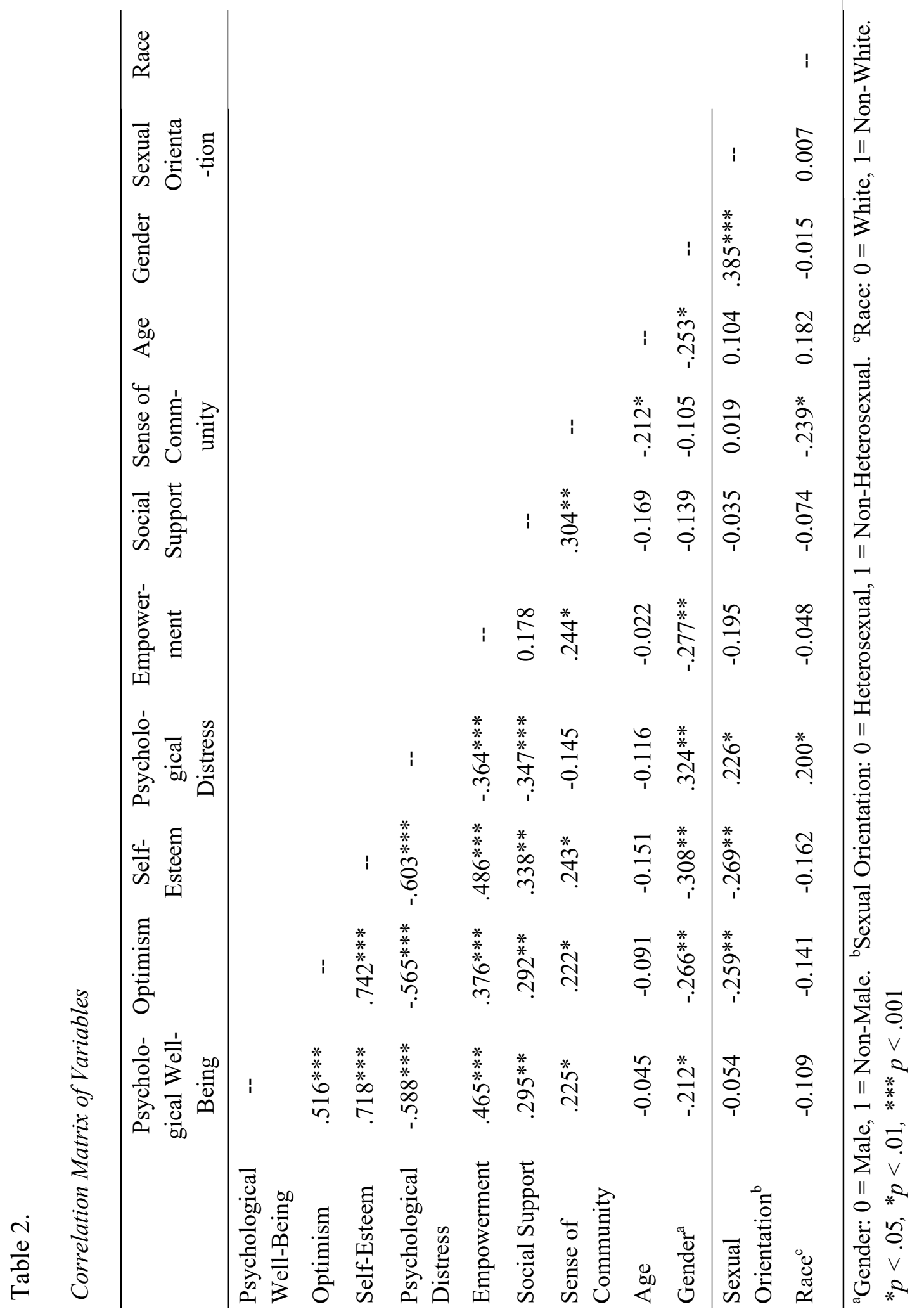


Table 3.

Linear Regression of Intrapersonal Variables Predicting Psychological Well-Being

\begin{tabular}{|c|c|c|c|c|c|}
\hline \multirow{2}{*}{ Variable } & \multicolumn{3}{|c|}{ Model 1} & \multirow{2}{*}{$\mathrm{t}$} & \multirow{2}{*}{$\mathrm{p}$} \\
\hline & $\mathrm{B}$ & $\mathrm{SE}$ & Beta & & \\
\hline (Constant) & 3.09 & .448 & & 6.896 & .000 \\
\hline Gender & .066 & .100 & .048 & .661 & .51 \\
\hline Self-Esteem & .746 & .125 & .647 & 5.98 & .000 \\
\hline $\begin{array}{l}\text { Psychological } \\
\text { Distress }\end{array}$ & -.22 & .071 & -.273 & -3.082 & .003 \\
\hline Optimism & -.092 & .090 & -.106 & -1.016 & .312 \\
\hline
\end{tabular}

$R=.749, R^{2}=.516, p<.001$ 
WELL-BEING AMONG YOUTH EXPERIENCING HOMELESSNESS

Table 4.

Linear Regression of Social-Contextual Variables Predicting Psychological Well-Being

\begin{tabular}{|c|c|c|c|c|c|}
\hline \multirow{3}{*}{ Variable } & \multicolumn{3}{|c|}{ Model 1} & \multirow{3}{*}{$\mathrm{t}$} & \multirow{3}{*}{$\mathrm{p}$} \\
\hline & & & $\beta$ & & \\
\hline & B & $\mathrm{SE}$ & & & \\
\hline (Constant) & 2.495 & .421 & & 5.924 & .000 \\
\hline Gender & -.094 & .126 & -.068 & -.745 & .458 \\
\hline Empowerment & .453 & .108 & .396 & 4.212 & .000 \\
\hline SOC & .075 & .114 & .061 & .652 & .516 \\
\hline Social Support & .005 & .003 & .196 & 2.11 & .038 \\
\hline
\end{tabular}

$R=.52, R^{2}=.27, p<.001$ 
Table 5.

Hierarchical Linear Regression of Intrapersonal and Social-Contextual Variables Predicting Psychological Well-Being

\begin{tabular}{|c|c|c|c|c|c|}
\hline & & & $\beta$ & & \\
\hline Variable & $\mathrm{B}$ & SE & & $\mathrm{R}^{2}$ & $\Delta \mathrm{R}^{2}$ \\
\hline Block 1 & & & & .045 & $.045^{*}$ \\
\hline (Constant) & 4.489 & .077 & & & \\
\hline Gender & -.291 & .136 & $-.212 *$ & & \\
\hline Block 2 & & & & .561 & $.516 * * *$ \\
\hline (Constant) & 3.09 & .448 & & & \\
\hline Gender & .066 & .100 & .048 & & \\
\hline Self-Esteem & .746 & .125 & $.647 * * *$ & & \\
\hline $\begin{array}{l}\text { Psychological } \\
\text { Distress }\end{array}$ & -.22 & .071 & $-.273 * *$ & & \\
\hline Optimism & -.092 & .090 & -.106 & & \\
\hline Block 3 & & & & .577 & .016 \\
\hline (Constant) & 2.615 & .514 & & & \\
\hline Gender & .091 & .101 & .066 & & \\
\hline Self-Esteem & .675 & .131 & $.585 * * *$ & & \\
\hline $\begin{array}{l}\text { Psychological } \\
\text { Distress }\end{array}$ & -.210 & .073 & $-.261 * *$ & & \\
\hline Optimism & -.095 & .090 & -.110 & & \\
\hline Empowerment & .152 & .091 & .133 & & \\
\hline SOC & .049 & .089 & .040 & & \\
\hline Social Support & .000 & .002 & .012 & & \\
\hline
\end{tabular}


Table 6.

Thematic Categories for the Open-Ended Well-being Question

\begin{tabular}{|c|c|c|c|}
\hline Thematic Category & Frequency & $\begin{array}{c}\text { Number } \\
\text { of } \\
\text { Participan } \\
\text { ts }\end{array}$ & Example \\
\hline Social Support & 88 & 62 & $\begin{array}{l}\text { "Friends have helped a lot in } \\
\text { this situation" }\end{array}$ \\
\hline Self-Care & 37 & 24 & "Exercise and healthy choices" \\
\hline Personal Outlook & 32 & 23 & $\begin{array}{l}\text { "Self-motivation not to give } \\
\text { up" }\end{array}$ \\
\hline $\begin{array}{l}\text { Recreational } \\
\text { Activities }\end{array}$ & 29 & 20 & "Reading", "listening to music" \\
\hline Service Center(s) & 26 & 25 & "Service center staff and youth" \\
\hline $\begin{array}{l}\text { Sense of Purpose } \\
\text { and Responsibility }\end{array}$ & 12 & 11 & $\begin{array}{l}\text { "Knowing that they [my kids] } \\
\text { look up to me for love and } \\
\text { support" }\end{array}$ \\
\hline $\begin{array}{l}\text { Learning or } \\
\text { Growth }\end{array}$ & 8 & 7 & "Being in school" \\
\hline Self-Expression & 7 & 6 & $\begin{array}{l}\text { "Being able to express myself } \\
\text { artistically" }\end{array}$ \\
\hline $\begin{array}{l}\text { Vocational } \\
\text { Activities }\end{array}$ & 7 & 7 & "Working at p:ear (barista)" \\
\hline Having Goals & 6 & 6 & "Having plans for future" \\
\hline Spiritual Beliefs & 3 & 3 & "Belief in a higher power" \\
\hline
\end{tabular}


Figures

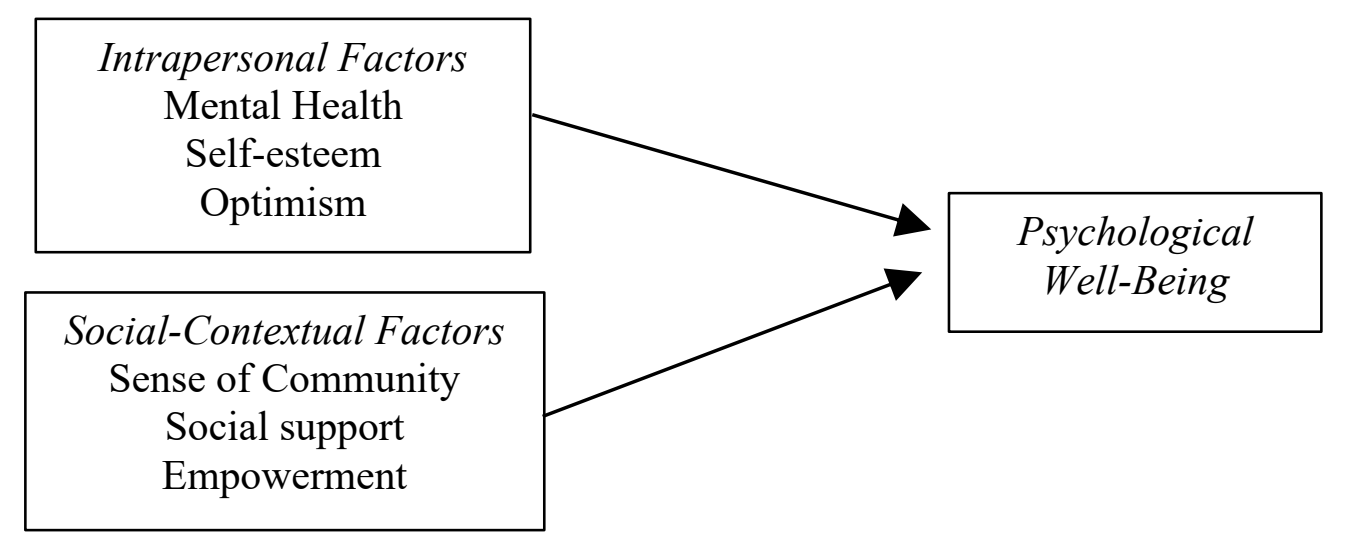

Figure 1. Hypothesized associations between psychological well-being and intrapersonal and social-contextual factors. 


\section{References}

Arnett, J. J. (2004). Emerging Adulthood: The Winding Road from the Late Teens Through the Twenties. Oxford: Oxford University Press.

Barczyk, A. N., Thompson, S. J., \& Rew, L. (2014). The impact of psychosocial factors on subjective well-being among homeless young adults. Health and Social Work, 39, 172-180. https://doi.org/10.1093/hsw/hlu020

Baumeister, R. F., Campbell, J. D., Krueger, J. I., \& Vohs, K. D. (2003). Does high selfesteem cause better performance, interpersonal success, happiness, or healthier lifestyles? Psychological Science in the Public Interest, 4, 1-44. https://doi.org/10.1111/1529-1006.01431

Bender, K., Thompson, S., McManus, H., Lantry, J., \& Flynn, P. (2007). Capacity for survival: Exploring strengths of homeless street youth. Child and Youth Care Forum, 36, 25-42. doi:10.1007/s10566-006-9029-4.

Berg, B.L. (2004). Qualitative Research for the Social Sciences, 5th ed. Boston: Pearson. Biswas-Diener, R., \& Diener, E. (2006). The subjective well-being of the homeless, and lessons for happiness. Social Indicators Research, 76, 185-205. https://doi.org/10.1007/s11205-005-8671-9

Boyatzis, R. E. (1998). Transforming Qualitative Information: Thematic Analysis and Code Development. Thousand Oaks, CA: Sage.

Braun, V., \& Clarke, V. (2006). Using thematic analysis in psychology. Qualitative Research in Psychology, 3, 77-101. doi: 10.1191/1478088706qp063oa 
Bronfenbrenner, U. (1979). The Ecology of Human Development. Cambridge, MA: Harvard University Press.

Castellow, J., Kloos, B., \& Townley, G. (2015). Previous homelessness as a risk factor for recovery from serious mental illnesses. Community Mental Health Journal, 51, 674-684. doi: 10.1007/s10597-014-9805-9

Carver, C. S., \& Gaines, J. G. (1987). Optimism, pessimism, and postpartum depression. Cognitive Therapy and Research, 11, 449-462. https://doi.org/10.1007/BF01175355

Carver, C. S., Scheier, M. F., \& Segerstrom, S. C. (2010). Optimism. Clinical Psychology Review, 30(7), 879-889. http://dx.doi.org/10.1016/j.cpr.2010.01.006

Chavis, D. M., Lee, K. S., \& Acosta, J. D. (2008). The Sense of Community Index (SCI) Revised: The Reliability and Validity of the SCI-2. Paper presented at the 2nd international Community Psychology Conference, Lisbon, Portugal.

Chipuer, H. M., Bramston, P., \& Pretty, G. (2003). Determinants of subjective quality of life among rural adolescents: A developmental perspective. Social Indicators Research, 61, 79-95. https://doi.org/10.1023/A:1021271831731

Christiani, A., Hudson, A. L., Nyamathi, A., Mutere, M., \& Sweat, J. (2008). Attitudes of homeless and drug-using youth regarding barriers and facilitators in delivery of quality and culturally sensitive health care. Journal of Child and Adolescent Psychiatric Nursing, 21, 154-163. doi: 10.1111/j.1744-6171.2008.00139.x

Cleverley, K., \& Kidd, S. A. (2011). Resilience and suicidality among homeless youth. Journal of Adolescence, 34, 1049-1054. doi: 10.1016/j.adolescence.2010.11.003 
Coates, J., \& McKenzie-Mohr, S. (2010). Out of the frying pan, into the fire: Trauma in the lives of homeless youth prior to and during homelessness. Journal of Sociology and Social Welfare, 37, 65-96. doi: 10.3868/s050-004-015-0003-8

Cochran, B.N., Stewart, A. J., Ginzler, J.A., \& Cauce, A.M. (2002). Challenges faced by homeless sexual minorities: Comparison of gay, lesbian, bisexual, and transgender homeless adolescents with their heterosexual counterparts. American Journal of Public Health, 92, 773-777. doi: 10.2105/AJPH.92.5.773

Cohen, S., \& Wills, T. A. (1985). Stress, Social Support, and the Buffering Hypothesis. Psychological Bulletin, 98, 310-357. doi: 10.1037/0033-2909.98.2.310

Davidson, W. B., \& Cotter, P. R. (1991). The relationship between sense of community and subjective well-being: A first look. Journal of Community Psychology, 19, $246-253$.

Diener, E., \& Diener, M. (1995). Cross-cultural correlates of life satisfaction and selfesteem. Journal of Personality and Social Psychology: Personality Processes and Individual Differences, 68, 653-663. doi10.1037/0022-3514.68.4.653

Diener, E., Oishi, S., \& Lucas, R. E. (2003). Personality, culture, and subjective wellbeing: emotional and cognitive evaluations of life. Annual Review of Psychology, 54, 403-425. doi: 10.1146/annurev.psych.54.101601.145056

Diener, E., \& Seligman, M. E. P. (2004). Beyond money: Toward an economy of wellbeing. Science in the Public Interest, 5, 1-31. doi: 10.1126/science.1191273 
Dishion, T., \& Connell, A. (2006). Adolescents' resilience as a self-regulatory process: Promising themes for linking intervention with developmental science. Annals New York Academy of Sciences, 1094, 125-138. https://doi.org/10.1196/annals.1376.012

Dolan, P., Peasgood, T., \& White, M. (2008). Do we really know what makes us happy? A review of the economic literature on the factors associated with subjective wellbeing. Journal of Economic Psychology, 29, 94-122. https://doi.org/10.1016/j.joep.2007.09.001

Durso, L. E., \& Gates, G. J. (2012). Serving Our Youth: Findings from a National Survey of Service Providers Working with Lesbian, Gay, Bisexual and Transgender Youth who are Homeless or at Risk of Becoming Homeless. Los Angeles, CA: The Williams Institute with True Colors Fund and the Palette Fund.

Eid, M., \& Diener, E. (2004). Global judgments of subjective well-being: situational variability and long-term stability. Social Indicators Research, 65, 245-277. https://doi.org/10.1023/B:SOCI.0000003801.89195.bc

Erikson, E. H. (1950). Childhood and Society. New York: W. W. Norton \& Company. Erwin, R. (2014). Adolescent development. Desktop Guide to Quality Practice for Working with Youth in Confinement. National Partnership for Juvenile Services and Office of Juvenile Justice and Delinquency Prevention. https://info.nicic.gov/dtg/node/10.

Farrington, A., \& Robinson, W. P. (1999). Homelessness and strategies of identity maintenance: A participant observation study. Journal of Community and Applied 
WELL-BEING AMONG YOUTH EXPERIENCING HOMELESSNESS

Social Psychology, 9, 175-194. https://doi.org/10.1002/(SICI)10991298(199905/06)9:3<175::AID-CASP497>3.0.CO;2-R

Felitti, V. J., Anda, R. F., Norenberg, D., Williamson, D. F., Spitz, A. M., \& Edwards, V. (1998). Relationship of childhood abuse and household dysfunction to many of the leading courses of death in adults. American Journal of Preventive Medicine, 14, $245-258$.

Ferguson, K. M., Kim, M. A., \& McCoy, S. (2011). Enhancing empowerment and leadership among homeless youth in agency and community settings: A grounded theory approach. Child and Adolescent Social Work Journal, 28, 1-22. doi: $10.1007 / \mathrm{s} 10560-010-0217-6$

Flanagan, C. A. (2004). Volunteerism, leadership, political socialization, and civic engagement. In R. M. Lerner \& L. Steinberg (Eds.), Handbook of Adolescent Psychology (pp. 721-746). New York: Wiley.

Friis-Hansen, E., \& Duveskog, D. (2012). The empowerment route to well-being: An analysis of farmer field schools in East Africa. World Development, 40, 414-427. doi: 10.1016/j.worlddev.2011.05.005

Gracia, E., \& Herrero, J. (2004). Determinants of social integration in the community: An exploratory analysis of personal, interpersonal and situational variables. Journal of Community and Applied Psychology, 14, 1-15. doi:

https://doi.org/10.1002/casp.746 
Gray-Little, B., Williams, V. S. L., \& Hancock, T. D. (1997). An item response theory analysis of the Rosenberg Self-Esteem Scale. Personality and Social Psychology Bulletin, 23, 443-451. https://doi.org/10.1177/0146167297235001

Grigsby, C., Baumann, D., Gregorich, S.E., \& Roberts-Gray, C. (1990). Disaffiliation to entrenchment: A model for understanding homelessness. Journal of Social Issues, 46, 141-156. http://dx.doi.org/10.1111/j.1540-4560.1990.tb01803.x

Haber, M. G., \& Toro, P. A. (2009). Parent-adolescent violence and later behavioral health problems among homeless and housed youth. American Journal of Orthopsychiatry, 79, 305-318. http://dx.doi.org/10.1037/a0017212

Hatzenbuehler, M. L., McLaughlin, K. A., \& Nolen-Hoeksema, S. (2008). Emotion regulation and internalizing symptoms in a longitudinal study of sexual minority and heterosexual adolescents. Journal of Child Psychology and Psychiatry, and Allied Disciplines, 49, 1270-1278. doi: 10.1111/j.1469-7610.2008.01924.x

Helliwell, J. F., \& Putnam, R. (2004). The social context of well-being. Philosophical Transactions of the Royal Society of London. Series B, Biological sciences, 359, 1435-1446. doi: 10.1098/rstb.2004.1522

Hodgson, K. J., Shelton, K. H., van den Bree, M. B., \& Los, F. J. (2013).

Psychopathology in young people experiencing homelessness: a systematic review. American Journal of Public Health, 103, e24-e37. doi: 10.2105/AJPH.2013.301318 Huberman, M., \& Miles, M.B. (2002). The Qualitative Researcher's Companion. Thousand Oaks, CA: Sage. 
Hudson, A. L., Nyamathi, A., Greengold, B., Slagle, A., Koniak-Griffin, D., Khalilifard, F., \& Getzoff, D. (2010). Health-seeking challenges among homeless youth. Nursing research, 59, 212-218. doi: 10.1097/NNR.0b013e3181d1a8a9

Huppert, F. A., \& Cooper, C. L. (2014). Wellbeing: A Complete Reference Guide, Interventions, and Policies to Enhance Wellbeing. Hoboken, NJ: John Wiley \& Sons, Inc.

Jetten, J., Haslam, C., Haslam, S. A., Dingle, G., \& Jones, J. M. (2014). How groups affect our health and well-being: The path from theory to policy. Social Issues and Policy Review, 8, 103-130. doi: 10.1111/sipr.12003

Johnstone, M., Jetten, J., Dingle, G. A., Parsell, C., \& Walter, Z. C. (2016). Enhancing well-being of homeless individuals by building group memberships. Journal of Community and Applied Social Psychology, 26, 421-438. doi: 10.1002/casp.2272

Joiner, T. E. (1995). The price of soliciting and receiving negative feedback: Selfverification theory as a vulnerability to depression theory. Journal of Abnormal Psychology, 104, 364-372. http://dx.doi.org/10.1037/0021-843X.104.2.364

Karabanow, J. (2006). Becoming a street kid: Exploring the stages of street Me. Journal of Human Behavior in the Social Environment, 1, 49-72.

Kessler, R. C., Andrews, G., Colpe, L. J., Hiripi, E., Mroczek, D. K., Normand, S. L., ... \& Zaslavsky, A. M. (2002). Short screening scales to monitor population prevalence and trends in non-specific psychological distress. Psychological Medicine, 32, 959-976. doi: 10.1017?S0033291702006074 
Kessler, R. C., Berglund, P., \& Demler, O., et al. (2005): Lifetime prevalence and age-ofonset distributions of DSM-IV disorders in the National Comorbidity Survey Replication. Archives of General Psychiatry, 62, 593-602. doi: 10.1001/archpsyc.62.6.593

Keyes, C. L. M. (2002). The mental health continuum: From languishing to flourishing in life. Journal of Health and Social Behavior, 43, 207-222. doi: 10.2307/3090197

Kidd, S. A. (2003). Street youth: coping and interventions. Child and Adolescent Social Work Journal, 20, 235-261. https://doi.org/10.1023/A:1024552808179

Kidd, S. A., \& Carroll, M. R. (2007). Coping and suicidality among homeless youth. Journal of Adolescence, 30, 283-296. http://dx.doi.org/10.1016/j.adolescence.2006.03.002

Kidd, S. A., \& Davidson, L. (2009). Homeless youth: The need to link research and policy. Finding home: Policy options for addressing homelessness in Canada, 1-9.

Kidd, S. A., \& Kral, M. J. (2002). Suicide and prostitution among street youth: A qualitative analysis. Adolescence, 37, 411-430.

Kidd, S., \& Shahar, G. (2008). Resilience in homeless youth: the key role of self-esteem. American Journal of Orthopsychiatry, 78, 163-172. doi: 10.1037/00029432.78 .2 .163

Kozloff, N., Cheung, A. H., Ross, L. E., Winer, H., Ierfino, D., Bullock, H., \& Bennett, K. J. (2013). Factors influencing service use among homeless youths with cooccurring disorders. Psychiatric Services, 64, 925-928. http://dx.doi.org/10.1176/appi.ps.201200257 
Kozloff, N., Stergiopoulos, V., Adair, C. E., Cheung, A. H., Misir, V., Townley, G., ... \&

Goering, P. (2016). The Unique Needs of Homeless Youths with Mental Illness: Baseline Findings From a Housing First Trial. Psychiatric Services, 67, 1083-1090. doi: 10.1176/appi.ps.201500461

Krauss, S. E., Collura, J., Zeldin, S., Ortega, A., Abdullah, H., \& Sulaiman, A. H. (2014). Youth-adult partnership: Exploring contributions to empowerment, agency and community connections in Malaysian youth programs. Journal of Youth and Adolescence, 43, 1550-1562. doi: 10.1177/0044118X15595153

Leary, M. R., \& MacDonald, G. (2003). Individual differences in self-esteem: A review and theoretical integration. In M.R. Leary, J.P. Tangney (Eds.), Handbook of self and identity (pp. 401-418). Guilford Press, New York, NY.

Lehman, A. F. (1983). The well-being of chronic mental patients: Assessing their quality of life. Archives of General Psychiatry, 40, 369-373. doi:

10.1001/archpsyc. 1983.01790040023003

Lin, C. C. (2015a). Self-esteem mediates the relationship between dispositional gratitude and well-being. Personality and Individual Differences, 85, 145-148. doi: 10.1016/j.paid.2016.01.020

Lindsay, E.W., Kurtz, D., Jarvis, S., Williams, N. R., \& Nackerud, L. (2000). How runaways and homeless youth navigate troubled waters: personal strengths and resources. Child and Adolescent Social Work Journal, 17, 115-140. https://doi.org/10.1023/A:1007558323191 
Maccio, E. M., \& Schuler, J. T. (2012). Substance use, self-esteem, and self-efficacy among homeless and runaway youth in New Orleans. Child and Adolescent Social Work Journal, 29, 123-136.

Makadon, H.J. (2011). Ending LGBT invisibility in health care: the first step in ensuring equitable care. Cleveland Clinical Journal of Medicine, 78, 220-224. doi: 10.3949/ccjm.78gr.10006

Mann, N., Hosman, C. M. H., Schaalma, H. P., \& deVries, N. K. (2004). Self-esteem in a broad-spectrum approach for mental health promotion. Health Education Research, 19, 357-372. doi: 10.1093/her/cyg041

Mazzoni, D., Cicognani, E., Albanesi, C., \& Zani, B. (2014). Quality of participation experience, sense of community and their impact on young people's social wellbeing. Giornale Italiano di Psicologia, 41, 205-228. https://doi.org/10.1421/77213

Meyer, B. (2001). Coping with severe mental illness: relations of the Brief COPE with symptoms, functioning, and well-being. Journal of Psychopathology and Behavioral Assessment, 23, 265-277. https://doi.org/10.1023/A:1012731520781

Morgan, M. L., Vera, E. M., Gonzales, R. R., Conner, W., Bena Vacek, K., \& Dick Coyle, L. (2011). Subjective well-being in urban adolescents: Interpersonal, individual, and community influences. Youth and Society, 43, 609-634. doi: $10.1177 / 0044118 X 09353517$

NAEH (National Alliance to End Homelessness). (2014). Youth. Available from: http://www.endhomelessness.org/pages/youth [last accessed 14 May 2016]. 
WELL-BEING AMONG YOUTH EXPERIENCING HOMELESSNESS

National Health Care for the Homeless Council. (2008). Child and youth homelessness: 2008 policy statements. Retrieved 12 November 2008, from http://www.nhchc.org/Advocacy/PolicyPapers/Child Youth2008.pdf

Peterson, N. A., Peterson, C. H., Agre, L., Christens, B. D., \& Mort, C. M. (2011). Measuring youth empowerment: Validation of a sociopolitical control scale for youth in an urban community context. Journal of Community Psychology, 39, 592605. https://doi.org/10.1002/jcop.20456

Pichler, F. (2006). Subjective quality of life of young Europeans: Feeling happy but who knows why? Social Indicators Research, 75, 419-444. https://doi.org/10.1007/s11205-004-4337-2

Piliavin, I., Sosin, M., Westerfield, A.H., \& Matsueda, R.L. (1993). The duration of homeless careers: An exploratory study. Social Service Review, 67, 576-598.

Pretty, G. M., Conroy, C., Dugay, J., Fowler, K., \& Williams, D. (1996). Sense of community and its relevance to adolescents of all ages. Journal of Community Psychology, 24, 365-379.

Prezza, M., Amici, M., Roberti, T., \& Tedeschi, G. (2001). Sense of community referred to the whole town: Its relations with neighboring, loneliness, life satisfaction and area of residence. Journal of Community Psychology, 29, 29-52. https://doi.org/10.1002/1520-6629(200101)29:1<29::AID-JCOP3>3.0.CO;2-C Prezza, M., \& Costantini, S. (1998). Sense of community and life satisfaction: Investigation in three different territorial contexts. Journal of Community and 
WELL-BEING AMONG YOUTH EXPERIENCING HOMELESSNESS

Applied Social Psychology, 8, 181-194. https://doi.org/10.1002/(SICI)10991298(199805/06)8:3<181::AID-CASP436>3.0.CO;2-4

Provencher, H. L., \& Keyes, C. L. (2011). Complete mental health recovery: Bridging mental illness with positive mental health. Journal of Public Mental Health, 10, 5769.

Ramirez-Valles, J., Garcia, D., Campbell, R. T., Diaz, R. M., \& Heckathorn, D. D. (2008). HIV infection, sexual risk behavior, and substance use among latino, gay, and bisexual men and transgender persons. American Journal of Public Health, 98, 1036-1042. doi: 10.2105/AJPH.2006.102624

Rappaport, J. (1987). Terms of empowerment/exemplars of prevention: Toward a theory for community psychology. American Journal of Community Psychology, 15, 121148. doi: 10.1007/BF00919275

Reeg, B. (2003). The Runaway and Homeless Youth Act and disconnected youth. In J. Levin-Epstein \& M.H. Greenberg MH (Eds.), Leave no youth behind: Opportunities for congress to reach disconnected youth. Washington, DC: Center for Law and Social Policy.

Reid, S., Berman, H., \& Forchuk, C. (2005). Living on the streets in Canada: A feminist narrative study of girls and young women. Issues in Comprehensive Pediatric Nursing, 28, 237-256. doi: 10.1080/01460860500396906 Rice, E., Milburn, N. G., Rotheram-Borus, M. J., Mallett, S., \& Rosenthal, D. (2005). The effects of peer group network properties on drug use among homeless 
WELL-BEING AMONG YOUTH EXPERIENCING HOMELESSNESS

youth. American Behavioral Scientist, 4, 1102-1123. doi:

$10.1177 / 0002764204274194$

Rosenberg, M. (1965). Society and the Adolescent Self-Image. Princeton, NJ: Princeton University.

Rosenberg, M. Schooler, C., Schoenbach, C., \& Rosenberg, F. (1995). Global self-esteem and specific self-esteem: Different concepts, different outcomes. American Sociological Review, 60, 141-156. http://dx.doi.org/10.2307/2096350

Roy, E., Haley, N., Leclerc, P., Sochanski, B., Boudreau, J., \& Boivin, J. (2004). Mortality in a cohort of street youth in Montreal. Journal of the American Medical Association, 292, 569-574. doi: 10.1001/jama.292.5.569

Ryff, C. D. (1989). Happiness is everything, or is it? Explorations on the meaning of psychological well-being. Journal of Personality and Social Psychology, 57, 10691081. http://dx.doi.org/10.1037/0022-3514.57.6.1069

Ryff, C. D. (1995). Psychological well-being in adult life. Current Directions in Psychological Science, 4, 99-104. https://doi.org/10.1111/1467-8721.ep10772395

Ryff, C. D., \& Keyes, C. L. M. (1995). The structure of psychological well-being revisited. Journal of Personality and Social Psychology, 69, 719-727. http://dx.doi.org/10.1037/0022-3514.69.4.719

Sarason, S. B. (1974). The Psychological Sense of Community: Prospects for a Community Psychology. San Francisco: Jossey-Bass. 
Scheier, M. F., \& Carver, C. S. (1985). Optimism, coping, and health: assessment and implications of generalized outcome expectancies. Health Psychology, 4, 219-247. http://dx.doi.org/10.1037/0278-6133.4.3.219

Scheier, M. F., Carver, C. S., \& Bridges, M. W. (1994). Distinguishing optimism from neuroticism (and trait anxiety, self-mastery, and self-esteem): A reevaluation of the Life Orientation Test. Journal of Personality and Social Psychology, 67, 10631078. doi: 10.1037//0022-3514.67.6.1063

Snow, D.A., \& Anderson, L. (1987). Identity work among the homeless: The verbal construction and avowal of personal identities. American Journal of Sociology, 92, 1336-1371. http://dx.doi.org/10.1086/228668

Sonn, C. C., \& Fisher, A. T. (1996). Aspirations to community: Community responses to rejection. Journal of Community Psychology, 24, 417-430. https://doi.org/10.1002/(SICI)1520-6629(199911)27:6<715::AIDJCOP6>3.0.CO;2-5

Suslow, T., Roestela, C., Ohrmanna, P., \& Arolta, V. (2003). The experience of basic emotions in schizophrenia with and without affective negative symptoms. Comprehensive Psychiatry, 44, 303-310.

Taylor, S. E., \& Armor, D. A. (1996). Positive illusions and coping with adversity. Journal of Personality, 64, 873-898. https://doi.org/10.1111/j.14676494.1996.tb00947.x 
Taylor, D. M., Lydon, J. E., Bougie, É., \& Johannesen, K. (2004). "Street Kids": Towards an Understanding of Their Motivational Context. Canadian Journal of Behavioural Science, 36, 1-16. http://dx.doi.org/10.1037/h0087211

Townley, G., Pearson, L., Lehrwyn, J. M., Prophet, N. T., \& Trauernicht, M. (2016). Using participatory mapping and GIS to examine the activity spaces of homeless youth. American Journal of Community Psychology, 57, 404-414. doi:

10.1002/ajcp. 12060

Usborne, E., Lydon, J. E., \& Taylor, D. M. (2009). Goals and social relationships: Windows into the motivation and well-being of "street kids." Journal of Applied Social Psychology, 39, 1057-1082. doi: 10.1111/j.1559-1816.2009.00472.x

Watson, D., Suls, J., \& Haig, J. (2002). Global self-esteem in relation to structural models of personality and affectivity. Journal of Personality and Social Psychology, 83, 185-197. http://dx.doi.org/10.1037/0022-3514.83.1.185

Weich, S., Brugha, T., King, M., McManus, S., Bebbington, P., Jenkins, R., Cooper, C., McBride, O., Stewart-Brown, S. (2011). Mental well-being and mental illness: Findings from the Adult Psychiatric Morbidity Survey for England 2007. British Journal of Psychiatry, 199, 23-28. doi: 10.1192/bjp.bp.111.091496

White, J. M., \& Jones, R. M. (1996). Identity style of male inmates. Criminal Justice and Behavior, 23, 490-504. https://doi.org/10.1177/0093854896023003005

White, J. M., Wampler, R. S., \& Winn, K. I. (1998). The identity style inventory: A revision with a sixth-grade reading level (ISI-6G). Journal of Adolescent Research, 13, 223-245. http://dx.doi.org/10.1177/0743554898132007 
Whitbeck, L. B., Hoyt, D. R., Johnson, K. D., \& Chen, X. (2007). Victimization and posttraumatic stress disorder among runaway and homeless adolescents. Violence and Victims, 22, 721-734. http://dx.doi.org/10.1891/088667007782793165

World Health Organization. (2014). Mental health: A state of well-being. Available online at: http://www.who.int.proxy.lib.pdx.edu/features/factfiles/mental_health/en/

van Wormer, R. (2003). Homeless youth seeking assistance: A research-based study from Duluth, Minnesota. Child and Youth Care Forum, 32, 89-103. https://doi.org/10.1023/A:1022589002915

Youniss, J., \& Yates, M. (1999). Youth service and moral-civic identity: A case for everyday morality. Educational Psychology Review, 11, 363-378.

Zimmerman, M., \& Rappaport, J. (1988). Citizen participation, perceived control and psychological empowerment. American Journal of Community Psychology, 5, 725750. https://doi.org/10.1007/BF00930023

Zlotnick, C., Robertson, M. J., \& Lahiff, M. (1999). Getting off the streets: Economic resources and residential exits from homelessness. Journal of Community Psychology, 27, 209-224. https://doi.org/10.1002/(SICI)15206629(199903)27:2<209::AID-JCOP8>3.0.CO;2-2 
Chapter III: Community and well-being: A qualitative study of how youth experiencing homelessness define community and its relations to their well-being

Stewart, K., \& Townley, G. (2020a). Community and well-being: A qualitative study of how youth experiencing homelessness define community and its relations to their well-being. Journal of Community Psychology, 48(3), 994-1009.

\begin{abstract}
Prior research with youth experiencing homelessness suggests that community experiences can play an important role in their resilience and well-being. This literature suggests that a sense of community and social support may be two key interpersonal factors related to the well-being of this population. However, quantitative research exploring these relationships has resulted in inconsistent findings, which may be due to a lack of understanding regarding youth's definitions of and experiences with community. This study utilized semi-structured, qualitative interviews with 24 youth experiencing homelessness to explore their definitions of community, how it is important to them, what communities they are a part of, and how these communities contribute to their wellbeing. Overall, findings suggest that 1) youth generally define community in ways that align with current theory on sense of community, 2) youth view community as important, and 3) their experiences within community settings promote their overall well-being in various ways. However, the findings also suggest that community is not always a positive experience for these youth. This research has implications for how to promote the wellbeing of youth experiencing homelessness, as well as how sense of community and social support may relate to the well-being of this population.
\end{abstract}




\section{Introduction}

Youth experiencing homelessness are unaccompanied adolescents and young adults (ages 12-24) who do not have stable dwellings, but instead live on the streets, in shelters, or other precarious situations (Kidd \& Davidson, 2009). Every year, at least 550,000 youth experience an episode of homelessness lasting longer than one week (National Alliance to End Homelessness, 2014).

Various factors may contribute to and sustain youth homelessness, including familial conflict or breakdown (Mallett, Rosenthal, \& Keyes, 2005), risk factors associated with street life (e.g., violence and abuse; Coates \& McKenzie-Mohr, 2010; Mallett, Rosenthal, \& Keyes, 2005), or structural and economic hurdles (e.g., financial barriers to accessing healthcare and difficulty accessing free or affordable housing and education; Christiani, Hudson, Nyamathi, Mutere, \& Sweat, 2008; National Health Care for the Homeless Council, 2008).

Further, the risk factors youth face both prior to and during homelessness contribute to the atypically high rates of mental illness, suicidal ideation, and attempted and completed suicide experienced by this population (Desai, Liu-Mares, Dausey, \& Rosenheck, 2003; Kamieniecki, 2001; Moore, 2005). This interaction between risk factors, structural barriers, and psychiatric distress has the potential to prolong homelessness and its negative impact among youth experiencing homelessness.

Despite the challenges faced by many youth experiencing homelessness, some research suggests that they have similar levels of well-being as their housed peers (Taylor, Lydon, Bougie \& Johannesen, 2004). Because youth experiencing homelessness 
cite high levels of optimism and a need to focus on positives in order to cope with their situations (e.g., Bender, Thompson, McManus, Lantry, \& Flynn, 2007; Kidd, 2003; Usborne et al., 2009), and because subjective well-being measures require comparisons to whatever standard is salient at the time of judgment (Diener, 2009), youth's quantitatively reported levels of well-being may be skewed in a positive direction. Furthermore, while prior research suggests that certain factors (such as sense of community and social support) are related to the well-being of youth experiencing homelessness (e.g., Stewart \& Townley, 2019), this research has yet to explore why these factors are important to the well-being of youth and how these factors operate in their daily lives. Even if the prior research on youth's well-being is not skewed, the quantitative results of this research will be more useful to service providers and communities if it is coupled with an understanding of the "how" and "why" of homeless youth's well-being.

Based on prior research demonstrating the importance of community experiences and social support to the well-being of youth experiencing homelessness (e.g., Bender et al., 2007; Karabanow, 2006; Morgan et al., 2011; Taylor et al., 2004; Townley et al., 2016; Stewart \& Townley, 2019), the current research focuses specifically on how sense of community and social support relate to the well-being of youth experiencing homelessness. By allowing youth to describe - in their own terms - their experiences of community, social support, and well-being, researchers can begin to understand (1) how youth understand and define these factors, (2) how these factors operate in the day-to-day lives of youth, as well as (3) directions for future research that applies these in-depth 
understandings of youth's relationships with their communities and peers and how those experiences impact their well-being.

\section{Sense of Community among Youth Experiencing Homelessness}

Sense of community is "the sense that one is part of a readily available, mutually supportive network of relationships" (Sarason, 1974, p. 1), and comprises (a) a feeling that members have of belonging; (b) a feeling that members matter to one another and to the group; and (c) a shared faith that members' needs will be met through their commitment to be together (McMillan \& Chavis, 1986). This conceptualization of sense of community has four components. First, membership, which is a feeling of belonging or of sharing a sense of personal relatedness. Second, influence is a sense of mattering to the group and of making a difference to the group. Third, integration and fulfillment of needs is a feeling that members' needs will be met by the resources received via group membership, typically based upon reinforcement and shared values. And finally, shared emotional connection is a commitment to and belief that members have shared and will share history, common places, time together, and similar experiences (McMillan \& Chavis, 1986).

Sense of community (SOC) has a well-established role in influencing well-being across the lifespan (e.g., Chipuer \& Pretty, 1999; Chipuer, Bramston, \& Pretty, 2003), and has been associated with increased psychological well-being (e.g., Prezza et al., 2001) and quality of life (Stevens, Guerrero, Green, \& Jason, 2017). Community participation has been shown to strengthen social bonds and sense of belonging, and to enhance individual and collective well-being (Wandersman \& Florin, 2000). With these 
findings in mind, it is unsurprising that youth experiencing homelessness cite the importance of the 'homeless youth community' and peer support networks as critical to their well-being (e.g., Bender et al., 2007). Further, emerging research suggests a positive relationship between sense of community and psychological well-being among youth experiencing homelessness (Stewart \& Townley, 2019), and prior research has found that youth's participation in social, recreational, and vocational activities was significantly related to both their SOC and psychological well-being (Townley et al., 2016).

\section{Social Support Among Youth Experiencing Homelessness}

Social support encompasses both formal and informal supports and is sometimes defined as an exchange between providers and recipients (Antonucci, 1985; House \& Kahn, 1985). It can include functional components (e.g., emotional support) and structural components (e.g., the size of an individual's social circle), as well as enacted support (e.g., receipt of supportive behaviors) and an individual's subjective perception of support from others (Cohen, 1988; House, Landis, \& Umberson, 1988; Lakey \& Lutz, 1996). Further, social support likely has some conceptual overlap with sense of community. For example, the components of the shared emotional connection and integration and fulfillment of needs within SOC have the potential to reflect the functional and enacted supports listed above, as prior literature has discussed (e.g., Felton \& Shinn, 1992).

Prior research suggests that the number and strength of an individual's social connections are two of the strongest predictors of well-being among various populations (e.g., Cohen \& Wills, 1985; Dolan, Peasgood, \& White, 2008; Helliwell \& Putnam, 
2004), while effective social support through social connectedness may enhance health and well-being (Cohen \& Wills, 1985; Jetten, Haslam, Haslam, Dingle, \& Jones, 2014). Interpersonal relationships and social support have been found to contribute to well-being among individuals experiencing homelessness (Biswas-Diener \& Diener, 2006; Stewart \& Townley, 2019), with more recent research suggesting that gains in social support can benefit well-being among individuals utilizing homeless services and housing programs (Johnstone, Aschkenasy, Herbers, \& Gillenwater, 2016).

Because homeless youth do not typically have supportive relationships with their families and can experience social exclusion and disaffiliation from conventional social structures (e.g., Cauce et al., 2000), they often develop peer social networks and rely on one another rather than on family members, service providers, or authority figures (Karabanow, 2006; Taylor et al., 2004). These networks of "street friends" contribute to a sense of belonging and connectedness, help youth combat feelings of loneliness and alienation, provide them with emotional support and assistance, and help them adapt to the complexities of street life (Bender et al., 2007). Considering that placing trust in close friendships is a buffer against feelings of insecurity and vulnerability (Taylor et al., 2004), these peer social support networks have the potential to aid the socialpsychological well-being and resilience of youth experiencing homelessness. Indeed, research suggests that the unexpectedly high level of well-being reported among this population may be due to the size and makeup of their social networks (Taylor et al., 2004; Usborne, Lydon, \& Taylor, 2009). However, it is important to note that the social support networks youth develop are not always associated with positive outcomes: some 
literature suggests that youth can be further victimized by others experiencing homelessness (e.g., Cauce et al., 2000), and that entrenchment in street culture can make exiting homeless more difficult (e.g., Ennett, Bailey, \& Federman, 1999).

\section{Current Research}

Despite the risk factors and challenges faced by many youth experiencing homelessness (e.g., Coates \& McKenzie-Mohr, 2010; Mallett, Rosenthal, \& Keyes, 2005), recent research suggests that youth are often resilient as they capitalize on both internal and external resources to survive on the streets (Cleverley \& Kidd, 2011; Kidd \& Carroll, 2007; Kidd \& Shahar, 2008). This adaptation in the face of adversity may be a key component to maintaining one's well-being while homeless, and emerging research points to the importance of community-factors and social support in bolstering the wellbeing of youth experiencing homelessness (e.g., Bender et al., 2007; Townley et al., 2016). Considering the strong relationship between resilience and well-being outcomes (e.g., Mak, Ng, \& Celia, 2011), examining the nature of well-being among homeless youth may be critical to understanding how youth are able to overcome the stressors of street life, as well as what can be done to bolster their chances of experiencing positive outcomes despite the adversities they face.

While prior scholarship on the well-being of youth experiencing homelessness provides a starting point for understanding how community experiences and social support might relate to their well-being, little empirical research has qualitatively examined the variety of communities with which homeless youth identify, and how involvement with these communities might impact their well-being. Prior literature 
suggests that sense of community and social support are important to the well-being of youth experiencing homelessness (e.g., Stewart \& Townley, 2019), but more nuanced research is needed to determine how these constructs operate in the daily lives of these youth, as well as how researchers and service providers might better support the wellbeing of youth through community and social support interventions.

\section{Research Questions}

The empirical research that has focused on well-being outcomes has not explored why certain factors are so crucial to the well-being of this population, particularly community-level factors. Specifically, prior research has yet to qualitatively explore the following questions:

1) What does 'community' mean to youth experiencing homelessness?

2) What aspects of youth's community-related experiences impact their wellbeing?

The current research draws on prior literature on how community experiences relate to the well-being of individuals as its foundation and extends this research to examine community experiences related to well-being among youth experiencing homelessness. We expect that the ways in which youth understand and experience community may contribute to their well-being and resilience during homelessness. However, it is also expected that some youth will have negative experiences of community and describe benefits gained by disengaging from community. This research has the potential to inform our understanding of the important connection between 
supportive community experiences and well-being among youth experiencing homelessness.

\section{Methods}

\section{Participants}

The participants in this study were 24 youth experiencing homeless who were engaged in the services provided by p:ear (project: education, art, recreation), a nonprofit youth mentoring center in the Pacific Northwest. This non-profit center focuses on building positive relationships with youth who are homeless or in transition, with programs focused on art, education, and recreation. The drop-in center also provides food and a space for youth to utilize during the daytime.

Of the 24 youth, thirteen identified as male, nine as female, and two as genderqueer. The age range was $18-24$, with a mean age of 21 . The sample was quite ethnoracially diverse compared to the broader city: thirteen were white, two were black, two Native American, one Latino, and six reported being multiracial.

We intentionally omit the socio-demographic characteristics of the individuals who are quoted in the results section. Due to the small sample size and the close relationships that are formed with youth in the community center where interviews were conducted, leaving demographic information detached from quotes protects anonymity for the youth participants.

\section{Procedures}

The interviews examined in this study comprised the second part of a three-part research project with 28 youth experiencing homelessness, with the first part involving 
the creation of activity maps with youth (see Townley et al., 2016) and the third part involving a brief quantitative survey. The data for this component of the project were collected via qualitative, semi-structured, one-on-one interviews with 24 of the 28 youth who started the project (four youth did not return to the community center after their initial visit). Youth were recruited directly from the community center via recruitment flyers and word of mouth. Youth were asked to commit to participating in all three parts of the project and were provided with small cash incentives at the completion of each part of the project.

Interviews were conducted at p:ear in a side room that is quieter and more private than the main room of the drop-in center. Before beginning interviews, research assistants obtained informed consent approved by our university's Institutional Review Board and p:ear staff. Interviews were 20 to 40 minutes in length and were audio-recorded and later transcribed by research assistants. Any identifying information was removed from the transcripts and replaced with other non-identifying words.

The interview protocol included the following questions, answers to which were incorporated into the current analysis:

5. What does the word 'community' mean to you?

6. Is the idea of 'community' important to you? Do you like participating in communities or would you rather stay more to yourself?

7. What types of communities do you belong to?

8. What things in your life have made your day-to-day living better or harder for you? 


\section{Data Analysis}

Data analysis consisted of a primarily deductive approach that incorporated previous research and theory on well-being, sense of community, and social support. While all codes were created based on text from the transcripts, prior research and theory were utilized to help determine theme titles and descriptions when codes overlapped with pre-existing concepts. However, the authors remained sensitive to counter-examples and utilized inductive reasoning when data suggested important points outside of existing theories and frameworks.

Both authors engaged in the data analysis process, primarily through a peerdebriefing model (Lincoln \& Guba, 1985): the first author conducted the primary analysis and the second author reviewed the process with her. The transcripts were first read to gain an overall understanding of what was discussed in the interviews. The coding process began with the second read-through, during which chunks of text were marked with the relevant codes. These marked chunks of text were then grouped together based on the question they referred to and the code they were assigned. After grouping text segments by codes, themes were created by combining similar codes. Next, previous research and theory were consulted to help organize and define the overarching themes. The themes and codes were then reapplied to the transcripts in order to check for accuracy and to identify additional text segments that might fit into the established themes. During peer debriefing, the second author reviewed all transcripts and codes with the first author and helped her clarify the basis for her interpretations and conclusions. Any discrepancies between authors were discussed in order to arrive at consensus. 


\section{Results}

Youth were asked questions pertaining to what community means to them, whether it is important to them, and what communities they are a part of, as well as questions regarding what makes their day-to-day living easier or more difficult. For the purposes of this paper, we focus on youth's responses to what community means and how it is important to them. Further, we utilize their descriptions of the communities they are a part of and what makes their day-to-day living easier or more difficult in order to elaborate on their explanations of what community means, why it might be important to them, and how it relates to their well-being. The following sections first present a general definition of the theme, followed by youth's descriptions of community that contributed to the creation of that theme. Youth's descriptions of their own community experiences that relate to their well-being are then provided as examples of the theme.

\section{Meanings of Community}

In response to the first question, "What does the word 'community' mean to you?", four themes emerged: Commonality, Membership-Acceptance, Social Support, and Collaboration. These themes are defined as follows: 1) Commonality: an experience of shared interests, shared history, common goals, or a binding force; 2) MembershipAcceptance: a feeling of belonging, personal relatedness, or acceptance within a group; 3 ) Social Support: an experience of having one's needs met by the group, a desire to support the needs of others in the group, and an overall sense of reciprocity; and 4) Collaboration: a group of people working towards a common goal and establishing their own rules for the sake of all members. 
While there was evidence of overlap among the four themes, each also stood out as being a distinct component of community in the descriptions provided by the youth. Some of the themes can precede or follow others. For example, shared experiences (commonality) can contribute to emotional connection and personal relatedness (membership-acceptance), while working together towards a common goal (collaboration) can overlap with having one's needs met by the group (social support) or shared experiences (commonality) (see Figure 1).

Commonality. The theme of commonality as it relates to community refers to an experience of shared interests, shared history, common goals, or a binding force.

Youth's definitions. Youth's definitions of community within this theme included "A group of people [who have a] common cause or interests or just something that binds them together." Further, youth described how "People that have something in common can be a community... [the group of people] needs to have some sort of commonality and shared interest" in order to be a community.

Youth's descriptions of their own community experiences reflected this idea of commonality, with youth elucidating how community is important because of "the hardships that we go through [together] and the friendships that we make," reflecting the idea of shared experiences.

Connections to well-being: Example 1. Specific to the community of youth experiencing homelessness, youth described how they are "bound together" with other youth "by the fact that we are homeless," again reflecting this idea of shared experiences contributing to the feeling of community. Further, one youth explained, "It's kind of good 
to be around other people that are my age and, [who are] going through the same things," and how this shared experience with other youth encouraged her to "do things for [her]self" and continue moving forward, despite the difficulty of her situation. In other words, it "helps you hang on a little bit to have people going through the same thing as you."

Example 2. In relation to activity- or interest-based communities, several youth described how participating in the art community showed them that there are "others [who] feel the same way I do," and expressed that this community "gives me an opportunity to share my interest with other people." Further, in relation to the queer community and the Sexual Minority Youth Resource Center (SMYRC), one youth described that "It's been nice to have a community that has experience with [homelessness] at times, or just rejection from other communities or place of birth," and that the shared experiences or identities within this community enabled a sense of acceptance.

Membership-Acceptance. While the theme of membership-acceptance overlapped with youth's descriptions of other themes, it also stood out as a distinct theme in itself. Membership and acceptance can be created by a sense of commonality or shared experiences but goes beyond commonalities to reflect a sense of belonging and acceptance. The theme of membership-acceptance refers to a feeling of belonging, personal relatedness, or acceptance by others. 
Youth's definitions. In explaining community in terms of membership, one youth describes how "Everyone knows everyone. [When we all know each other] we act like this little tribe." More specifically, youth talked about acceptance and belonging:

Definition 1: "One of the most essential [pieces of community] is acceptance. Having acceptance within your community."

Definition 2: "That sense of belonging, that's what you can call [community]."

One youth talked about "community [as a] family," explaining that members of a given community "accept each other for [their] faults." Further, youth described how, within a specific community, "Everyone knows me... it's nice to have that acceptance because I didn't have that [before]."

Youth's general comments about the idea of membership-acceptance included the notion that "Humans can't exist independently for their whole life." Further, one youth described how "If people know you, you feel a little bit better. Like you mean something" to the group.

Connections to well-being: Example 1. Youth described how it is "good to have people to know in the homeless community if you're homeless yourself, so you're not alone or feel alone." Further, youth described how the shared experience of homelessness contributed to a sense of acceptance by others within that community, stating: "Other people who are in the same situation as me, they're easier to relate to... I'm accepted [in this community]," and that others experiencing homelessness "know what we are all going through. They accept how you're acting cause they understand." 
Example 2. In relation to other communities, youth described the idea of "fitting in" to different settings, or that specific communities "ignore the flaws of the people that [join]" and thus are more accepting. Specific to the queer community, youth described how they participate partly as a reflection of the culture of acceptance within that community, explaining: "I take a part in because I am have an open mind and I'm accepting of [other sexual and gender identities]." Further, one youth stated that the "Queer people of color community... that's like the only one where I would honestly feel like that I am able to be myself and feel like I have these fundamental qualities [of community]."

Social Support. The theme of social support includes an experience of having one's needs met by the group, a desire to support the needs of others in the group, and an overall sense of reciprocity. Youth talked about this idea of social support and reciprocity within community via descriptions, such as "Everybody provides services to each other based on their skills in exchange for the basic needs of life," and "Everybody's got each other's backs... [it] helps you just stay out of trouble. If I ever need anything, they'll have my back. Makes me feel safe."

Youth's definitions. More specifically, one youth described how, in being a part of a community, "I can give and it gives back... I get support from all the older mentors and staff members, and I get that support back and I give it to others. Kinda like paying it forward." Another youth described reciprocity with acts of kindness, stating that "Occasionally someone will reach out and do something really nice and unexpected for 
you and it's like...you really appreciated it [and] pass on the favor in a different way to somebody else."

Youth also explained how social support manifests within their communities, stating that "If I need something, need help, need people to be with I can just seek them out." Further, youth described specific types of social support, such as physical and emotional resources:

“There's a lot of support [in this community] as far as resources. Places to eat, clothes to wear. Support from the other people who are also homeless. They can tell when something's bothering you. And [they will] talk to you, ask you what's wrong and stuff. So, it's like peer counseling."

Connections to well-being: Example 1. Specific to the community of youth experiencing homelessness, participants described how "The homeless community helps me find resources" and that "They provide like protection... they are there if you need them." The overarching idea related to social support being that "We all kind of look out for each other." These descriptions of social support within this community also related to the "word of mouth" phenomenon of finding resources, with one youth describing, “The homeless community... they're for me right now because there are basic needs that I have and that [I can get] through services within the community."

Example 2. Within the queer and SMYRC community, youth described a psychological form of social support. These youth stated that, within this community, "We nurture and we help their creativity and their intelligence and their inquisitiveness 
grow," and that "It helps me meet more people and learn about what else is going on in the world and what's going on with other people."

Collaboration. While the idea of collaboration overlaps with ideas of reciprocity, this theme stood out in its emphasis on self-governance and social change. The theme of collaboration refers to a group of people working towards a common goal of change-forthe-better (e.g., social change), as well as establishing their own rules for the sake of all members. In youth's own words, they described this idea of "collaboration within your community" as "A lot of people working together to establish a common goal, to create a safe environment for everyone."

Youth's definitions. The idea of collaboration also related to social support in descriptions such as, "Ideas are shared and that's always a good thing... [it] helps [people] learn about each other and also what they could do to help the rest of the community."

Further expanding on the ideas of collaboration, some youth described ideas of self-governance within a community, stating that "In the description of a community there would need to be some form of self-governance... To become a community like this, we govern ourselves." The idea of self-governance within their own communities stood out as uniquely important to these youth:

"Our community is stronger than any form of government... we should stop working for our government and the people that control us... I wish people could see that they're ten times more powerful standing together than anything else." 
One youth in particular described how, within this concept of collaboration and self-governance, they wanted to contribute to the community: "My whole thing in community is I'm supposed to start a change... that's my whole point in community."

Connections to well-being: Example 1. Youth explained the benefits of collaboration generally, stating "I think everybody needs to stick together. Especially, when times get tough... help each other out." Descriptions such as this overlap with the Social Support theme above, but for many youth, the idea of collaboration with others was specific and separate from social support in its focus on shared goal setting and social change.

\section{Counter Examples: When Community is Harmful}

While youth overwhelmingly described community in positive terms and elaborated upon the ways that being part of a community is important to them, several youth reported not belonging to any community and not seeing it as important, or that they saw community as something negative. Descriptions of non-belonging and negative aspects of community often overlapped or intertwined, making it unclear whether or how negative aspects of community contributed to youth distancing themselves from communities; or, alternatively, if they justified their distance by emphasizing the downsides of communities. Despite this lack of clarity, the following examples suggest that a more critical and nuanced lens should be employed when examining the community and well-being experiences of youth experiencing homelessness.

Descriptions of the negative aspects of community revolved around the harms that can stem from interactions with others in a given community, such as "group mindsets" 
that are destructive or the "negative outlook on life" that some groups within the community of youth experiencing homelessness can have. These comments suggest that certain aspects of community, such as negative or pessimistic orientations toward life, are something that youth view as potentially detrimental to their own well-being. These youth explained that they feel it would be better not to associate or identify with a specific community, or with communities in general.

For example, one youth cited oppression and stigma as a negative aspect of community, stating "I've suffered microaggressions within communities that I associate myself with, as well as outside of communities that I have never associated myself with." This comment in particular highlights that negativity or harm may come from within one's own community and/or from other communities. Moreover, youth described the negative experience of disagreements or conflicts within communities, stating how "Violence is a negative aspect of the community" or that "Sometimes small fights will break out. With every kind of community there's always going to be a few different sides, or people argue and people will see things differently." These youth emphasized that community was not as important to them because of the negative aspects that they associated with it.

Other youth described a desire not to participate in community because of the potential difficulties of doing so, such as one youth's description that "I just like to [keep] everything to myself for the most part... As far as getting close to somebody, I don't really like to because it is hard to trust [others]." Or, youth explained that "friends are 
important" but that "the community thing really isn't." One youth described that whether or not community is important depends on the context or circumstances:

"[It] depends on which community that I'm trying to put myself [into]. I want to be around community that will change my life for the better, [but] I feel like I'm standing alone. I don't feel like I'm in any community."

This youth's explanation may suggest that, rather than being a part of a community that does not benefit them, it might be better to just not be a part of any community at all.

Moreover, some youth described that they thought community was important, but that they didn't feel like they were a part of a community:

Example 1: "I don't really belong to any community. I hang out with all of them. I know people from all of them. But, I don't really stick with one particular."

Example 2: "I feel like I'm so different from everyone else in every way, like I'm kinda just there not in any community at all. I guess I haven't found anyone I can relate to... I'm pretty much a floater.”

Example 3: 'I feel like I'm standing alone. I don't feel like I'm in any community... I mean I could go be in a community, that's nothing hard. But the one I want to be in I have to be off the streets."

These explanations suggest that there are barriers to youth's ability to participate in the communities that they want to. Some of these barriers include a lack of relatability to others, or seeing participation in the available communities as not conducive to longerterm goals. 
Youth who suggested that community was not as important to them focused on the potentially harmful and negative aspects of community, such as the mindsets of individuals or the drug use they associated with the homeless community. In discussing factors that make their day-to-day lives more challenging, several youth noted the potentially detrimental influence of others within the homeless community:

Example 4: "More negative people around me. There have been a lot of negative people and negative environments... People who have selfdestructive tendencies like drinking or drugs or bad social habits or... [they're] not really interested in making positive relationships."

Example 5: “They're all good people... it's just when you're living homeless or on the streets there's a lot of drugs, activities that aren't super mainstream."

Furthermore, many of the youth who emphasized positive aspects of community and reported community to be important also mentioned some of the negative aspects of community. For example, one youth who reported feeling that they are a part of the homeless youth community also reported feeling that they were getting "too close," and that they felt accepted but like they do not truly belong.

\section{Discussion}

Many of the above descriptions of community experiences reflected the manner in which communities that youth are a part of support their well-being. While many youth expressed feeling ostracized from mainstream society, they also described commonalities with hobby or interest groups and with other youth experiencing homelessness. Youth 
further described experiences of acceptance, social support, and collaboration within these communities, and that these experiences helped them navigate the stressors of their situation and find hope despite the challenges they face. This suggests that these youth are able to draw upon social supports and other resources that foster their well-being despite the hardships and adversity they face. These descriptions reflect the notion that youth often build resilience in the face of their adversities, and that this resilience stems at least in part from their community experiences.

This study expands upon our understandings of the connections between community experiences, social support, and well-being among youth experiencing homelessness. To our knowledge, it is also the first qualitative analysis to apply and adapt the most prominent sense of community theoretical framework (McMillan \& Chavis, 1986) to the community experiences of this population. Below, we summarize study findings, situate findings within the sense of community and well-being literature, and discuss limitations before outlining the implications of this work for future research and theory pertaining to youth experiencing homelessness.

\section{Summary of Results and Connections to the Broader Literature}

Overall, the results suggest that youth experiencing homelessness define community in terms of: (1) commonality, (2) membership-acceptance, (3) social support, and (4) collaboration. These themes reflect McMillan \& Chavis' (1986) theoretical framework of sense of community, the four dimensions of which overlap with the descriptions that youth provided of how they conceptualize community, their general 
experiences of community, and the specific examples they provided about the communities they are part of.

The theme of Commonality that emerged from the findings is parallel to the shared emotional connection dimension in McMillan and Chavis' (1986) sense of community framework. According to these authors, shared emotional connection includes a recognition of the shared history, common places, time together, and experiences among a group of people or within a community. Further, youth described how shared hobbies and experiences gave them opportunities to connect with others, and how the communities grounded in shared experiences enabled them to feel supported and provided them with a sense of emotional connection to others. These ideas reflect various facets of both psychological (Ryff \& Keyes, 1995) and social well-being (Keyes, 1998, 2002). Further, these descriptions relate directly to the other themes of community described by participants, including Membership-Acceptance and Social Support.

The theme of Membership-Acceptance drawn from youth's descriptions parallels McMillan \& Chavis' (1986) membership dimension of sense of community, which includes a feeling of belonging or of sharing a sense of personal relatedness, a sense of identification, and personal investment. The idea of membership and being accepted by others likely contributes to the well-being of these youth, as they can experience ostracization from other domains of society. Specifically, this theme relates to the social well-being domains of social integration and social acceptance (Keyes, 1998, 2002), the psychological well-being domains of positive relations with others and self-acceptance 
(Ryff \& Keyes, 1989), as well as subjective well-being through its impact on positive affect (Diener et al., 1985).

The results focused on Social Support experiences shared by youth reflect numerous types of social support, such as emotional and structural, as well as both enacted support and perceptions of support (Cohen, 1988; House, Landis, \& Umberson, 1988; Lakey \& Lutz, 1996). This theme further reflects McMillan and Chavis' (1986) dimension of integration and fulfillment of needs within a sense of community, which refers to a feeling that one's needs will be met by the resources received via group membership. This integration and fulfillment of needs, as well as tangibly received social support from others, can contribute to the subjective, psychological, and social well-being of these youth through the likely impacts on positive affect (Diener et al., 1985), mastery of the surrounding environment and purpose in life (components of psychological wellbeing; Ryff \& Keyes, 1989), as well as social integration and contribution (components of social well-being; Keyes, 1998, 2002).

Finally, the theme of Collaboration relates to the McMillan \& Chavis (1986) dimension of influence, which is a sense of mattering to the group and of making a difference to the group (McMillan \& Chavis, 1986). Collaboration with community may contribute to the well-being of participants through its impact on positive relations with others, mastery of the surrounding environment, and a sense of purpose, which are all components of psychological well-being (Ryff \& Keyes, 1995). Further, collaboration may also contribute to a sense of social contribution, integration, coherence, and actualization - all components of social well-being (Keyes, 1998, 2002). 
While many of the youth described community membership as important to their survival on the streets, other youth saw the homeless community and/or their experience of being homeless as a hindrance to their ability to participate in the communities that they want to be a part of. This relates to Brodsky's (1996) argument that a negative sense of community can, in some contexts, be beneficial to the well-being of individuals if strong associations with a given community would be harmful to them in some way.

Overall, youth's comments about negative components of community and wanting to disengage from community were heavily intertwined, suggesting that an inclination toward disengagement may stem from negative community experiences, or that youth may justify their lack of engagement by pointing out the negative aspects of community. On the other hand, some youth may have simply been taking a more balanced approach to assessing what community means to them and their desired level of engagement. The current study was unable to determine which of these scenarios may be at play, or whether alternative explanations better support these counterexamples. What these findings point to, however, is that a more open-ended and nuanced approach to understanding community experiences and well-being among youth experiencing homelessness should be considered, as current theories that typically highlight only the positive features of community may not be fully applicable to members of this group.

\section{Limitations}

While the current study illuminates some of the community experiences of youth experiencing homelessness, there are several limitations that should be noted. First, data were collected from a relatively small sample in one city of the United States and was 
conducted at a community center supporting homeless and transition-aged youth. The youth in this sample may differ markedly from those who are not accessing community services. For instance, youth accessing services may identify more with other youth experiencing homelessness or have different opportunities for social support than those not accessing services. Unfortunately, engaging youth who are not accessing community services and supports can be quite difficult, and thus research has yet to determine how their community experiences and well-being may differ from those youth who are engaged with these services. A limitation of the analysis itself is that the authors were unable to engage in member checking with the youth who participated to ensure that the data were presented in a way that most accurately reflected their experiences. Future research that is more participatory in nature could engage youth in many components of the research to bolster the trustworthiness of findings.

While findings from this study may not apply uniformly across all settings and populations, the results of the current analysis can inform how service centers promote well-being among the youth who visit their organizations. Further, results can inform service centers about the various ways in which youth perceive and process their community experiences, which can then allow staff to take a more nuanced and personalized approach to supporting the well-being of youth in their unique contexts.

Another potential limitation is that the researchers who conducted this research have not experienced homelessness and experience privileged status based on their race, gender- and sexual-identities, and economic status. While this 'outsider' perspective might be of benefit in some situations, there were times when the analysis might have 
benefited from additional follow-up questions with and/or feedback from the youth who participated in the study. Related to this, a final limitation is that inferences were drawn between sense of community and well-being, and youth may not have directly stated connections between the constructs as presented in the results. Justifiably, this was an exploratory approach to examining how components of SOC are related to the well-being of youth, as reflected in the youth's narratives.

Follow-up research could more explicitly engage youth in describing how experiences of community and social support directly impact their day-to-day well-being. Further, future research could engage youth in reflection on how their sense of community has changed over time and in various contexts in order to better understand the unique impact of homelessness on sense of community and well-being. Future research should also examine other dimensions of community that may be important to homeless youth (e.g., political, spiritual, geographic, and virtual). This inquiry could include questions surrounding youth's membership in multiple communities based on their varied identities and experiences.

\section{Implications and Future Directions}

While the overwhelming conclusion for most of the youth interviewed in this study was that community is a positive experience, other youth described negative experiences and a general disaffiliation from community. Much of the prior research on sense of community has an underlying assumption that community is an inherently positive experience, reflected in the low-to-high conceptualization of the construct as opposed to a negative-neutral-positive conceptualization. The current results point to the 
importance of considering the ways in which engaging with community might be harmful to well-being (e.g., Brodsky, 1996), and in what contexts or circumstances this might be the case. Future research should explore the specific context of when community is important to youth - under what circumstances and for whom is a stronger sense of community beneficial to the well-being of these youth, and what community experiences promote their well-being while experiencing homelessness? Further, this research should examine why some youth choose to disengage from community, and how that distance from community supports their well-being while homeless. Future research could also examine the long-term consequences to well-being based upon whether and to what extent youth engage in different types of communities while homeless.

Researchers and service centers should be sensitive to the potential for negative community experiences among youth experiencing homelessness. Ideally, service centers would find ways to support youth by: a) offering opportunities to cultivate social support that they might not receive otherwise; b) providing them with a safe space to disengage from community if they need to; and c) recognizing that they may have different needs and experiences than other youth accessing the service center, and thus all youth should be treated as individuals with specific needs. These recommendations may require that service centers inquire about youth's perspectives, needs, and goals upon their initial engagement with services, and that they should establish a method for youth to periodically update the service center as those perspectives and needs may change over time. 
Study findings also suggest that, while youth's descriptions of what community means to them were parallel to the theory of sense of community presented by McMillan and Chavis (1986), particular elements of that theory may be more important to them than others; and youth may include other critical components of community that the theory does not articulate. Future research should work closely with youth using participatory action research methods similar to those recommended by Kidd and colleagues (2018) to more critically examine how youth define sense of community, whether it parallels current theories of the construct, and how measures and definitions of sense of community might better align with the ways in which youth define their experiences.

Expanding this research in such a way would enable researchers to explore and interrogate common assumptions that sense of community is an unequivocally positive experience and one that always supports well-being, as well as how sense of community is defined and experienced by different populations. Similarly, this research would elucidate how well-being is defined and experienced by different populations and what factors contribute to their well-being when it is defined in their own terms. Inherent in this research would be questions concerning the value of the constructs and theories we rely upon as a discipline and whether or how they are relevant to populations that fall outside of the "invisible norm" - or typical standard of comparison - of western, educated, industrialized, rich, and democratic populations (WEIRD; Henrich, Heine, \& Norenzayan, 2010). This research in particular points to the notion that not all phenomena are experienced in the same way by different populations and subpopulations, 
and we as a discipline should consider how our research assumes generalizability and whether this is a beneficial or harmful assumption. In the case of youth experiencing homelessness, community connections appear to be an important component of their well-being and resilience; however, they also face unique challenges to cultivating supportive relationships that must be considered in future research and service delivery. 


\section{Figures}

Figure 1.

\section{Qualitative themes and definitions.}

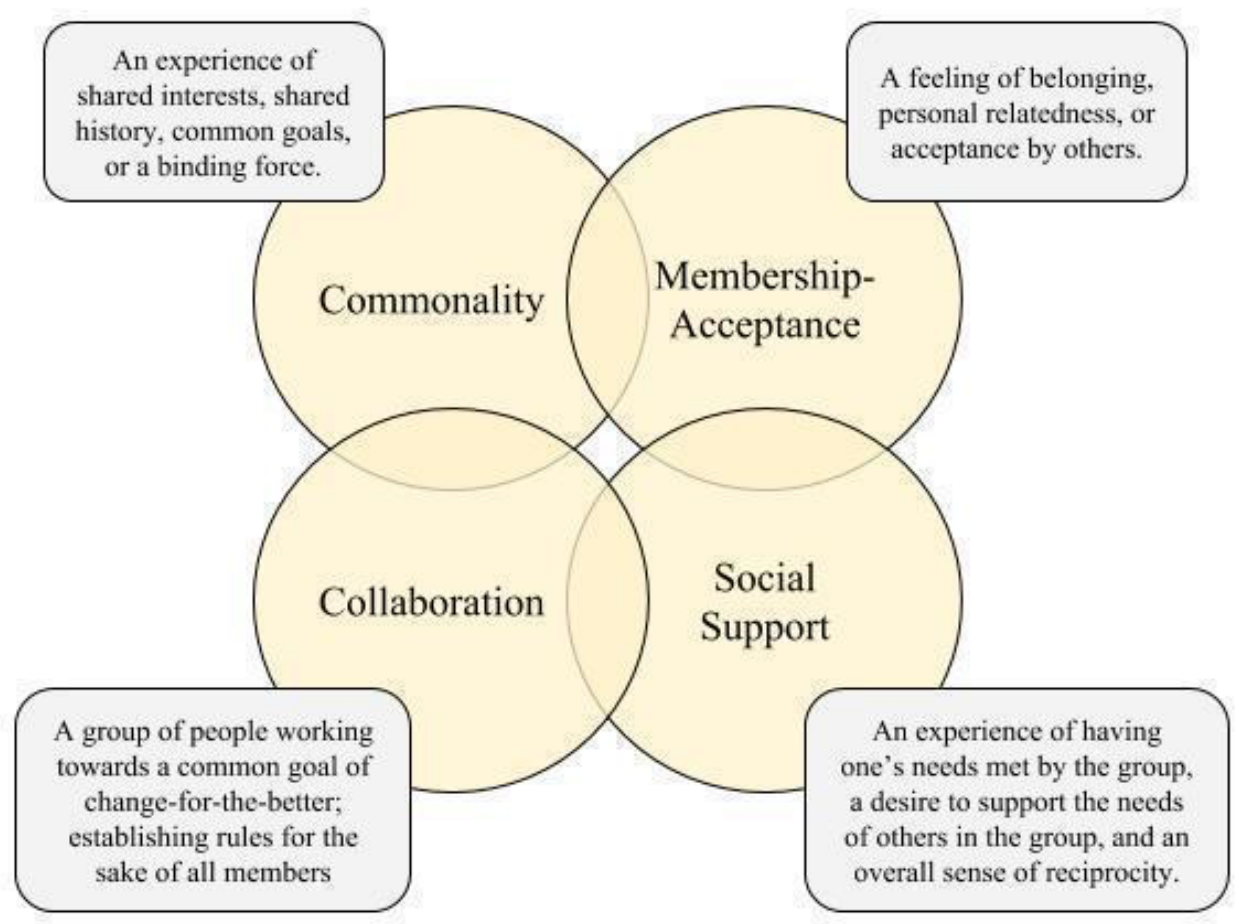




\section{References}

Antonucci, T. C. (1985). Personal characteristics, social support, and social behavior. In R. H. Binstock, \& E. Shanas (Eds.), Handbook of Aging and the Social Sciences (pp. 94-128). New York: Van Nostrand-Reinhold.

Bender, K., Thompson, S., McManus, H., Lantry, J., \& Flynn, P. (2007). Capacity for survival: Exploring strengths of homeless street youth. Child and Youth Care Forum, 36(1), 25-42.

Biswas-Diener, R., \& Diener, E. (2006). The subjective well-being of the homeless, and lessons for happiness. Social Indicators Research, 76, 185-205.

Brodsky, A. E. (1996). Resilient single mothers in risky neighborhoods: Negative psychological sense of community. Journal of Community Psychology, 24(4), 347363.

Cauce, A. M., Paradise, M., Ginzler, J. A. et al. (2000). The characteristics and mental health of homeless adolescents: age and gender differences. Journal of Emotional and Behavioral Disorders, 8, 230-239.

Chipuer, H. M., \& Pretty, G. M. (1999). A review of the sense of community index: Current uses, factor structure, reliability, and further development. Journal of Community Psychology, 27(6), 643-658.

Chipuer, H. M., Bramston, P., \& Pretty, G. (2003). Determinants of subjective quality of life among rural adolescents: A developmental perspective. Social Indicators Research, 61(1), 79-95. 
Christiani, A., Hudson, A. L., Nyamathi, A., Mutere, M., \& Sweat, J. (2008). Attitudes of Homeless and Drug-Using Youth Regarding Barriers and Facilitators in Delivery of Quality and Culturally Sensitive Health Care. Journal of Child and Adolescent Psychiatric Nursing, 21(3), 154-163.

Cleverley, K., \& Kidd, S. A. (2011). Resilience and suicidality among homeless youth. Journal of Adolescence, 34(5), 1049-1054.

Coates, J., \& McKenzie-Mohr, S. (2010). Out of the frying pan, into the fire: Trauma in the lives of homeless youth prior to and during homelessness. Journal of Sociology and Social Welfare, 37(65).

Cohen, S. (1988). Psychosocial models of the role of social support in the etiology of physical disease. Health Psychology, 7, 269-297.

Cohen, S., \& Wills, T. A. (1985). Stress, Social Support, and the Buffering Hypothesis. Psychological Bulletin, 98(2), 310-357.

Desai, R. A., Liu-Mares, W., Dausey, D. J., Rosenheck, R. A. (2003). Suicidal ideation and suicide attempts in a sample of homeless people with mental illness. Journal of Nervous Mental Disorders, 191, 365-371.

Diener, E. (2009). Assessing Well-Being: The Collected Works of Ed Diener. Dordrecht Heidelberg London New York: Springer.

Diener, E., Emmons, R. A., Larsen, R. J., \& Griffin, S. (1985). The satisfaction with life scale. Journal of Personality Assessment, 49, 71-75. 
Dolan, P., Peasgood, T., \& White, M. (2008). Do we really know what makes us happy? A review of the economic literature on the factors associated with subjective wellbeing. Journal of Economic Psychology, 29, 94-122.

Ennett, S. T., Bailey, S. L., Federman, E. B. (1999). Social network characteristics associated with risky behaviors among runaway and homeless youth. Journal of Health and Social Behavior, 40(1), 63-78.

Felton, B. J., \& Shinn, M. (1992). Social integration and social support: Moving "social support" beyond the individual level. Journal of Community Psychology, 20(2), 103115.Helliwell, J. F., \& Putnam, R. (2004). The social context of well-being. Philosophical Transactions of the Royal Society of London. Series B, Biological sciences, 359, 1435-1446.

House, J. S., \& Kahn, R. L. (1985). Measures and concepts of social support. In S. Cohen, \& S. L. Syme (Eds.), Social Support and Health (pp. 83-108). New York: Academic Press.

House, J. S., Landis, K. R., \& Umberson, D. (1988). Social relationships and health. Science, 241, 540-545.

Jetten, J., Haslam, C., Haslam, S. A., Dingle, G., \& Jones, J. M. (2014). How groups affect our health and well-being: The path from theory to policy. Social Issues and Policy Review, 8, 103-130.

Kamieniecki, G. W. (2001). Prevalence of psychological distress and psychiatric disorders among homeless youth in Australia: A comparative review. Australia and New Zealand Journal of Psychiatry, 35, 352-358. 
Karabanow, J. (2006). Becoming a street kid: Exploring the stages of street Me. Journal of Human Behavior in the Social Environment, 13(2), 49-72.

Keyes, C. L. M. (1998). Social well being. Social Psychology Quarterly, 61(2), 121-140.

Keyes, C. L. M. (2002). The mental health continuum: From languishing to flourishing in life. Journal of Health and Social Behavior, 43(2), 207-222.

Keyes, C. L. M. (2005). Mental illness and/or mental health? Investigating axioms of the complete state model of health. Journal of Consulting and Clinical Psychology, 73, 539-548.

Kidd, S. A. (2003). Street youth: coping and intervention. Child and Adolescent Social Work Journal, 20(4), 235-261.

Kidd, S. A., \& Carroll, M. R. (2007). Coping and suicidality among homeless youth. Journal of Adolescence, 30(2), 283-296.

Kidd, S. A., \& Davidson, L. (2009). Homeless youth: The need to link research and policy. Finding home: Policy options for addressing homelessness in Canada, 3, 19.

Kidd, S., Davidson, L., Frederick, T., \& Kral, M. J. (2018). Reflecting on participatory, action-oriented research methods in community psychology: Progress, problems, and paths forward. American Journal of Community Psychology, 61(1-2), 76-87.

Kidd, S., \& Shahar, G. (2008). Resilience in homeless youth: the key role of self-esteem. American Journal of Orthopsychiatry, 78(2), 163-172. 
Lakey, B., \& Lutz, C. J. (1996). Social support and preventive and therapeutic interventions. In: G. R. Pierce, B. R. Sarason, \& I. G. Sarason (Eds.), Handbook of Social Support and the Family (pp. 435-465). New York: Plenum.

Lincoln, Y., \& Guba, E. (1985). Naturalistic Inquiry. Beverly Hills, CA: Sage.

Mak, W. W. S., Ng, I. S. W., \& Wong, C. C. Y. (2011). Resilience: Enhancing WellBeing Through the Positive Cognitive Triad. Journal of Counseling Psychology, $58(4), 610-617$.

Mallett, S., Rosenthal, D., \& Keyes, D. (2005). Young people, drug use and family conflict: Pathways into homelessness. Journal of Adolescence, 28, 185-199.

McMillan, D. W., \& Chavis, D. M. (1986). Sense of community: A definition and theory. Journal of Community Psychology, 14(1), 6-23.

Moore, J. (2005). Unaccompanied and homeless youth: Review of the literature (19952005). National Centre for Homeless Education.

Morgan, M. L., Vera, E. M., Gonzales, R. R., Conner, W., Bena Vacek, K., \& Dick Coyle, L. (2011). Subjective well-being in urban adolescents: Interpersonal, individual, and community influences. Youth and Society, 43(2), 609-634.

National Alliance to End Homelessness. (2014). Youth. Available from: http://www.endhomelessness.org/pages/youth [last accessed 14 May 2016].

National Health Care for the Homeless Council. (2008). Child and youth homelessness: 2008 policy statements. Retrieved 12 November 2008, from http://www.nhchc.org/Advocacy/PolicyPapers/Child Youth2008.pdf 
Prezza, M., Amici, M., Roberti, T., \& Tedeschi, G. (2001). Sense of community referred to the whole town: Its relations with neighboring, loneliness, life satisfactions, and area of residence. Journal of Community Psychology, 29(1), 29-52.

Ryff, C. D. (1989). Happiness is everything, or is it? Explorations on the meaning of psychological well-being. Journal of Personality and Social Psychology, 57, 10691081.

Ryff, C. D., \& Keyes, C. L. M. (1995). The structure of psychological well-being revisited. Journal of Personality and Social Psychology, 69(4), 719.

Sarason, S. B. (1974). The Psychological Sense of Community: Prospects for a Community Psychology. San Francisco: Jossey-Bass.

Stevens, E., Guerrero, M., Green, A., \& Jason, L. A. (2018). Relationship of hope, sense of community, and quality of life. Journal of Community Psychology, 46(5), 567574.

Stewart, K., \& Townley, G. (2019). Intrapersonal and social-contextual factors related to psychological well-being among youth experiencing homelessness. Journal of Community Psychology, 47(4), 772-789.

Taylor, D. M., Lydon, J. E., Bougie, É., \& Johannesen, K. (2004). "Street Kids": Towards an Understanding of Their Motivational Context. Canadian Journal of Behavioural Science, 36, 1-16.

Townley, G., Pearson, L., Lehrwyn, J. M., Prophet, N. T., \& Trauernicht, M. (2016). Utilizing participatory mapping and GIS to examine the activity spaces of homeless 
youth. American Journal of Community Psychology, 404-414.

https://doi.org/10.1002/ajcp.12060

Usborne, E., Lydon, J. E., \& Taylor, D. M. (2009). Goals and social relationships:

Windows into the motivation and well-being of "street kids." Journal of Applied

Social Psychology, 39, 1057-1082. 
Chapter IV: A qualitative exploration of community supports, well-being, goals, and the COVID-19 pandemic among youth experiencing homelessness.

\begin{abstract}
Social-contextual factors (such as sense of community and social support) have been widely studied in relation to well-being among various populations and in diverse contexts, including among youth experiencing homelessness. However, most of this work has been quantitative, correlational research utilizing measures that may or may not be fully applicable to (and valid with) the population and context under study. One way to address this is to ask the population what these phenomena mean to them, and how they see these factors operating in their lives. Qualitative research on these topics can illuminate youth's definitions of well-being and their community experiences, and whether and how they see these factors relating to their goals and outcomes. Thus far, little qualitative research on the topics of well-being, community experiences, and social support has been conducted with youth experiencing homelessness. The current study addresses this gap in the literature by interviewing 17 youth experiencing homelessness about their community supports and well-being, with a focus on how youth understand the relationships between these factors and how they relate to youth's goals for their lives, as well as how the COVID-19 pandemic has impacted these factors. Results demonstrate the ways that youth define their well-being; how youth perceive their wellbeing, community experiences, and goals interacting in their lives; and how the pandemic impacted each of these factors. Findings can inform future research and potential
\end{abstract}


intervention work aimed at supporting the well-being of youth experiencing homelessness. 


\section{Introduction}

Youth experiencing homelessness are individuals aged 24 and under who are houseless, in precarious living situations, and typically unaccompanied (Kidd \& Davidson, 2009). While the point-in-time count for Portland and Multnomah County suggests that around 4,000 individuals were experiencing homelessness during 2019 (Multnomah County, 2019), research that includes individuals who are doubled-up or in precarious living situations suggests that closer to 38,000 people were experiencing homelessness in the Tri-County region (Zapata, Liu, Everett, Hulseman, Potiowsky, \& Willingham, 2019). Of those experiencing homelessness, at least 6-10\% are youth (Multnomah County, 2015; United States Interagency Council on Homelessness, 2018).

Much of the literature on youth homelessness has outlined the familial breakdown (Hyde, 2005; Samuels et al., 2019; Reeg, 2003; Zufferey, 2017), trauma, and abuse (Coates \& McKenzie-Mohr, 2010; Ferguson, 2009; Haber \& Toro, 2009; Reeg, 2003; Tyler, Cauce \& Whitbeck, 2004; US DHHS, 2009; Zerger, Strehlow \& Gundlapalli, 2008) that often precedes homelessness for this population. Further, this literature has emphasized the various negative consequences and implications for homeless youth as compared to their housed peers, such as adult homelessness (Johnson \& Chamberlain, 2008) and worse mental-emotional and physical health outcomes (Busen \& Engebretson, 2008; Cochran et al., 2002; O’Connell, 2004; Parks, Stevens, \& Spence, 2007; Robertson \& Toro, 1999; Salomonsen-Sautel et al., 2008; Slesnick \& Prestopnik, 2005; Smollar, 1999; Wrate \& McLoughlin, 1997. 
Despite the many challenging circumstances faced by youth experiencing homelessness and the importance of addressing the needs that arise from those difficulties, practitioners and researchers alike have come to understand that solving youth homelessness requires a holistic approach to the whole person and coherent interventions that go beyond addressing youth's day-to-day basic needs (Kidd, 2012). In the words of one local organization working with homeless youth, "We believe that to thrive, young people need more than their basic needs met" (Outside the Frame, 2019). Many service organizations and researchers recognize the importance of supporting the holistic well-being of youth — such as through the support of their mental-emotionalspiritual needs (e.g., Grabbe, Nguy, \& Higgins, 2012; Kidd, 2008)—in tandem with meeting more basic physical needs such as food and healthcare (e.g., Kidd \& Davidson, 2007; Outside the Frame, 2019; p:ear, 2019; Stewart \& Townley, 2019; Townley et al., 2016). The current study aims to contribute to this more holistic approach to conceptualizing and supporting the well-being of youth experiencing homelessness.

Of special relevance to the current study is the COVID-19 (coronavirus) pandemic that began devastating the United States in February of 2020 and continues through to the final writing of this research. To date, very little research has been conducted examining the impacts of the pandemic on youth experiencing homelessness. The minimal research that is currently available on this topic has examined health outcomes of youth or reported on clinical trials of risk reduction programs related to COVID-19 (e.g., Tucker et al., 2020). However, none one of the published research has examined the impacts of the pandemic on youth's well-being, community experiences 
and social supports, and their goal pursuits. However, other research suggests that the pandemic has had drastic economic, social, and health impacts on the majority of the population (e.g., Haleem, Javaid, \& Vaishya, 2020), particularly among communities of color (Oppel et al., 2020). New research has also documented the effects of the pandemic on the housing and food security of populations closer in age to youth experiencing homelessness, such as college students (e.g., Townley, Stewart, Green, and Petteni, 2020).

\section{Current Understanding of Well-Being and Community Supports among Youth}

Much research has been conducted exploring how well-being relates to sense of community (Stewart \& Townley, 2020b). More specifically among youth experiencing homelessness, quantitative research has explored the relationships between well-being and a variety of other factors, including both sense of community and social support (e.g., Stewart \& Townley, 2019). Generally, these studies have reported positive associations between well-being and variables such as sense of community and social supportamong both the general population and also homeless youth specifically. While the quantitative research on these topics has recently begun to incorporate more sophisticated analyses, such as multiple time points and latent-profile analysis (e.g., Coulombe \& Krzesni 2019; Obst \& Stafurik, 2010; Prati et al., 2016; Wang et al., 2015), the results of these studies point to highly complex and nuanced interactions between these variables that may differ considerably across individuals and contexts (Coulombe \& Krzesni, 2019). 
Furthermore, prior research on well-being, sense of community, and social support among youth experiencing homelessness has utilized quantitative measures that have been standardized among members of the general population-as opposed to with this specific population. The utility of such procedures has come under question previously because of the potential lack of applicability these measures have to the lives of youth experiencing homelessness (Stewart \& Townley, 2019). For example, homeless youth typically respond similarly to their housed peers on measures of subjective wellbeing (e.g., Barczyk, Thompson, \& Rew, 2014; Usborne, Lydon, \& Taylor, 2009). This could be because subjective well-being requires a salient standard of comparison at the time of measurement (Diener, 2009). However, standards of comparison for youth experiencing homelessness are likely different than those of their housed peers, which may lead to higher levels of perceived well-being than if they had the same lived experience as their housed peers. Further, some quantitative measures of well-being are intended to be utilized over time in order to produce more accurate results (Diener, 2009); however, the vast majority of studies with youth experiencing homelessness collect data at only one time point given the highly mobile nature of this population.

Similar to the above shortcomings with measuring well-being among youth experiencing homelessness, measures of social support also present dilemmas. Homeless youth often find social support in peer networks and service centers as opposed to family (Bender et al., 2007; Karabanow, 2006; Morgan et al., 2011; Taylor et al., 2004), and thus current measures of social support may not be as applicable to this population. For instance, if responses pertaining to the amount of support received from family are 
included in analyses, it may suggest low levels of social support, when in reality youth may experience high levels of social support from peers and trusted service organizations that may compensate for this lack of familial support. Alternatively, youth may rate their levels of social support from peers and service centers as quite high given that their basis of comparison could be the lack of support they receive(d) from their families.

Likewise, a handful of quantitative studies have explored sense of community (SOC) among homeless youth (e.g., Townley et al., 2016; Stewart \& Townley, 2019). However, there is an underlying assumption in this research that youth perceive and experience both SOC and the other variables measured (e.g., well-being) similarly to the general population, and that the items comprising these measures reflect important aspects of youth's lived experiences of community. Prior measurement of SOC among youth experiencing homelessness has also not considered the possibility of multiple SOC (Brodsky \& Marx, 2001) and how this may impact the well-being of youth. Multiple senses of community (MSOC) is the idea that individuals have multiple identities and roles connected to multiple communities, and thus they may have a sense of community with multiple, separate communities; and/or, they may have multiple nested communities and experience different kinds of belonging at each expanding level of community (Brodsky \& Marx, 2001). When applied to youth experiencing homelessness, this theory would suggest that they may have different experiences of SOC depending on whether the homeless youth community is the referent community, compared to a different community to which they are a member (e.g., a geographic community or a hobby community). 
Many of the quantitative measures of sense of community, social support, and well-being utilized at one time point with youth experiencing homelessness are limited in their ability to demonstrate how the constructs actually operate within an individual's life. While utilizing these measures at multiple time points may alleviate some of this problem, longitudinal research with such a mobile population is quite difficult to achieve (Kidd, 2012). Considering the many limitations of quantitative measurement to understand these phenomena among youth experiencing homelessness, research with this population should incorporate other methodologies that can capture more accurate, thorough understandings of youth's experiences with their specific life context in mind.

Research into the well-being and community experiences of youth experiencing homelessness is expanding, yet only a minimal amount of research in this area has incorporated other methodologies that might be better suited to capturing how these variables manifest within the dynamics of an individual's unique ecological context. Considering that initial qualitative research on topics of community and well-being among marginalized populations suggested complex and nuanced relationships between these variables (e.g., Brodsky, 1996), coupled with the decades old call for more qualitative research on the topic (e.g., Chavis \& Pretty, 1999), it is surprising that little research has expanded beyond quantitative methodologies to explore these relationships. While a variety of qualitative studies have been conducted with youth experiencing homelessness (e.g., Ferguson, Kim, \& McCoy, 2011; Kidd, 2003; Kidd \& Davidson, 2007), only one known empirical study (Stewart \& Townley, 2020a) has specifically examined how well-being and community experiences manifest in the daily lives of 
youth experiencing homelessness. This previous research is an important starting point for further, more in-depth examination of these topics.

Finally, as many community psychologists and researchers have long espoused (e.g., Kelly, 1986; Trickett 1984; Trickett, Kelly, \& Vincent, 1985; Trickett \& Mitchell, 1991), interventions - and thus the research that informs the development of interventions - need to be tailored to specific contexts in order to be useful, applicable, and effective. Methodologies that invite participant perspectives can help researchers and practitioners understand how these variables play out in the day-to-day lives of the population under consideration.

Prior research on the well-being of youth experiencing homelessness has not considered how youth understand their own well-being and how the social contexts impact their well-being. There is a greater need for community research that incorporates the unique context and perspectives of youth experiencing homelessness, which can allow for more nuanced data that tell us the how and why of youth's well-being and community experiences, as opposed to only the numerical what and how much. The results of this research can point to opportunities for further research, intervention, needed services or modification of existing services, as well as the development of more applicable and culturally relevant quantitative measures that could be used with larger samples of youth (Maton, 1993). 


\section{The Role of Qualitative Methodologies in Better Understanding Youth's}

\section{Experiences}

Qualitative research utilizes words (instead of numbers) as a form of data in order to discover and explore subjective meaning (Hesse-Biber, 2017), thereby constructing knowledge that does not cater to the more traditional positivistic paradigm that promotes reductionist descriptions and generalizations to larger society (DeLyser, Herbert, Aitken, Crang, \& McDowell, 2010).

The quantitative methodologies utilized with youth experiencing homelessness have thus far assumed that measures developed and validated among members of the general population are relevant to homeless youth's experiences; and, further, that isolation of phenomena through quantitative metrics will contribute to understandings that help society address the well-being needs of this population. However, while quantitative measures and analyses with this population have pointed to factors that might correlate with the well-being of youth experiencing homelessness (e.g., Stewart \& Townley, 2019; Taylor et al., 2004; Usborne, Lydon, \&amp; Taylor, 2009), the mechanisms behind these associations are not clear and may not be easily captured with quantitative methodologies. Further, the positivist paradigm within which much quantitative research operates posits the researcher as knower, dismissing the perspectives and voices of the population under study; it future promotes the idea of an absolute, objective truth that the researcher-as-knower can find with quantification and a mechanical breakdown of component parts in analyses (Hesse-Biber, 2017). 
Qualitative methodologies, on the other hand, can allow researchers to arrive at more ecologically sensitive understandings of behavior (Trickett, 1996) and can promote culturally anchored research (Hughes \& DuMont, 1993) that more accurately reflects the myriad contextual influences on a given population. For example, qualitative methodologies may capture information about contextual influences on an individual's well-being that are not considered in quantitative measures focused at the individual level of analysis; or, they can elucidate the reasons why an individual may experience a lower or negative SOC in a given community (e.g., Brodsky, 1996). In addition to helping researchers arrive at more nuanced understandings of phenomena in context, qualitative methodologies can also help challenge misconceptions about marginalized populations that are perpetuated by the use of quantitative measures developed with more mainstream samples (e.g., Dumka, Gonzales, Wood, \& Formoso, 1998). For instance: a quantitative measure may reflect a marginalized population as having a lower sense of community or well-being than members of the general population, while qualitative methodologies might illuminate facets of those measures that are not as relevant to the population under consideration, and thus explain the differences in those metrics.

While much research on well-being and sense of community has occurred over the last several decades, researchers have continually pointed to the need for more qualitative studies on these topics (e.g., Chavis \& Pretty, 1999; Stewart \& Townley, 2019; Townley et al., 2011) in order to provide the field and focal communities with more nuanced, culturally anchored, in-depth understandings of how these phenomena operate within the specific ecologies of different populations. A key example of how 
qualitative research can help us understand the contextual-ecological influences on the phenomena we study as community psychologists is Brodsky's (1996) study of sense of community among African American mothers in an impoverished neighborhood. Brodsky's research found that a negative sense of community can be important to the resilience and well-being of individuals in certain contexts, and that sense of community should be conceptualized as either positive or negative - as opposed to a unipolar, positive-or-null variable. This discussion of ecologically situated sense of community spurred important advancements in research, including the concepts of multiple senses of community (Brodsky \& Marx, 2001) and the community-diversity dialectic (Townley, Kloos, Green, \& Franco, 2011).

Numerous quantitative studies have been conducted on the topics of sense of community and well-being (see Stewart \& Townley, 2020b). However, there is still only minimal empirical research that incorporates other methodologies, such as qualitative interviews and place-based methods. Prior studies with youth experiencing homelessness have successfully utilized qualitative methods to understand their resilience and ability to survive the adversity of homelessness (Bender, Thompson, McManus, \& Lantry, 2007; Ferguson, Kim, \& McCoy, 2011; Kidd \& Carroll, 2007; Kidd \& Davidson, 2007; Lindsey, Kurtz, Jarvis, Williams, \& Nackerud, 2000; Mallett, Rosenthal, \& Keys, 2005). While many of these studies have suggested the importance of community supports for the well-being of youth experiencing homelessness (e.g., Bender et al., 2007; Ferguson, Kim, \& McCoy, 2011; Kidd \& Davidson, 2007), only one published study has specifically examined the intersections between youth's community supports and their 
well-being (Stewart \& Townley, 2020a). This study primarily focused on how youth define their community experiences, and as a secondary aim explored how those community experiences related to their well-being. This study suggested a need for further qualitative investigation on the topics of community experiences and well-being with youth experiencing homelessness.

The current investigation draws from key literature on qualitative methods to guide the process of inquiry with the aim of elucidating the subjective, multiple, nuanced experiences of homeless youth. Incorporation of qualitative methodologies for this area of inquiry can help to ground researchers, practitioners, and service providers in culturally relevant and more ecologically valid (e.g., Bronfenbrenner, 1994; Lincoln \& Guba, 1985) understandings of the lives of youth experiencing homelessness, which can also help researchers determine whether youth's experience generalize to our current theories on the topics of well-being and community experiences, or whether more contextually-specific theories and measures should be developed for this population.

\section{Study Purpose and Research Questions}

Studies utilizing qualitative methods can allow youth to share their perspectives on their own experiences, enlightening researchers to nuanced understandings of this population that they might not be able to capture otherwise. Because contextual factors and their effects can be both subtle and in continual flux (Johns, 2006), it is important to ground this research in youth's perceptions and expertise, as opposed to what researchers or practitioners view as the most salient context. The use of qualitative methodologies can help to elucidate how youth understand their well-being and community experiences 
as well as the relationships between these factors. The findings of such an inquiry can help expand researcher's understanding of these phenomena in the lives of youth, which can address currents gaps in the literature on these topics and can also be a foundation for additional research and intervention work that explores how to best support youth's wellbeing while homeless.

Based on recent quantitative and qualitative research demonstrating positive, yet nuanced, relationships between sense of community, social support, well-being, and other variables among youth experiencing homelessness (e.g., Stewart \& Townley, 2019; Stewart \& Townley, 2020a), the current investigation utilized qualitative interviews to explore these phenomena more closely. Further, to begin to understand how these factors (well-being, community experiences, social supports) impact youth's outcomes, the current study explored how these factors relate to youth's personal goals. Finally, given the context of the COVID-19 pandemic, this study also investigated how the pandemic impacted well-being and community supports among youth.

Specifically, the current study examined the following research questions:

1. How do youth experiencing homelessness define their well-being?

2. How do youth connect their community experiences and social supports to their well-being, and how does the relationship between these factors manifest in their daily lives?

3. How do community experiences and social supports, as well as personal wellbeing, impact youth's goals for the future? 
4. How has the COVID-19 pandemic impacted the well-being, community experiences and social supports, and the goals of youth experiencing homelessness?

Exploring these four research questions will allow researchers to better understand how youth understand and experience their own well-being, and the connections between their community experiences, well-being, and goal pursuits. Further, these research questions will help researchers understand how the COVID-19 pandemic impacted these factors for youth.

\section{Method}

\section{Overview}

The current investigation used semi-structured interviews to explore the above research questions. The use of a semi-structured interview protocol enabled a mostly guided conversation that allowed room for participants to talk about what is of most interest or importance to them, which can elucidate information or knowledge that I may not have thought of in advance (Hesse-Biber, 2017).

The original plan for this research included follow-up focus groups with participants in order to engage in member-checking, clarification, and further exploration of topics from the interviews. However, due to the COVID-19 pandemic, these focus groups were not feasible or safe to conduct. First, the pandemic created health concerns and service center limitations that would not enable a group of individuals to sit in close enough proximity (with privacy) to engage in a focus group. Moreover, due to changes in service center access and in youth's lives due to the pandemic, I could not expect the 
same youth to be available for follow-up focus groups. Finally, conducting focus groups virtually was not feasible for the youth given the inequity of resources available to them (e.g., computers, internet access, or even a space to be inside for long enough), and we could not identify a way for the service center to support such an endeavor.

\section{Researcher Positionality Statement}

During the time this research was conducted, I was in my late-20's while they were mostly in their early 20 's. While I could relate to them on an interpersonal level and understand some of the experiences they shared with me just based on our close age proximity and the life events that come with it, I have never identified as homeless nor have I utilized homelessness services. I have experienced numerous episodes of unstable and precarious housing, and when a broader definition of homelessness is considered (e.g., doubling up, staying with friends), I have technically experienced homelessness on multiple occasions. Thus, I could - to an extent - relate to the stress, anxiety, and other negative mental health impacts of insecure housing that youth expressed, though I would not consider myself a member of this population - nor did the youth view me as such.

There are other ways I related to the participants' described experiences that are similar to the ways I would relate to many other people regardless of whether they are a youth experiencing homelessness or not: the activities they enjoy, their interactions with their friends, their searching for purpose and meaning, as well as some of the other adversities they described both in their interactions with others and within themselves, such as struggles with mental health. 
All of the many ways in which I could relate to the participants' experiences inclined me toward a compassionate view of them: I had a lot of empathy for the negative experiences they were grappling with, but I resonated with their descriptions of their own resilience. This compassionate stance - which I have had since I first started working with this population several years prior to the current research - impacted my participation in the research in several ways.

First, I believe that my compassionate stance was present in the interviews with youth and influenced how I spoke with them. I was not judgmental or surprised by anything they shared (in part because of prior research and interactions with the population), nor was I neutral: I very clearly was "on their side" and tried to convey my empathy for their experiences through both my words and my body language and facial expressions. My hope is that this expression of understanding and compassion allowed them to be more open with me during the interviews.

Second, it made me inclined to want to interpret and present the research in a way that both (1) describes the very difficult realities many youth experiencing homelessness are facing and how those experiences are negatively affecting their well-being, and (2) show the ways in which this population is not helpless, but rather is quite resilient and resourceful. My interpretation of the data is an attempt at striking a balance between the call-to-action that hopefully improves the lives of this population and the call-torecognition of how capable and resilient this population is - despite how frequently they are spoken of and treated by society in negative terms. 
In relation to the service organization where the data was collected, I have collaborated with them on multiple efforts, including two other research projects, program evaluations, and participation in their community events. Moreover, I have developed close working relationships with multiple staff members there and have a close familial-like relationship with a board member of the organization. Because of these multiple close ties to the organization, I infrequently cross paths with the staff members in personal life, and we have developed a healthy rapport and acquaintanceship over the years.

Finally, I am a member of the broader community of which these youth and the service organization are also members. In the past, I have run into research participants from this service center in other contexts. Further, I care deeply about the ongoing homelessness crisis in this community and am an active member of the research community working toward solutions.

My familiarity with both the service center where data was collected and with the broader community - including other service centers - likely helped me to establish rapport with my participants. They undoubtedly saw my interactions with the service center staff, and it is likely that the ways in which participants viewed and interpreted those interactions influenced their willingness to sit down with me for an interview. Further, when participants would bring up other service centers or locations in the city or even specific activities at the service center where data collection occurred - I was already familiar with these places and their operations, and thus I could readily understand what youth were talking about and didn't need to ask for clarification (for 
example, about what an acronym for a service center meant or what that service center does), but rather I was able to ask specific questions related to those places because I was familiar with them. It is likely that this helped youth to see me as an "insider," which probably helped to build rapport during the interviews and encouraged them to open up more to me than they would have otherwise.

\section{Description of the Partnering Organization Before and During the Pandemic}

The community organization I partnered with for this research, p:ear (project: education, art, recreation) is a local homeless youth service and advocacy center whose mission is to "mentor [the city's] homeless youth to affirm personal worth and create healthier lives and communities."

Prior to the pandemic, p:ear was a space for youth to be inside (out of the elements); eat freshly prepared food for breakfast and lunch; charge their phones; engage with peers and staff; make music and art; read, relax, and play games; and focus on schoolwork or other projects. Youth could engage in multiple programs at the service center: training programs for employment (barista school and a bike mechanic program); educational programs; recreational and outdoor activities; and music nights. The staff also helped youth with numerous other practical needs, including finding a place to live, getting ID's, completing paperwork, enrolling in school, finding employment, securing public benefits (e.g., SNAP), and accessing transportation.

The main space had ample tables and chairs, art supplies, musical instruments, and other resources for youth to use, and was next to a large, open kitchen. Youth could 
help themselves to a "closet" with clothing they could take; and they could access other supplies on their own or ask staff for assistance with supplies.

Adjacent to this main space was a large gallery. This gallery had a small coffee station and coffee window where the barista school occurs and was where youth can play music or do other programmed activities. Youth were also able to display and sell the artwork they create in the gallery, including during the monthly art walks hosted by the neighborhood.

Prior to the pandemic, p:ear was a space of community, support, and joy for youth, many of whom would try to visit every day that p:ear was open. The staff knew all of the youth by name, remembered their interests, and created an uplifting atmosphere that allowed youth to feel welcome, at home, and safe.

During the time of the interviews, there were drastic changes to the p:ear space and operations due to changes and precautions in light of the COVID-19 pandemic. The main space described above was closed off to youth, and instead the tables and chairs were stacked, and the space was filled with supplies that staff would provide to youth. Further, the kitchen was used solely to prep to-go meals for youth, which were prepared before p:ear opened each day.

The gallery space became the designated space for youth to use. Tables were spread out with one youth allowed per table. The large doors to the gallery space were fully open, and there were fans turned on at the doors to increase air circulation in the space. The organization had to limit the number of youth that could be in the space at once, and youth had to eat their to-go meals at outdoor tables. If p:ear reached their 
maximum capacity of 10 youth inside at a time, youth signed up for rotating shifts and would only be allowed in the space for one hour at a time.

Youth's engagement with the p:ear also changed due to the pandemic, with many youth utilizing less services overall because they were shut down or had limited hours. Some of the youth who visited p:ear before the pandemic did return once allowed, but most have not, and the overall numbers of engagement are far below pre-pandemic times. Further, youth expressed nostalgia for the way p:ear used to be and explained that part of why they do not visit as often is because they cannot engage the ways they used to through music, art, trainings, community, and being able to stay in one place for most of the day.

The ways in which p:ear fostered a communal and safe space for youth to explore their interests and identities, develop their sense of self-worth and self-esteem, and engage in healthy peer-to-peer and peer-to-staff relationships were no longer present due to the pandemic. Overall, p:ear's operations - and youth's engagement with p:ear - were drastically changed due to COVID-19.

\section{Participants}

A total of 17 youth participated in the interview. All participants were accessing services at p:ear at the time of the interview. Their ages ranged from 18 to $25(M=23)$. Ten youth (59\%) identified as heterosexual; six (35\%) as gay, bisexual, or demisexual; and one $(6 \%)$ chose to not disclose their sexual orientation. Eleven participants $(65 \%)$ were Black, Indigenous, and other people of color (BIPOC); six youth (35\%) reported being White. 
When asked about their current housing status, seven youth (41\%) indicated living in transitional, low-income, or temporary housing or a shelter (thus still meeting criteria for homelessness according to the US Department of Housing and Urban Development); and ten youth (59\%) described living on the streets, out of a car, or couch surfing.

\section{Measures}

Before each interview began, youth were asked a series of open-ended questions about their racial or ethnic background, age, gender identity, sexual orientation, and their current living situation. In the semi-structured qualitative interviews, youth were asked the following primary questions:

1. How do you define your well-being?

2. What kinds of community experiences or social supports do you benefit from regularly?

3. How do your community experiences and social supports impact your well-being on a day-to-day basis?

4. How has the COVID-19 pandemic impacted your community experiences and social supports?

5. How has the COVID-19 pandemic impacted your well-being?

6. How might the community supports in your life impact your ability to achieve your goals?

7. How might an increased sense of well-being impact your ability to achieve these goals? 
8. How has the COVID-19 pandemic impacted your progress towards your goals?

\section{Procedures}

The original recruitment and selection strategies for this study had to be reconfigured given the context of the COVID-19 pandemic. Initially, I had intended to recruit, screen, and select participants based on seeking as heterogenous of a sample as possible. However, there were drastic changes to how the partnering service organization was operating during the pandemic. Most notably, the number of youth visiting p:ear each day declined drastically during the time of data collection due to a number of factors related to the pandemic. Because of this change, recruitment and selection consisted primarily of convenience sampling. However, I continually tailored recruitment based on who was participating. For example, I intentionally sought out participants who did not identify as male after several interviews with male-identified individuals. I also asked youth about their willingness and ability to talk in depth about topics of well-being, their community experiences, and the pandemic in order to ensure they could provide rich responses and that it would not be too emotionally taxing for them to participate.

Youth were asked to read and sign two consent forms: (1) a university-provided COVID-19 consent form that outlined the risks of participating in face-to-face research at this time, safety procedures, and a form for the youth to fill out with their information for purposes of contact tracing should anyone involved in the research become ill; and (2) a standard consent form about the research project and interview process. Youth were given an incentive of twenty dollars cash upon completing the interview. 
Interviews took place in the main room, which was free of other youth since they were all located in the gallery space. Only staff came into the main room during interviews to access supplies, but the interview table was set up in the back corner-far away from any foot traffic. Further, while conversations echo in many other parts of the main room, the back corner was the one space where conversations echoed very minimally. All of these factors provided the highest level of privacy and lowest level of distraction possible for interviews in that space.

The interviews were rarely interrupted. One interview was interrupted for a staff member to ask me if a specific youth could go next, but this did not seem to bother or derail the participant I was interviewing, especially because it occurred at the very end of the interview. Otherwise, there were some distractions in the space, but youth were mostly able to stay focused and seemed undeterred by staff walking by or doing things in the space. The youth sat across from me at the table, with their back to the main room (so as to minimize distractions) and the recording device was placed in the middle of the table. The entire interview station was sanitized between each interview, and everyone involved wore masks.

The interviews were audio recorded and averaged 30 minutes in length. The primary questions that the researcher was hoping for youth to share information about were: (1) how they define their well-being and what it looks like in their daily life, (2) how they understand their community experiences and social supports (or lack thereof) relating to their well-being, (3) how these factors relate to their goal striving, and (4) how the pandemic has impacted all of the above. Some of the questions outlined in the semi- 
structured interview protocol (Appendix A) were meant to help the participant think and talk about a topic before getting to the primary question, while others were meant as additional probes or other ways of asking about the topic if the participant provided a short answer or struggled to answer a question.

\section{Data Analysis}

After each day of interviews, I listened to the recordings and transcribed the interviews, taking notes and engaging in reflexive journaling. Transcribing each set of interviews before conducting the next set allowed me to recognize where I skipped a question, should ask a question differently, or should probe more extensively, and I adjusted future interviews accordingly.

Data analysis focused first on the interview process itself, where I took notes on things that stood out in the interview, my own feelings and experiences, and any responses or observations about the participant that were not captured in the recording. This included my general feeling during and after each interview about the participant's overall attitude towards the researcher and the interview as well as their level of engagement in the interview.

During the transcription process, I noted interesting or unique points of discussion from the participants as well as potential themes and counterexamples that were beginning to emerge. Reflexive journaling continued throughout this process with questions, ideas, potential themes, and observations that came up while transcribing the interviews. All transcriptions were double-checked for accuracy. 
Once all interviews were transcribed, I re-read through each interview and began the data analysis process. Data were analyzed with an inductive thematic approach (Hesse-Biber, 2017; Strauss \& Corbin, 1990) that included multiple read-throughs of the transcripts, coding, and development of themes. Codes were based directly upon participants' responses to a question. For example, in coding the parts of the interview where youth were asked to define their well-being, the codes came directly from their answers: if a participant said, "well-being means getting enough food to eat" then it was coded as "enough food to eat." Sections of text were highlighted and coded with short phrases similar to this example. These highlighted sections were then transferred to multiple pages of an excel spreadsheet, where participants' responses were sorted into their respective codes. After this first round of read-through and coding, the PI re-visited the transcripts and read through them while listening to the audio recording, noting anything else that stood out and might be relevant.

Once all of the coded sections of the transcripts were transferred to the excel spreadsheets, these codes were then grouped into similar categories (e.g., "getting enough food to eat" and "water, food, shelter" were grouped into a "basic needs" category). I then created themes that grouped together similar categories, and thus those categories became subthemes (e.g., "physical health" and "basic needs" became subthemes of “physical well-being”).

I then went back through each transcript and ensured no information was missed and that the themes and subthemes accurately represented what youth shared in their interviews and were based directly on the data in each transcript. I then selected quotes 
that could be used in the results section of the manuscript, focusing on those that captured the essence of each theme, while also striving to include both common and unique examples for each theme and/or subtheme. I purposely selected longer quotes that captured the context of each example, and then in the write-up shortened most quotes by providing my own text summaries related to the theme or subtheme corresponding with the quote.

In order to meet the criteria for a high level of quality in qualitative research, the PI drew upon principles of trustworthiness, reflexivity, and representation (Merrick, 1999) throughout the entire research process. First, I engaged in ongoing peer debriefing (Lincoln \& Guba, 1985) throughout data collection, analysis, and interpretation in order to elucidate other perspectives as well as areas of consensus. For example, after the first set of interviews, I debriefed with my academic advisor on how they went, what came up, and my general experience. He was able to reflect back to me important considerations to keep in mind, how to elicit more information from the participants, and other considerations for my ongoing data collection. I also debriefed with him throughout the transcription and analysis processes, discussing what was coming out of the data and my thoughts about it so far. He provided thoughtful reflections on points I might be missing and different ways to approach my analysis and interpretation of the data.

In order to promote the transferability of findings (a component of trustworthiness), this chapter contains "thick descriptions" of the research context, the youth's experiences, and quotes directly from the participants that provide readers with 
enough information to determine whether conclusions and understandings drawn from the current research can be transferred to other populations.

Further, I practiced reflexivity throughout the research process by keeping an ongoing journal of my experiences, thoughts, ideas, and reflections. Many of the reflections from this journal are presented in the above Researcher Positionality section as well as in the Researcher Reflexivity section of the Discussion in order to help the reader understand the perspectives and experiences that could be sources of bias in the research process.

Finally, representation refers to the researcher's explanation of the experiences of participants (Altheide \& Johnson, 1994), utilizing the above-mentioned reflexivity to carefully engage in interpretive authority (Kidder \& Fine, 1997) of the data. I engaged in reflexive processes throughout the research process in order to carefully decide how I would represent youth experiencing homelessness through how I present the data; and my intention with including statements on my positionality is so the reader can decide how my own stance may have impacted the representations of the data. I will also create publicly accessible documents and present the results to local service centers in order to support them in potential application of the findings.

\section{Results}

In this section, I describe and interpret the major findings that resulted from the analysis plan described above, organized by the four primary research questions. Most youth were fully engaged in the interview process and gave thoughtful answers to each question. Two participants seemed uncomfortable with some of the questions and alluded 
to a history of trauma and anxiety. Two other participants had an overall defensive attitude towards the questions and did not display the same level of openness to the interview as other participants. While not every participant provided information related to each section or question, responses from all 17 participants are included throughout the results section. Each quote is cited as a participant number (e.g., P01) to help the reader recognize when quotes are being provided by different participants as well as to demonstrate both the variety of participant quotes included in the results and to allow the reader to connect a single participants' quotes if they would like to.

\section{How Youth Defined Well-Being}

To begin the interviews, youth were asked to describe their own well-being and define what it means to them. When youth described their well-being, I then asked them follow-up questions such as, "What would you include in the idea of well-being for yourself? Or how would you define it?" The following section outlines the themes that emerged from this section of the interviews, including quotes from youth to demonstrate those themes.

\section{General Ideas of Well-Being}

Several participants easily defined what well-being means to them, explaining that it includes ideas of physical and mental wellness: "It's like how you're feeling mentally and physically" (P17). Initial responses also included broad ideas such as "the idea that you're okay" (P11) as well as "Mental well-being and my physical well-being. Along with my social well-being" (P12). 
Most youth eventually came up with definitions of well-being after I asked them additional questions, while three participants struggled to define or describe what wellbeing means to them. Some of these youth explained that it was hard for them to define because they didn't "understand what well-being is exactly" (P15) or "[Because] it varies from day-to-day. It just depends on the day and what's going on and what troubles are going on" (P11). One youth explained that they struggle with how to define well-being because they don't feel like they've ever had a high level of well-being:

I've never really had a good scale of what my well-being should be just cause I've always been way down here my whole life, so I don't really know what 'up there' means in the future. But I'm looking forward to feeling that and just feeling safe.

Overall, most of the participants $(n=14)$ were able to discuss how they would define well-being and what it looks like in their daily lives, and their definitions were often multidimensional (e.g., both physical and mental wellness). More specifically, youth's definitions of well-being clustered into the following themes: physical well-being ( $n=13)$; mental well-being $(n=10)$; attitude toward self $(n=7)$; self-actualization $(n=$ 3); and social well-being $(n=6)$. Table 1 includes each of these themes, including subthemes and their descriptions.

Table 1. How youth defined well-being $\left({ }^{*} n=14\right)$

\begin{tabular}{lrlrl}
\hline Theme & $n$ & Subtheme & $n$ & Description \\
\hline $\begin{array}{l}\text { Physical } \\
\text { well-being }\end{array}$ & 13 & $\begin{array}{l}\text { having basic needs } \\
\text { met }\end{array}$ & 11 & $\begin{array}{l}\text { Food, a safe place to live, money, } \\
\text { actual mention of basic needs }\end{array}$ \\
\cline { 2 - 4 } & physical health & 3 & $\begin{array}{l}\text { Specific health desires (e.g., } \\
\text { exercise); overall physical wellness }\end{array}$ \\
\hline
\end{tabular}




\begin{tabular}{|c|c|c|c|c|}
\hline \multirow[t]{2}{*}{$\begin{array}{l}\text { Mental } \\
\text { well-being }\end{array}$} & \multirow[t]{2}{*}{10} & mindset & 7 & $\begin{array}{l}\text { Keeping a positive, optimistic, or } \\
\text { hopeful perspective }\end{array}$ \\
\hline & & mental health & 5 & $\begin{array}{l}\text { Maintaining mental health; } \\
\text { managing anxiety, depression }\end{array}$ \\
\hline \multirow[t]{2}{*}{$\begin{array}{l}\text { Attitude } \\
\text { toward self }\end{array}$} & \multirow[t]{2}{*}{7} & self-care & 6 & $\begin{array}{l}\text { Taking care of oneself, maintaining a } \\
\text { desired lifestyle }\end{array}$ \\
\hline & & self-love & 2 & $\begin{array}{l}\text { Loving oneself, not being too hard } \\
\text { on oneself }\end{array}$ \\
\hline \multirow[t]{3}{*}{$\begin{array}{l}\text { Self- } \\
\text { actualization }\end{array}$} & \multirow[t]{3}{*}{3} & personal growth & 2 & $\begin{array}{l}\text { Personal development, growing as a } \\
\text { person, learning about oneself }\end{array}$ \\
\hline & & making a difference & 2 & $\begin{array}{l}\text { Making a difference in others' lives; } \\
\text { helping others }\end{array}$ \\
\hline & & success & 1 & Having a successful career \\
\hline \multirow[t]{2}{*}{$\begin{array}{l}\text { Social well- } \\
\text { being }\end{array}$} & \multirow[t]{2}{*}{6} & social interaction & 4 & $\begin{array}{l}\text { Having the capacity for healthy } \\
\text { social interactions with others }\end{array}$ \\
\hline & & $\begin{array}{l}\text { supportive } \\
\text { relationships }\end{array}$ & 2 & $\begin{array}{l}\text { Having supportive relationships in } \\
\text { one's life }\end{array}$ \\
\hline \multicolumn{5}{|c|}{$\begin{array}{l}\text { *Note: the } n \text { at the top of each section indicated the number of youth who provided a } \\
\text { response to that interview topic. The } n \text { 's for the theme and subtheme categories } \\
\text { indicate the number of responses that fell into each theme and subtheme. Participants' } \\
\text { responses may have been coded into multiple themes or subthemes. }\end{array}$} \\
\hline
\end{tabular}

\section{Physical Well-Being}

The majority of youth $(n=13)$ defined well-being in terms of physical wellness, which included the subthemes of having their basic needs met $(n=11)$ as well as broader ideas of physical health $(n=3)$.

The basic needs subtheme included having access to sufficient food, feeling safe or having a safe place to live, having money to meet one's basic needs, and actual mentions of "basic needs" by youth: "I have access to food and stuff... like my basic needs are met" (P04). Related to this subtheme, youth explained that well-being is 
"Having a stable place to live... Having my medications, having food in my stomach... Having a roof over my head" (P13).

The physical health subtheme included general ideas of "am I healthy" (P16) or “making sure that I'm... just generally looking after myself" (P10), with one participant specifically mentioning physical exercise (P12) as a part of well-being.

However, some participants expressed slightly more ambivalence with this theme of physical well-being. One participant discussed that she definitely wants to have her basic needs met, but that striving to meet those needs in a more stable way (e.g., by being housed) can bring other negative factors, which in turn could be bad for her well-being. This participant explained, "I think that me getting inside and having a job and everything will make things better" (P17) and described how this might support her wellbeing through allowing her to meet her basic needs. However, she expressed uncertainty around how much this would help her well-being, explaining:

But honestly, I don't know cause I've never been so stressed out [as] when I was living inside and paying rent and working at my job... The first three weeks [of living inside] I was feeling super rejuvenated. Refreshed... And then I realized how hard it was just to keep up. (P17)

In this case, the struggle to maintain physical well-being through being housed created stressors that took a toll on her mental well-being.

Similar to this idea of struggling to balance different aspects of well-being, another participant described a back-and-forth balance between seeking to have their basic needs met and pursuing other aspects of their well-being: 
Well-being would mean having enough money to basically take care of my needs... my basic needs being taken care of; my wallet not being touched by other people... When you're homeless, people are not acknowledging what money does for the well-being. So, it starts there. Most of the time I'm only able to focus on food, so like, it all breaks down to food... But at the same time, sometimes I have to sacrifice the money issue for my well-being in [other areas]. (P06)

This participant recognized that, while physical well-being is important to their wellbeing, they can't often meet multiple aspects of well-being at once, and thus have to choose what to focus on. In this case, they described that they end up primarily focusing on their physical needs.

\section{Mental Well-Being}

Parallel to physical well-being, most youth $(n=10)$ also included ideas of mental wellness in their definitions of well-being. This theme included the subthemes of mindset $(n=7)$ and mental health $(n=5)$.

Within responses categorized under the mindset subtheme, youth explained that well-being means keeping a positive, optimistic, or hopeful perspective on life. One youth explained that "Being homeless is kind of like a downer. I don't really have a whole lot of happy days," but that he tries "to stay positive. Try to stay happy" (P04) in order to maintain his mental well-being. Similarly, youth defined well-being as "My mental space -- if I am able to think positively... If I'm able to be optimistic or hopeful, 
I'm doing pretty alright for myself I would say. So, my well-being would be pretty good" (P05).

Overlapping with the mindset subtheme, youth also defined mental well-being as mental health, which included ideas of managing anxiety, depression, or other mental health concerns. One youth explained that well-being includes the idea of "My mental state. If I feel like I'm about to have a mental breakdown or something, or like a panic attack, or something" (P16). This youth elaborated that, in order to have a high level of well-being, "I would have my mental health issues under control -- anxiety and depression" (P16). Similar to this and overlapping with the mindset subtheme, another youth explained that well-being is "How happy I am and how motivated I am and whether I'm not depressed or not and how my mental health is" (P12). These youth described well-being as having mental health concerns, such as depression, under control. More broadly related to mental health, one youth described that well-being looks like "Someone that's in control of themselves... [whose] thoughts aren't outta control" (P09), which reflects these ideas of keeping anxiety or depression at bay.

Most of the themes capturing youth's definitions of well-being overlapped, and youth described how they interact with each other. One youth described mental wellbeing as the foundation to other parts of well-being, explaining how the instability of homelessness can prevent her from creating that foundation:

Being mentally stable. Cause if you're not mentally stable you're not going to be physically stable or be able to keep your own place or keep a job. I feel like that's what's wrong with me: I'm not all the way stable so I can't keep stuff going, and 
I'm also homeless and don't have a place to live, so I can't immediately just have a regular life like everyone else. And I feel like well-being is having all those things in line. Having a job, a palace, a family, and being happy. It's just most of us homeless people don't have all those things. (P13)

\section{Attitude Toward Self}

Youth also defined well-being in terms of one's attitude toward themselves ( $n=$ 7), explaining how self-care and self-love are important parts of well-being. These subthemes included ideas of taking care of oneself, being able to maintain daily activities that support one's happiness, and attitude toward self.

Youth who defined well-being according to self-care $(n=6)$ explained that wellbeing means "That you try to take care of yourself and do a lot of self-care" (P07), and the "ability to take care of yourself" (P09). This idea of self-care often overlapped with the prior two themes of physical well-being and mental well-being. One youth explained that self-care includes "Getting help for both mental and physical issues that are harder for myself to resolve... doing what I need to be doing” (P10). In defining well-being, one youth explained that this includes the idea of having a "habitual lifestyle," describing self-care as "If I'm able to maintain a practice or a style or something every day, and keep that up, I'd say that that makes me happy... habitual practices, daily" (P14).

Overlapping with self-care was the subtheme of self-love, which included ideas of “Me supporting and loving myself" (P08) and "not [being] too hard on yourself" (P09). Overall, these three themes of physical well-being, mental well-being, and attitude 
toward self all included ideas of ensuring that one is well-cared for in multiple aspects of life, with youth elaborating that this care comes, in part, from themselves.

\section{Self-Actualization}

Related to the idea of how youth view themselves, three youth defined well-being in terms of self-actualization $(n=3)$, which included their desires to grow, make a difference, and be successful.

Two youth described personal growth as a part of well-being, explaining that "learning self-awareness" (P10) is important to their well-being. One youth explained personal growth in terms of "developing my identity," explaining that they are "finding my transformation into who I am going to be, cause I'm still growing up" (P06), and that this process of personal growth is crucial to their well-being at this time.

Two youth also described that making a difference in other people's lives is important to their well-being, explaining that well-being means "Having myself established to the point where I can help other people" (P10), such as through a career in social services.

Finally, in this idea of self-actualization, one participant described well-being in terms of both making a difference and being successful:

My ideal well-being: I have made a pretty successful career -- doesn't matter what I'm doing as long as it's successful -- and a sense of self-achievement... Having a successful music career... I would like to have made a difference. Like, I would like to see the work I put out and the music I put out impact people's lives and... also, open their mind -- like just basically change the way they're thinking. (P08) 
While many participants discussed ideas of personal growth, making a difference in others' lives, and being successful throughout the interviews, only these three youth explicitly defined well-being in terms of such self-actualization.

\section{Social Well-Being}

While most youths' definitions of well-being focused internally on the relationship they have with themselves, some youth also defined well-being in terms of their social relationships. The theme of social well-being $(n=6)$ included subthemes of social interactions (having the capacity for healthy social interactions with others) as well as supportive relationships (having supportive relationships in one's life). This theme often overlapped with other themes that emerged from youth's definitions of well-being, with youth explaining how their social relationships interact with their mental health and their attitudes towards themselves.

In describing the social interaction $(n=4)$ aspect of social well-being, youth explained that well-being includes "socializing with others" (P12). When discussing healthy social interactions, one participant explained that someone with a high level of well-being would be "Somebody that can approach anybody_somebody that's approachable... someone that can walk and talk and speak and say what they feel" (P09). This description suggests that someone with social well-being would be able to approach others and talk about their mental-emotional world, demonstrating how the social wellbeing theme overlapped with the theme of mental health.

Similarly, another youth explained, "If I'm just sitting around just doing nothing then I kind of get down and depressed cause I'm homeless and I'm doing nothing. Versus 
if I get up... maybe go hangout with some people" and explained that social life "kind of helps" his well-being, that "it's like a distraction" from being homeless (K04). In this case, social interactions are a part of well-being in how they help to keep him from feeling depressed.

Youth also described how supportive relationships are a part of their well-being ( $n$ $=2)$. One youth explained that "just knowing that I have people that will help me" (P13) helps provide her with a sense of stability, and that this is a part of her well-being. Similarly, another participant described that well-being means having "people who love and support me" (P08).

While youth included these ideas of social well-being in their definitions of wellbeing, their descriptions included the idea that social relationships support their wellbeing - creating a grey area around whether this social aspect is truly part of the definition of well-being, or whether the social aspect of their lives simply supports their well-being. However, it was included as a theme because youth explicitly included these ideas in responding to the question asking how they define their well-being.

\section{How Community Experiences \& Social Supports Impact Well-Being}

After defining their well-being, youth were then asked to discuss the community experiences and social supports that they have in their lives. Their responses included one or more local service centers $(n=17)$; friends or significant others $(n=7)$; family or family-of-choice $(n=5)$; the downtown community or homeless community $(n=4)$; as well as highly specified community groups that individuals were part of $(n=3)$. After describing these community and social supports, youth were then asked to describe how 
these community experiences and social supports impact their well-being. Their responses clustered around three themes of how these community and social supports benefit their well-being, as well as one theme where youth described disengagement from community and potential downsides to social engagement (Table 2).

Table 2. How community experiences \& social support impact well-being $\left({ }^{*} n=17\right)$

\begin{tabular}{|c|c|c|c|c|}
\hline Theme & $n$ & Subtheme & $n$ & Description \\
\hline \multirow[t]{3}{*}{$\begin{array}{l}\text { Emotional or } \\
\text { Mental Health } \\
\text { Support }\end{array}$} & 15 & $\begin{array}{l}\text { emotional } \\
\text { support }\end{array}$ & 10 & $\begin{array}{l}\text { Actual mention of emotional support; support } \\
\text { that helps to uplift one's mood, combat } \\
\text { loneliness, maintain or find a sense of peace }\end{array}$ \\
\hline & & $\begin{array}{l}\text { mental health } \\
\text { support }\end{array}$ & 7 & $\begin{array}{l}\text { Support that helps to improve or maintain } \\
\text { mental health, manage mental health issues; } \\
\text { having something to do, which distracts from } \\
\text { mental health problems }\end{array}$ \\
\hline & & self-esteem & 3 & $\begin{array}{l}\text { Support that helps to boost self-esteem and } \\
\text { allows one to feel good about themselves }\end{array}$ \\
\hline \multirow[t]{2}{*}{$\begin{array}{l}\text { Tangible } \\
\text { Support }\end{array}$} & 10 & $\begin{array}{l}\text { use of } \\
\text { services }\end{array}$ & 9 & $\begin{array}{l}\text { Practical support received from the use of } \\
\text { service centers, including access to resources, } \\
\text { support acquiring housing, or activities }\end{array}$ \\
\hline & & skills & 1 & Survival skills taught by the community \\
\hline \multirow[t]{2}{*}{$\begin{array}{l}\text { Self- } \\
\text { actualization } \\
\text { support }\end{array}$} & 8 & $\begin{array}{l}\text { personal } \\
\text { growth }\end{array}$ & 5 & $\begin{array}{l}\text { Opportunities for learning and growth in } \\
\text { tangible skills (e.g., art) or mentally- } \\
\text { emotionally (e.g., being a better person) }\end{array}$ \\
\hline & & motivation & 3 & $\begin{array}{l}\text { Motivation to keep going, look towards the } \\
\text { future, engage in activities }\end{array}$ \\
\hline \multirow[t]{4}{*}{$\begin{array}{l}\text { Disengagement } \\
\text { from } \\
\text { community }\end{array}$} & 5 & $\begin{array}{l}\text { Negative } \\
\text { interactions }\end{array}$ & 2 & $\begin{array}{l}\text { People who are hurtful; drama between } \\
\text { individuals; not wanting to hurt others }\end{array}$ \\
\hline & & $\begin{array}{l}\text { Negative } \\
\text { influences }\end{array}$ & 1 & $\begin{array}{l}\text { Not wanting to be influenced by others' ideas } \\
\text { or perspectives }\end{array}$ \\
\hline & & Self-reliance & 1 & Not wanting to rely on others \\
\hline & & Trauma & 1 & $\begin{array}{l}\text { A traumatic experience that led to } \\
\text { disengagement }\end{array}$ \\
\hline
\end{tabular}


In general, most youth described community experiences and social supports as beneficial to their well-being. This included the emotional or mental health support $(n=$ 15), tangible support $(n=10)$, and self-actualization support $(n=8)$ that youth received from their communities and social supports, all of which benefitted youth's well-being.

\section{Emotional or Mental Health Support}

The theme of emotional or mental health support $(n=15)$ that emerged from youth's discussion of how community experiences and social supports impact their wellbeing included the subthemes of emotional support $(n=10)$, mental health support $(n=$ 7), and the ways that these experiences benefit their self-esteem $(n=3)$.

Emotional support included explicit mentions of "emotional support" or support from others that helps to uplift one's mood, combat loneliness, and maintain or find a sense of peace. One participant explained that "having the social time with somebody else" is emotionally beneficial, and that if they're "in a bad mood," they can go spend time with friends and doing so "brings [their] mood up" (P11). Another participant described how their friends and 'family' support them emotionally by "just letting me talk to them and [by] giving me advice. And that's really all a friend can do" and they are "there when I need to talk to them or a shoulder to cry on" (P13).

Similar to the support received from friend groups, youth also described how service centers provide them with emotional support that benefits their well-being. One participant described how visiting a service center helped get them out of a negative mindset, and that frequently visiting this place helped them find a sense of peace: 
I really wasn't a happy person before I came here. That's because I didn't really have any place to be by myself to think [and] collect my thoughts... [coming here] helped me get my peace back. (P03)

This subtheme of emotional support overlapped considerably with the subtheme of mental health support that youth described receiving from the communities and social networks. Youth described that the support they receive helps them to improve or maintain their mental health, and that interaction in the community gives them outlets when they might otherwise be overwhelmed by mental health problems. For example, one participant described, “I feel like if I wasn't doing [the music and art here], I'd be depressed all the time," and explained that those activities at the service center are a “creative outlet... it's a distraction so you're not sitting here thinking 'aww man I'm homeless, this sucks' all the time" (P04).

While this youth described the support from a service center as benefitting his well-being by providing healthy outlets and distractions, other youth described the help they receive from a service center when they're struggling with a mental health issue:

Whenever I have an issue, whenever I'm trying to figure something out in my life, I just go there and end up getting help with that in some way or another. Even if it's just me having a panic attack, I'm still able to go there and talk to some people and get some clarity from an outside perspective from people that I trust. (P10)

Much of the support received from friends or service centers revolved around youth having others to talk with when experiencing difficulties and receiving support 
from those people in a way that benefits their mental health. For example, one participant explained how the staff at a service center are "super supportive," elaborating that “Anytime I've looked down, they've asked me if I need someone to talk to. They make me feel like I'm not falling into a dark hole" (P17). In reference to his friend group, one youth described, "We all just kind of uplift each other. We try not to think like the cup is half empty," and explained that they all help each other keep a positive mindset (P04).

Sometimes, youth's descriptions of the emotional or mental health support they receive from their communities or social networks also related to the practical support they receive from those people. One participant explained that she had a severe injury that made her "crippled for six months," and that her friend took care of her the entire time. The injury made her feel like she "didn't want to be around anymore because of how bad" it was, but that the care and love from her friend "made me not want to leave" (P17). This participant eluded to thoughts of suicide due to the severity of her injury, but that the support of her friend helped her decide to continue living.

Finally, some youth described that the interactions they have with service centers, friends, or others in their communities benefits their self-esteem, which also supports their well-being. One participant discussed his community experience of playing music on the street and explained "It really doesn't matter if I'm making any money from playing music," and explained that when the people he encounters give him feedback, it helps “ a lot with my self-esteem and the way I look at myself” (P08). Another participant described a similar boost to their self-esteem through interactions with a service center, explaining how the staff "always pushed me towards the potential that I 
feel like I don't have sometimes," which helped him feel more confident in himself and his ability. He further explained, “They seem to remember my name, or at least my face, and they're enthusiastic about it" and that this "sense of community" at this service center helps him feel good about himself, which supports his well-being (P09).

\section{Tangible Support}

In describing the positive ways that community experiences and social supports impact their well-being, eleven participants described the tangible support that they receive from others, citing both the use of services $(n=9)$ and also the skills they've learned from others in his community $(n=1)$.

Most of the participants' discussion of tangible support centered around the use of services, which provided them with access to resources, support in acquiring other needs (e.g., housing, paperwork), or activities provided by the service centers. Several participants described how "[Services] help [my well-being] a lot because they help you get some of your basic necessities if you don't have them" (P04), or that they "Make it easier to have a warm tent at night, versus being on the sidewalk somewhere" and summarized that services benefit her well-being because "They help me be able to have the basic needs to survive" (P07).

One participant explained how a service center helped him get affordable housing and trained him in the job he works in, describing that "They really enable me to have my life." He further explained that they help him by giving him "all of my free medical services, my food for the month every month" and concluded that, without these services, "I wouldn't be in school" (P05). By supporting him in his employment and with his basic 
needs, this participant was able to pursue other goals - in this case, school - all of which directly and indirectly supported his well-being.

Another participant reflected these sentiments in describing how the support of service centers has enabled them to find more stability by getting them into a housing program "that's specifically for LGBT youth," a community they identify with. Moreover, they described that this two-year housing program has "helped me figure out what it's like to be stable" and has taught them how to be more independent, all of which benefitted their well-being (P01).

Other participants explained that service centers provide "recreational activities" that support their well-being (P12), or that service centers provide "basic things" (P06) like "clothes, food, showers" and a space to be inside, which helps youth meet their basic needs and thus supports their well-being. Finally, one participant explained that the community "taught me a lot of survival skills," which helped support his well-being while homeless (P02).

Overall, this tangible support received primarily from service centers, but also from the broader community, had a large impact on youth's well-being by helping them meet their basic needs, supporting them in other endeavors like acquiring housing, and by teaching them survival skills while experiencing homeless.

\section{Self-Actualization Support}

A third positive way that youth described their community experiences and social supports as benefitting their well-being was through self-actualization support $(n=8)$. Here, youth described the opportunities for personal growth $(n=5)$ they've had through 
community and social experiences, as well as the ways in which people in their lives help to motivate them $(n=3)$.

In describing the personal growth they experience in community settings and how this benefits their well-being, one participant explained how the people they are close to have encouraged them to "change as a person" and "become a better person." In describing how this supports their well-being, they explained that the growth they experienced helped them learn, 'I'm more capable than I've grown up to believe. I'm capable of learning and stopping bad behaviors and all of that to further help me later on in life" (P10).

Similarly, another participant described that their community experiences helped them grow by allowing them to "[become] a lot more social," which in turn fostered a sense of gratitude, more life opportunities, and helped them "figure out what I want to do in life and figure out how to develop a sense of community" (P01), which supported their well-being. This participant also described how a service center helped their growth through the art programs offered, which fostered their growth by helping them "channeling all of that energy into something I'm really good at" (P01).

Other participants echoed this description of how service centers support their well-being through personal growth. For example, one participant explained how "[Service centers] help me try new things and help me learn new skills," which "builds my well-being." When asked how it builds his well-being, this participant explained, "It makes me feel happier, it makes me feel empowered, it makes me feel like I've learned something. It makes me look to a brighter future and focus on the present” (P12). 
Related to this subtheme of personal growth, a few youth described that giving back to others is a part of their well-being, and that some of their growth stems from the opportunities they have had to give back to others. One participant explained that it "makes me feel good as a person to know that I'm actually helping someone who is going through the same thing... [Giving back to others] helps me grow" (P01). Similarly, another participant similarly described how helping others and trying to make a positive different in the world gives him a sense of purpose every day. In reference to his work in the activism community:

Being an activist and being in that community and getting that support and giving that support -- is really impactful for my well-being... it just makes me feel like I'm doing good. Whether I am or I'm not, if I feel that way it's much easier for me to get up in the morning and it's much easier for me to go out and work, it's much easier for me to get through the day... When I'm out there and when I'm doing my best, that makes me feel like I'm contributing, I am doing what I can. (P05)

Participants also described how the community and social supports in their lives help to motivate them, which also benefits their well-being. For example, one participant explained that the staff at a service center "makes me want to go to work and make money in order to get back into housing and not just give up" (P07). Similarly, another participant described how the service center "motivated me to paint," which helped fulfill his desire "to be creative" and made him feel like he "didn't waste the past two hours." He elaborated that he felt like that time was "spent very well compared to what I 
would've been doing [otherwise]" (P09). These descriptions suggest that the community supports in these youth's lives help motivate them to make the most of their days, which supports their well-being by encouraging them to pursue activities that are meaningful to them.

Overall, this theme of self-actualization focused on how community and social supports help youth more clearly see their potential in life, encouraging them to believe in and focus on a positive future.

\section{Disengagement from Community}

While participants' descriptions of how their community experiences and social supports impact their well-being were overwhelmingly positive, several participants also described a level of disengagement from community $(n=5)$, explaining that this disengagement came from the potential for community and social experiences to have a negative impact on their well-being. This included negative interactions with others $(n=$ $2)$, negative influences that come from social interactions with others $(n=1)$, preferring to be self-reliant $(n=1)$, and an experience of trauma that led to disengagement $(n=1)$.

Two youth explained the potential for negative interactions in social settings to negatively impact their well-being. One participant explained that she prefers to keep her social circle small because when she had more friends, "people just ended up being mean people, talking behind your back and doing all these things that people shouldn't do" (P13). In the same vein, another participant explained that she feels like people want something from her and "that's why they're around me." She elaborated, "I don't really talk to them about stuff that's going on because it's like there's always some kind of 
drama that's going to start" and that she doesn't have close friends because of this (P17). These two participants focused on the potential negative interactions - such as people being mean - that led them to find social interactions as more detrimental than beneficial to their well-being.

Similarly, a third participant discussed that he does not want other people's harmful influence on his life, explaining, "When I'm around [a certain] energy and people who subscribe to [different] ideals, it's very hostile for me," and elaborated that he feels the need to "keep distance away from people cause they're not going to understand my lifestyle" (P14).

This participant and another seemed to hint at not wanting to spend their energy on social relationships, with the second participant explaining "If somebody wants to be in my life, they're going to put the effort to be in my life. But a lot of people I can't tolerate being around me." This participant explained further, "I don't rely on nobody... I try not to rely on nobody" and alluded to the potential for being let down by others if you try to invest your energy into a relationship with them or if you try to rely on them (P03).

Reflecting this idea of being let down in some way if they invest in relationships with others, a final participant described the death of a close friend and how this led him to disengage from community experiences and social relationships, which negatively impacted his well-being:

When that happened, I pretty much withdrew from everything. I just cut everything and everyone off... My mental health definitely was hit pretty hard, in a negative way. Because of that, I don't want to get close to anybody other than 
my girlfriend... I just feel like the pain of losing her - even though I wouldn't really be losing her like I lost my friend - I just can't do it. [This disengagement] is stopping me from being able to reach out and access the resources that could potentially be available to me. (P16)

While this participant's narrative focused on the pain of losing his friend and the negative impact that had on his well-being - and thus why he has disengaged from social relationships - he also described how this disengagement negatively impacts his wellbeing, as he has not been accessing services that could help him. In this case, while he recognizes that community or social supports could benefit his well-being, he engages those supports as minimally as possible due to his fears around the pain he might experience.

All the participants who discussed a level of disengagement from community and the negative impacts of community that led to their disengagement - also described some benefits of community experiences and social supports, demonstrating that these experiences are not mutually exclusive, but rather that community can have both positive and negative impacts on youth's well-being.

\section{Short- and Long-Term Goals}

After defining their well-being and discussing how their community experiences and social supports benefit their well-being, youth were asked to discuss how their community support and well-being impact their short- and long-term goals. Youth's short-term goals included finding better housing situations; gaining employment or some kind of income; starting or continuing job training; practical to do's (e.g., acquire a new 
identification card); begin school; creative pursuits; and specific goals related to physical or mental health. Their long-term goals included not being homeless anymore; helping the people they care about; education; and pursuing creative endeavors.

\section{Impact of Community Supports on Goals}

Thirteen participants described how community and social supports impact their ability to achieve their goals. The majority of these responses referred to both tangible and emotional support from service centers.

Table 3. Impact of community supports on goals $(n=13)$

\begin{tabular}{|c|c|c|c|c|}
\hline Theme & $n$ & Subtheme & $n$ & Description \\
\hline \multirow[t]{3}{*}{$\begin{array}{l}\text { Tangible } \\
\text { support }\end{array}$} & \multirow[t]{3}{*}{13} & $\begin{array}{l}\text { Practical } \\
\text { needs }\end{array}$ & 10 & $\begin{array}{l}\text { Support in working toward practical needs } \\
\text { (e.g., ID card, paying a bill; finding } \\
\text { employment), which allows them to work } \\
\text { toward their goals }\end{array}$ \\
\hline & & Basic needs & 6 & $\begin{array}{l}\text { Support in meeting immediate basic needs } \\
\text { (e.g., food; hygiene), which allows them to } \\
\text { focus on their goals }\end{array}$ \\
\hline & & $\begin{array}{l}\text { Skill } \\
\text { development }\end{array}$ & 3 & $\begin{array}{l}\text { Opportunities to develop skills, which } \\
\text { supports goals }\end{array}$ \\
\hline \multirow[t]{2}{*}{$\begin{array}{l}\text { Emotional } \\
\text { support }\end{array}$} & \multirow[t]{2}{*}{5} & Uplift & 3 & $\begin{array}{l}\text { Feeling emotionally uplifted and } \\
\text { empowered to continue towards goals }\end{array}$ \\
\hline & & Motivate & 2 & $\begin{array}{l}\text { Being motivated by others to continue } \\
\text { striving towards goals }\end{array}$ \\
\hline
\end{tabular}

Tangible Support. Tangible supports included the ways in which community and social supports helped youth with practical needs $(n=10)$, basic needs $(n=6)$, and skill development $(n=3)$, all of which helped them work towards their goals.

Support in meeting their practical needs included things like getting an ID card, paying a bill, or finding employment. One youth explained, “They'll help support 
anyone's goals if they have the funding for it... you just have to talk to them, and it has to be within their power to do it" (P03). This participant gave examples of paying a phone bill and getting new clothes, and specifically mentioned that the service center got him a gym membership. Other participants explained that they can help from service centers with their goals of going to school (K09) and pursuing artistic ambitions (P04, P08), and that the job training $(\mathrm{P} 10)$ and other resources provided by service centers help them continue working towards their goals.

Overlapping with these practical needs, youth also describe specific basic needs that community and social supports help them meet, which allows them to focus their energy on their goals. One participant summed this up well:

Without p:ear, I really wouldn't have some of my basic necessities for my wellbeing which would really get me down. And then it would probably really hinder my whole arts and working and stuff like that... [having basic needs met] is like one less thing to stress about. Even though it seems like it wouldn't impact me that much, it really does. (P04)

Having their basic needs met - food, clothing, acquiring housing - through the support of service centers allowed youth to focus on their other goals, such as school, work, and artistic endeavors.

A few participants also described how these community supports help them develop their skills in art (P04, P14), in a specific kind of job (P05), or in social interactions (P01, P06) — all of which helped them work towards their goals. 
Emotional Support. Participants also described how the community experiences and social supports in their lives provide them with a level of emotional support $(n=5)$ that enables them to continue working towards their goals. This emotional support helped to keep them emotionally uplifted $(n=3)$ and empowered to continue towards their goals, and also helped to motivate $(n=2)$ them to continue towards their goals, ideas which often overlapped in youth's descriptions of how these supports impact their goals striving.

One youth explained that "the community keeps my head up," but also that they motivate him because he doesn't want to end up like them: "They encourage me and motivate me cause I don't want to be there. I don't want to live that life. I don't want to end up like [them]" (P02). On the other hand, he explained that service centers also motivate him, but in the opposite way, by showing him "that there are good people in this world" (P02).

Similarly, another participant explained how the emotional support of his friend group impacts his goals, explaining "We all help each other out a lot... When one person is motivated, they'll motivate the rest of us if we're not as motivated that day" (P04), which he described as helping him stay focused on and working towards his goals.

Overall, youth described how the tangible support and emotional support that they receive from their communities and social groups supports their ability to continue striving towards their goals. These tangible and emotional supports provided youth with survival necessities so that they could focus their time and energy on their goals; with other practical needs such as finding employment so that they can work towards their 
goals; and with skill development that both directly and indirectly supported their goals. Youth's communities and social supports also provided them with uplifting and motivational emotional support that encouraged them to continue working towards their goals.

\section{Impact of Well-Being on Goals}

Participants were also asked how their well-being might impact their goals. While some participant struggled to connect their well-being to their goal striving, eleven youth discussed how their well-being can have both a positive and negative impact on their ability to strive towards their goals. Specifically, youth explained that maintaining a high degree of mental and emotional well-being would help them stay motivated and focused on their goals. On the other hand, if their mental or emotional health is diminished, they explained that this would put a strain on their ability to work toward their goals.

Table 4. Impact of well-being on goals $(n=11)$

\begin{tabular}{|c|c|c|c|c|}
\hline Theme & $n$ & Subtheme & $n$ & Description \\
\hline \multirow[t]{2}{*}{ Mental } & \multirow[t]{2}{*}{7} & Mindset & 7 & $\begin{array}{l}\text { Maintaining a high level of well-being allows } \\
\text { one to keep a positive mindset, stay motivated } \\
\text { to work on goals }\end{array}$ \\
\hline & & Mental health & 3 & $\begin{array}{l}\text { Maintaining well-being through managing } \\
\text { mental health allows on to keep working on } \\
\text { goals }\end{array}$ \\
\hline \multirow[t]{2}{*}{ Emotional } & \multirow[t]{2}{*}{4} & $\begin{array}{l}\text { Presence of } \\
\text { positive } \\
\text { emotional } \\
\text { states }\end{array}$ & 3 & $\begin{array}{l}\text { Overall mood and feeling happy supports } \\
\text { working towards goals }\end{array}$ \\
\hline & & $\begin{array}{l}\text { Lack of } \\
\text { negative } \\
\text { emotional } \\
\text { states }\end{array}$ & 1 & $\begin{array}{l}\text { Lack of stress or depression would allow them } \\
\text { to work towards their goals }\end{array}$ \\
\hline
\end{tabular}


Mental health and emotional health are separated in these results because youth discussed them as separate ideas, with some youth specifically referencing their mental health and others describing their emotions and emotional health. However, throughout the interviews, there was often overlap in discussions of these two components of wellbeing, suggesting that they are not strictly distinct or separate, but rather two component parts of well-being that have conceptual similarities and differences and often work in tandem.

When discussing how their mental well-being impacts their goal striving, participants described the importance of both positive mental health and a positive mindset in working towards their goals. One youth described how working towards one's goals requires a specific mindset: "You have to have the right attitude for it. You have to have the determination and willingness to accept and take some blows, some falls" (P11), and that a high level of mental well-being would support this mindset. Similarly, one participant described how a higher degree of mental well-being would allow her to "be more focused and positive to get stuff done" (P17), which would positively affect her ability to achieve her goals.

On the other hand, youth also described how a low sense of mental well-being can negatively impact their ability to achieve their goals. One participant explained, "If I'm not in a good mental space and I'm not really motivated and really positive about it, I'm not as productive" and that his "mental space and well-being" are even more important to his goal striving when his social supports are not as robust (P05). 
Parallel to how mental well-being impacts youth's goal striving, participants described how their emotional well-being can impact their capacity for working towards their goals. As distinguished from mental well-being, within this theme, participants specifically discussed their emotions, mood, and feelings - as opposed to their thoughts, mindset, or mental state. One participant described how their "overall energy, overall mood" and how they present themselves can depend a lot on their ability to cope with their anxiety, and that coping effectively can help them meet their goals. This participant in particular described a scenario in which they did well at a job interview because of this improvement in their emotional well-being (P10). Another participant explained that an increased well-being "will only make me feel better," which in turn would empower him to focus on his goals (P12). Similarly, one participant summarized, "If I have an increase of well-being, then I feel better overall, and I'm able to tackle tasks" (P14).

Participants also described how experiences of stress or depression can inhibit their ability to work on their goals. One participant described how "I have a lot of things to do. I just don't have the time to be depressed," (P05), and another participant explained that when he had a tough day "I couldn't really do everything that I normally do, because I was just in my head a lot, like stressing" and that this mindset can inhibit his ability to work on his goals (P04).

In sum, participants described how experiences of low well-being can prevent them from being able to work on their goals, while an increase in their well-being would help them keep a positive mindset, manage their mental health, and keep their mood and 
energy high, which then enables them to more effectively tackle the tasks related to their goals.

\section{Impacts of the COVID Pandemic}

The COVID pandemic has impacted youth in numerous ways. For most youth, the largest impact was on their access to resources and service centers. Several participants also lost their employment, had to stop job training, or could not acquire a job that they hoped to get. This lack of access to resources and employment had other impacts on youth, such as losing housing or falling behind on bills.

Youth were asked to describe the impacts of the pandemic on their well-being, on their community experiences and social supports, and on their ability to pursue their goals. The following sections review the topics and themes that emerged from youth's descriptions of how the pandemic has impacted their lives. The topics are based on the questions youth were asked in the interview, while the themes reveal the ways youth discussed each of those topics (e.g., how the pandemic impacted their well-being). The results were organized this way instead of in the manner used throughout the remainder of the results section because the question topics are not necessarily overarching themes, while youth's discussions of these topics were too varied (and too specific) to reveal any consistent subthemes. Thus, only over-arching themes are discussed.

Table 5. Impacts of the COVID-19 pandemic $(n=17)$

\begin{tabular}{lllll}
\hline Topic & $n$ & Theme & $n$ & Description \\
\hline Well-being & 16 & $\begin{array}{l}\text { Negative } \\
\text { impact }\end{array}$ & 11 & $\begin{array}{l}\text { Mental (increases in stress, depression, } \\
\text { and fear); negative mental health } \\
\text { impacts }\end{array}$ \\
\hline
\end{tabular}




\begin{tabular}{|c|c|c|c|c|}
\hline & & Neutral impact & 3 & $\begin{array}{l}\text { Some impacts, but well-being has mostly } \\
\text { been maintained }\end{array}$ \\
\hline & & $\begin{array}{l}\text { Positive } \\
\text { impact }\end{array}$ & 2 & $\begin{array}{l}\text { Opportunities to focus more on } \\
\text { improving well-being (e.g., self-work); } \\
\text { opportunities that improved well-being } \\
\text { (e.g., housing) }\end{array}$ \\
\hline \multirow[t]{2}{*}{$\begin{array}{l}\text { Community } \\
\text { experiences, } \\
\text { social } \\
\text { support }\end{array}$} & \multirow[t]{2}{*}{17} & $\begin{array}{l}\text { Changes to } \\
\text { resource } \\
\text { access }\end{array}$ & 14 & $\begin{array}{l}\text { Loss of and/or reduced access to access } \\
\text { to needed resources and services (e.g., } \\
\text { service centers) }\end{array}$ \\
\hline & & $\begin{array}{l}\text { Changes in } \\
\text { social } \\
\text { relationships }\end{array}$ & 9 & $\begin{array}{l}\text { Social isolation, loss of supportive } \\
\text { networks or relationships }\end{array}$ \\
\hline \multirow[t]{3}{*}{ Goals } & \multirow[t]{3}{*}{14} & Services & 14 & $\begin{array}{l}\text { Loss of access to service centers to meet } \\
\text { basic needs, which inhibits goal striving }\end{array}$ \\
\hline & & Employment & 8 & Job loss or the inability to acquire a job \\
\hline & & $\begin{array}{l}\text { Other } \\
\text { activities }\end{array}$ & 7 & Cannot engage in other desired activities \\
\hline
\end{tabular}

\section{Well-Being}

Most participants $(n=16)$ described some kind of impact that the pandemic had on their well-being: eleven youth described a negative impact; three youth described a neutral impact (e.g., some good, some bad); and two youth described a slightly increased well-being because of the impacts of the pandemic.

The negative impacts of the pandemic that youth described focused on the ways in which it affected their mental health. Youth discussed how the pandemic contributed to increases in stress, depression, and fear, as well as how the pandemic created a loss of community supports, employment, or other resources that negatively impacted their wellbeing. 
Reflecting the mental health impacts of the pandemic, many participants reported experiencing declines in their mental health, which included urgent some mental health crises among participants. One participant explained, "I [was] suicidal... [I was] really depressed and my well-being was not okay" (K01). Other youth reflected this experience, explaining "It's been depressing" and described a sense of confusion created by misinformation during the pandemic: "It's kind of one of those things where I don't know a lot about it cause a lot of it's become propaganda at this point, unfortunately, to the point where I'll wear a mask, but there's just so much drama behind it and so much information that it's all just very confusing" (P10).

More specifically, youth also described an increase in stress and fear about themselves or their loved ones getting sick, explaining, "It's definitely stressing me out. Socially and mentally, it's been pretty weighing" (P08) and "It definitely frightened me a little bit and I was kind of afraid of it... I have obligations I got to take care of, I got things that love me in this world" (P02).

Related to these feelings of depression, stress, and fear, another participant explained the impact that the pandemic had on her mental state and ability to cope in the face of all the stressors brought about by the situation:

I'm kind of scared of how everything gets, but I'm just taking it day by day, cause honestly, I don't know how long this is going to go on and I don't really want to think about it. I just feel like I'm surviving... me not making any money, I don't feel like I'm going to thrive during COVID - and that really worries me, and that kind of affects my mental state, but I try not to think about it. (P17) 
Similar to this narrative, another participant — who had been housed for a year and continued to use services because he could not afford all of his needs on his owndescribed the stress of losing his job and his fear of becoming unhoused again:

I wake up stressed every day. It's hard for me to get a good night's sleep anymore. When you have that much back-rent weighing on your mind... When you're homeless for six years and then you pull yourself out of it, you do not want to be homeless again. Unless you've been homeless, you don't know how hard that is... I just don't want to [be homeless] again. (P05).

The above quotes demonstrate how the pandemic negatively impacted youth's well-being through their increased levels of stress and fear about physical illness, as well as increases in general feelings of depression. Youth's narratives also revealed negative impacts on their well-being through the financial strain that pandemic-induced societal changes had on their lives.

Some participants also described how the pandemic negatively impacted their well-being through the loss of community supports. One participant explained that he felt "disempowered" by the loss of outdoor activities provided in the community, and that having to stay indoors "has done a huge drain on my mental health" (P12). Another participant explained that she hasn't been able to see her therapist, which made it "difficult to reach out for help" with her mental health and to receive the medications she needed to manage her mental health effectively (P07). Finally, one participant described that because the pandemic has shut down so many services, it has been "difficult to find what I need," including easy access to a restroom and hygiene services (P06). 
Overall, the pandemic had a multi-layered negative impact on youth's well-being: participants described both the stress and fear of the pandemic directly, as well as the emotional strain created by not being able to access services or community supports and not being able to support themselves financially.

Alternatively, three participants described a more neutral impact of the pandemic on their well-being, explaining that in some ways it impacted their well-being, while in other ways their well-being is the same as it would be otherwise.

These participants explained that the impact of the pandemic on their well-being has been "kind of bad, kind of good" and that, aside from some limitations to where they can go, their well-being is "just the same as always" (P11). Along these lines, participants described that sometimes the pandemic is "just kind of annoying," but that they are “neutral on it" (P04).

For the two participants who described a positive impact of the pandemic on their well-being, one participant explained that "It's actually kind of made [my well-being] better, enhanced it. Cause I've been able to work on myself' (P14). Another described how it was beneficial to his well-being because a living and employment opportunity arose that wouldn't have without the pandemic: "In a way it gave me a slightly safer place to stay because of the [homeless] camps opening up. And that also temporarily gave me a job cause they were employing some of the villagers... I guess that's one positive thing that came out of it" (P16).

While these neutral and positive descriptions of how the pandemic impacted participants' well-being demonstrate a capacity for optimism and ability to find 
something positive in difficult situations, they represent isolated counterexamples to the predominant narrative of how the pandemic negatively impacted youth's well-being. And while a handful of participants explained either neutral or positive impacts of the pandemic on their well-being, their descriptions of how the pandemic impacted their community experiences, social supports, and goals were all negative.

\section{Community Experiences and Social Supports}

All 17 participants discussed the impacts of the pandemic on their community experiences and social supports. These descriptions focused primarily on changes to resource access and social relationships - which, as noted above, also had an impact on their well-being.

A total of 14 participants described changes in their ability to access needed resources because of how the pandemic forced societal changes, such as service centers shutting down or severely limiting their indoor capacity and services. Youth explained how "in the beginning, it was really rough cause everything was shut down" (P02) and "a lot of the resources that were there are closed now. Or there's a very long waiting list" (P16). Youth also explained that the changes created by the pandemic "made it so that services are harder to get to because of how many people can be in the building" (P17) and that "it's really hard to get to most of the resources that were there before" (P15).

Youth described how this loss of access to services impacted their ability to acquire food, clothing, and other resources; their access to clean restrooms and places to take care of their hygiene needs; and left them without some of the services that had 
previously provided them with programming that supported their well-being, such as art and recreational activities.

In describing how the pandemic impacted their community experiences and social supports, youth also explained changes in their social relationships $(n=9)$ that had a negative impact on them. This included increases in social isolation created by the need to social distance, as well as the loss of supportive networks or relationships.

In describing the increases in social isolation that they experienced, one participant explained, "I have to be very careful how close I am to people" because she is immunocompromised. She went on to describe how this made face-to-face interactions difficult, and said, "that kind of isolation has really changed me as a person" (P07). Other youth described similar experiences of isolation, explaining "I don't see anyone ever, really, so it's like I'm kind of alone" (P17), and how this eventually led them to become disheartened by the thought of trying to engage socially: "The whole social distancing thing kind of makes it a little bit difficult to be social... you just get to the point where you don't want to hang out with anybody. It's been isolating” (P08).

Youth also described how the social isolation has negatively impacted the social supports that they used to rely on. For example, one participant described, “I just don't see [my best friend] anymore. She was a huge support for me" and that he had lost friends due to the COVID-19 virus (P05). He went on to describe larger-scale negative impacts through the ways his social network and community could no longer gather, explaining that the social distancing "Makes it so much harder to work together, to help 
each other, to find out who needs support. All these things we all did for each other have just gotten so much more difficult" (P05).

Similarly, another participant described how the pandemic has "severely restricted how I can reach out to others and build community" (P12). Another participant reflected this sentiment, explaining that she can no longer "be close to anybody... we can't touch each other, we can't be next to each other, have to wear face masks," and that these changes to her social interaction have "definitely taken a huge impact on my community itself” (P13).

Overall, these changes to participants' social environments - both the service centers they used to rely on as well as the friendships and relationships that were once a major support for them - impacted their well-being negatively because it compromised their ability to meet their needs and have the emotional support of others during such a difficult time.

\section{Goal Striving}

To conclude the interviews, participants were asked how the pandemic impacted their ability to work toward their goals. Fourteen youth described the ways in which the pandemic created barriers to working on their goals. As one participant directly explained, "It has inhibited all of [my goals]" (P16). For most youth, the pandemic contributed to delays in their goals through its impact on service access $(n=14)$. This limited access to services had a negative impact on their ability to meet their basic needs, on professional training programs they were in, and on other ways that service centers supported them, such as by helping them get on waitlists for housing. With all of these 
supports severely limited, youth had to focus more of their time and energy on these needs, some of which were foundational to their stated goals.

For example, some youth described how one of their goals was to acquire a job so that they could financially support themselves, or that they needed to be employed in order to work on other goals they had. However, due to the pandemic and its impact on employment, their goals were delayed because they either lost or couldn't find a job. One participant explained, 'It feels like it's slowed [my goals] down just cause of how long it took [to get a job]. Cause you need money for everything" (P17). Other participants described a similar experience, explaining how it has slowed down their goals because they cannot get a job (e.g., P15, P08). Another participant described, "[I had] my dream job lined up right before this," but that the program they were planning to work for got cancelled due to the pandemic. They went on to explain, "That would've been the ideal job for me," and that having that job "probably would've gotten me off the streets" (P11).

Participants also described other activities related to their goals that they could no longer engage in, such as job trainings (P01, P12), their musical pursuits (P15, P08), school or education (P01, P05, P09, P15), or social activities related to their goals (P10). Many of these activities were linked to public spaces or service centers that they now had limited access to.

In sum, the pandemic created barriers and delays to participants' abilities to work towards their goals, primarily by limiting their access to services that previously support their goals - either indirectly through helping them meet their basic needs, or directly through specific services and opportunities that were offered. However, other general 
social changes also inhibit youth's goal striving, such as the social isolation imposed on them and how that has impacted their ability to engage in in-person activities. One participant's response captured the essence of these multilayered, negative effects of the pandemic:

It's been really hard for me to be able to get adequate food, really hard for me to be able to get to the support or medical needs that I have. So those have been really hard. It's been hard for me to go out and have conversations with people and talk about things with people. No one that you weren't super close to before is willing to hang out with anyone cause it's just not safe, and that's the smart thing to do... It's very much poked gaping holes in the foundation of my life... when all of your [resources and] foundation stuff has been wiped out, if you have a bad day it affects everything. And it's like a snowball effect. And it's really easy to have bad days right now... There are so many key things that just don't happen anymore. Or so many resources that I needed that don't happen anymore. And you basically have to refigure out how to get everything done if you relied on anybody but yourself. (P05)

\section{Discussion}

\section{Overview}

The current investigation sought to incorporate the perspectives of youth experiencing homelessness into research focused on their well-being, community experiences and social supports, goals, and impacts of the COVID-19 pandemic. Exploring how youth perceive and understand these topics can inform researchers about 
what is relevant and important to the well-being of this population, what will help them better achieve their goals, and how to better serve youth during rapidly changing social circumstances such as a pandemic and political unrest.

In this qualitative study, youth described how their community experiences and social supports positively impact their well-being, but also how other factors have impacted their well-being in both positive and negative ways - including the COVID-19 pandemic. Throughout their responses and narratives, participants demonstrated a high degree of resilience and ability to adapt to their rapidly changing social circumstances, which have drastically impacted both their goal pursuits as well as their day-to-day experiences while homeless. Below, I will review the primary findings, limitations, and implications of this work, and also reflect upon challenges and lessons learned about conducting research with youth experiencing homelessness during a global pandemic.

\section{Well-Being}

Current Assessment of One's Own Well-Being. Many youth described their well-being as mixed — not necessarily good or bad, but somewhere in the middle (though not necessarily neutral). They seemed to engage in a quick comparative analysis of the past and assess their current well-being based on that; or they considered their current circumstances (e.g., homelessness) and decided that they are doing fairly well all things considered.

This comparative analysis seemed to reflect the salient standard of comparison required for assessment of one's subjective well-being (Diener, 2009). Considering this during the analysis stage after interviews had been completed raised the question of what, 
exactly, was the standard of comparison for each of these youth as they assessed their well-being? Relatedly, should subjective well-being assessments ask participants about their thought processes and what they are making their comparison against? Or is this comparison even a fully conscious process that a participant could readily answer, or would thinking about it more consciously change their answers?

The standard of comparison seems important given the circumstances that youth are facing and the potential consequences of different standards of comparison. Given the tendency towards positivity and optimism in this population (e.g., Bender et al., 2007; Usborne et al., 2009), it is unsurprising that youth reported moderate to good well-being and seemed to use a standard of comparison that made them feel better about where they are right now. This was apparent in youth's responses, such as "It definitely could be worse -- it has been worse" (K17), or "I think I'm pretty okay for being homeless" (K04). Using a standard of comparison that makes them feel better in the present moment could be a way to cope - to not get too disheartened about their current circumstances and to continue striving towards a better life. If they were to use a standard of comparison that is 'better' than their current circumstances (e.g., if they were housed prior to the pandemic), that would likely have a negative impact on their well-being, which in turn could affect the level of energy and motivation they have to continue working towards their goals, which is covered later in the discussion.

Defining Well-Being. In defining what well-being means to them, many youth discussed having their basic needs met as well as other aspects of their well-being, such as mental or physical health or personal growth. Given that even the participants who 
were housed or sheltered still struggled to meet all of their basic needs, it makes sense that basic needs fulfillment was a point of focus for them and a major component of their well-being. Many explained that they would be better able to strive towards their goals if they had their well-being increased through more stability in their basic needs.

Perhaps youth's basic needs were more salient at this time because of the pandemic and large societal shifts that have occurred in this city since March of 2020. Beyond the 'normal' level of instability a youth experiencing homelessness might face, there has been increasing uncertainty and unrest in society, and their access to resources has been drastically limited due to changes brought on by the pandemic. Before March of 2020 , youth may not have been able to buy their own food or have an indoor place to sleep, but they may have been able to consistently rely on service centers for food, an indoor space to be, medical services, and other needs. The drastic changes that youth faced due to the pandemic may have created a heightened focus on their basic needs, as they have struggled to have those needs consistently and reliably met.

However, some youth explicitly discussed setting aside their basic needs to work on other components of their well-being, and others alluded to a more back-and-forth process of focusing on different needs or components of well-being at different times. Most youth described focusing equally on both their basic needs and other components of their well-being (e.g., mental health, personal growth, social relationships) over time. These descriptions from youth are in line with prior research (e.g., Tay and Diener, 2011) demonstrating that while there are universal needs for well-being among humans, the order in which we attend to these needs varies considerably. 
All of the ways that youth defined their well-being aligned with different aspects of different theories of well-being, including both the satisfaction with life theories of well-being (e.g., Diener, Emmons, Larsen, \& Griffin, 1985) and the self-actualization and social theories of well-being (e.g., Ryff \& Keyes, 1995). While some theories of wellbeing are more holistic in their attempts to capture emotional, psychological, and social well-being (e.g., Keyes 2005, 2007), none of the current theories align perfectly with the results of the current investigation. The Future Directions section discusses this further.

While some youth struggled to define what well-being means to them, all youth were able to describe how their well-being interacts with or is impacted by other experiences. This suggests that youth have a general feeling or intuition about what wellbeing is, even if they are not able to readily define it for themselves.

\section{Community Experiences \& Social Supports}

Participants overwhelmingly described that their community experiences and social supports benefit their well-being, and youth's definitions of well-being directly reflected the themes of how their community supports impact their well-being. For example, the emotional or mental health support that youth received from their community supports directly impacts the mindset or mental state component of how they defined well-being. Similarly, the resources or practical support theme from community supports directly impacts the physical health and basic needs component of well-being. Finally, the personal growth and fulfillment definition of well-being is directly reflected in how community experiences in youth's lives helped support their well-being through creating a sense of growth or purpose. While this seems straightforward, it shows that 
even youth who struggled to define their well-being were able to discuss how community experiences and social supports impact their well-being, and that across the participants there was consistency in how youth described these phenomena in their daily lives. Further, many of these themes were intertwined, with friends and/or social services providing youth with basic needs (e.g., food, resources), emotional support and motivation during difficult times, creative outlets, and opportunities for growth and learning.

Within youth's descriptions of their community experiences and social supports, and how these factors influence their well-being, youth described elements of the Sense of Community theory (McMillan \& Chavis, 1986; Sarason, 1974), including membership, influence, integration and fulfillment of needs, and shared emotional connection. These four elements of Sense of Community theory were present in statements such as: (1) "We're all in the same boat together out here, all of us being homeless" (K11), reflecting the membership dimension; (2) "Being a part of [the SMYRC community] I've actually been able to help them grow as well' (K01), influence dimension; (3) "I know I'm going to get help from these people because they genuinely care. That's what draws me back" (K10), integration and fulfillment of needs dimension; and (4) “[Being a part of this community] makes me realize I'm not the only person who sees these things, other people have come to the same conclusions I have, they see the same things that are wrong with our world" (K05), reflecting the shared emotional connection dimension. 
Considering that these elements of sense of community are reflected in youth's responses about the community experiences and social supports that influence their wellbeing, these results support prior research suggesting that sense of community positively impacts the well-being of youth experiencing homelessness (Stewart \& Townley, 2020a), and has generally positive associations with well-being among broader populations as well (Stewart \& Townley, 2020b).

Disengagement from Community. Some youth described a high degree of selfimposed independence and an overall disengagement from community. Some youth described social interactions as harmful to some degree, which is aligned with prior research demonstrating this perspective among some youth experiencing homelessness (Stewart \& Townley, 2020a) and other marginalized populations (e.g., Brodsky, 1996).

Other youth didn't necessarily state that harmful social interactions were the reason for their disengagement but described other experiences that led them to disengage. These experiences were typically negative, such as the death of a friend, a fear of interacting with others in a negative way, or not wanting to rely on other people. With the latter two examples, the participants did not elaborate on what experience(s), exactly, led them to this disengagement from community. However, the notion of not wanting to rely on others has come up in prior research with youth experiencing homelessness (e.g., Kidd, 2003).

Varying levels of engagement or disengagement from community experiences and social supports seemed to have both positive and negative impacts on youth's wellbeing. On the one hand, youth were able to avoid experiences that they did not want to 
have (e.g., negative interactions with others or disappointment with social relationships) by keeping their social circles small or avoiding relationships with others in their community, which supported their well-being through preventing potentially painful or harmful experiences. On the other hand, if this disengagement is taken to an extreme level, youth may not be able to access needed services or have social supports to rely on during times of difficult, which has a negative impact on well-being. Overall, most youth seemed to find a balance or level of engagement with community and social circles that optimized their well-being.

Goals

At the time of the current study, no known prior research had been conducted on the goals of youth experiencing homelessness. All of the participants in the current study easily described their personal short- and long-term goals. Youth's discussions of their goals revolved around housing, employment, job training, income, education, artistic endeavors, or working on their physical and mental health, and also included specific tasks that would support them in accomplishing other goals. Many of the participants' short-term goals were achievements that would eventually support their long-term goals. For example, several youth discussed the importance of stability in housing and/or income as a way to support their other long-term goals, such as school, their relationships, or their artistic pursuits.

The relationships between youth's community and social supports, well-being, and goals were highly intertwined. For example, the community supports in youth's lives directly impacted their goal striving: youth discussed how these supports provided them 
with resources and opportunities that directly made it possible or easier to achieve their goals (e.g., job training that would affect their employment goals). Similarly, these community supports also directly impacted youth's well-being in positive ways. For example, youth described how service centers or social relationships provided them with mental health support or friendships that supported their well-being. Further, youth described how their well-being impacts their ability to strive towards their goals, with a greater sense of well-being having a positive impact on their energy and motivation to work on their goals. In all, some youth described how their community supports would sometimes impact their goal striving directly, but that their community supports could also impact their goal striving through their well-being, with the positive impact of community supports on their well-being helping them continue to strive towards their goals.

Overall, the discussion of youth's goals and how their community experiences and social supports impact those goals (whether directly or through well-being) demonstrated how essential those community and social supports are to youth's daily lives and, potentially, their long-term outcomes. In discussing their short- and long-term goals, participants listed numerous ways that their loved ones, friends, and service centers are supporting them in their goals. Further, many youth alluded to the fact that many of these goals would not be possible — or would, at least, be much more difficult to achieve and likely take much more time - were it not for the service centers and other supports that they draw upon. This study expanded prior literature about youth experiencing 
homelessness by examining how their goals relate to their community experiences and well-being.

\section{COVID-19 Pandemic}

Participants reported that the COVID-19 pandemic impacted them both directly and indirectly, and in primarily negative ways. Many youth reported stress, fear, and anxiety related to the pandemic, which took a direct toll on their well-being. Indirectly, youth reported that the pandemic negatively impacted their access to services and resources and their ability to rely on community and social supports, both of which negatively impacted their well-being. The impacts of the pandemic also hindered and delayed youth's progress in reaching their goals, primarily by taking away opportunities and access to resources, but also through its negative impact on their well-being.

Despite these difficult impacts of the pandemic, many youth also expressed a level of optimism and resilience. Numerous participants described how the beginning of the pandemic was very difficult: they experienced major emotional and lifestyle upheavals (including the loss of employment), and they had to learn how to navigate a drastically altered and minimized resource system. However, by the time of the interviews (eight months after the pandemic began), most of the youth interviewed described being in at least a slightly better mental state — that the beginning of the pandemic was difficult, but they were doing better now. Further, other negative impacts of the pandemic were beginning to show improvement for some youth: some had regained employment, found housing, or were more recently able to access service centers again. Nevertheless, most of the interviews had an energy or attitude of "I'm 
doing my best, given the circumstances," reflecting the resilience noted in other research with this population (e.g., Kidd \& Davidson, 2007).

Interestingly, several youth explained that their well-being is better because of the pandemic: that it brought about opportunities for housing or employment, or that they were able to focus more on their internal worlds or themselves, which improved their well-being. This could be the case for many reasons. For example, the global pandemic forced governments and communities to create safe spaces for people experiencing homelessness to sleep and be, including designated areas for tents or alternative shelters and camps, some of which were staffed and structured with oversight from local government (Levinson, 2020). This is how one of the participants was able to acquire shelter and temporary employment. Similarly, several youth were able to get into a shelter or transitional housing because of governmental changes made to due to the pandemic, and simply having a small space - like a bed - to rest and be alone gave them the opportunity to focus inward, process, and heal, and thus improved their well-being.

While the social isolation of the pandemic was hard on many youth, there is also the consideration that many youth often do not feel safe enough to be fully alone and/or do not even have the opportunity or space for alone time because they do not have a safe place to be or to rest. While many people may think of shelter as a place to sleep and be that is outside of the elements, that line of thinking only considers the physical needs of a person. The current research demonstrates that youth are focused on much more than their physical needs, and that in order to maintain a sense of well-being, youth need opportunities and resources that allow them to simultaneously focus on other areas of 
their well-being - such as the sense of safety and alone time that allows them to rest, process, think, and be at peace.

It took the pressures of a global pandemic for the government to invest in the urgent needs of those experiencing homelessness - needs that were present long before the pandemic started, but that of course were heightened during the time of the pandemic. While some resources for youth experiencing homelessness were taken away during the pandemic, other resources and opportunities were added. Ideally, going forward, no resources are removed and the government and communities can understand the everpresent urgency of the variety of needs that we all have, including those experiencing homelessness, and work to address those needs in a more holistic way.

\section{Researcher Reflexivity}

\section{Working with Youth Experiencing Homelessness}

Having engaged with this population and this particular service center over multiple research projects, I was encouraged to reflect on my degree of "expertise" throughout this current research process - including my perceptions of the youth and how the interviews contained so much more than was captured on the recordings or in transcripts.

Some of the participants expressed optimism about their lives, while others seemed depressed or lacking hope and simply trying to survive each day. I do think that the variety of experiences I witnessed in the interviews is probably more reflective of the reality of the population than is captured in some of my prior work or other research with this population: some youth are connected, socially active, have high levels of support, 
and are actively working on goals; others are isolated, withdrawn, deep in depression or trauma, and seem to be coasting or hopeless.

The service center I worked with typically draws a certain kind of youth into their space: those who want to work on themselves, engage in activities, and be social. Their limited services and minimal activity offerings during the pandemic (i.e., mainly providing food and help with practical logistics like acquiring ID cards and jobs) has also limited who was accessing and attending the service center. There were certainly many of the same youth who attended prior to the pandemic, but not as many, and thus there was more of a balance between the regular attendees and those who came primarily for food and other basic needs resources.

In the interviews, the youth who attended the service center regularly prior to the pandemic talked more generally about the things they loved about the place, the people, the activities, etc. I think if I was doing these interviews at p:ear under normal (i.e., nonpandemic) circumstances, I might have ended up recruiting a larger proportion of youth who were more regularly engaged with p:ear, and fewer youth who went to p:ear primarily for food or basic needs. In some ways, this made conducting the interviews during the pandemic a helpful comparison to previous studies I have done with p:ear, and I believe I achieved a better balance and more accurate representation of the diversity of homeless youth's experiences rather than only those who regularly visit this one particular organization.

Another consideration for working with youth experiencing homelessness is the variety of ways they might engage with an in-depth interview. Youth experiencing 
homelessness have been described as distrusting of people they don't know (e.g., Pederson, Tucker, \& Kovalchik, 2016), which may cause them to withhold information or prevent them from sharing information that makes them feel vulnerable in an interview with a stranger. In the interviews, some youth were unwilling to discuss certain topics or would not elaborate on a response when I pulled for more information.

Further, even with multiple follow-up questions, most of the youth would quickly reply that they had nothing else to say on the topic. For the most part, youth seemed open to the topics and shared their responses readily, but even the youth who were fully engaged and spoke in more detail about the interview topics would state that they didn't want to discuss certain topics or had nothing further to say on a given topic. While 30 minutes for an in-depth interview may seem short, much of that time was spent with the youth talking and responding to the questions. There are numerous lengthy monologues in each interview transcript that provide nuanced and in-depth details about certain topics or questions; thus, the relatively short duration of each interview was not as much of a concern given the richness of information each provided.

\section{Reflections on Conducting In-Person Interviews During a Pandemic}

While many components of this research endeavor did not go as planned and were altered due to the ongoing pandemic, I gained many insights from this experience that directly apply to the challenges of conducting research in dynamic community settings. Most notably, I had to practice an incredible amount of patience and flexibility. Although my research had been approved, and I was planning to begin recruitment in late March 2020, I had to wait six months to gain approval from the university to conduct in-person 
interviews. Given my prior experience with this population, I knew that trying to conduct interviews over phone or video conferencing would both limit who I was able to interview and also create a different dynamic that might lead to less rich data. This meant that some aspects of the research had to be changed, both to incorporate the salient context of the pandemic but also to ensure everyone's health and safety. I was also under pressure to complete the interviews within a short period of time because the service center I was conducting them at was not sure how long they would be able to continue their operations, and the university might require a cessation of in-person research activities at any time. Youth were also concerned about the length of the interviews given the service center's limited operations and rules pertaining to how long youth could remain inside at any given time.

The social interaction with staff and youth at the service center, and throughout the in-depth interviews, felt intense after being relatively non-social for so long during the pandemic. It took several days of being around new people and talking with them for me to feel like it was normal again.

A lot of youths' traumas and difficulties came up in the interviews, and this was also emotionally taxing to take on. In many ways, this is an inherent part of the process that I expect and felt fully equipped to hold space for (witnessing, Stein \& Mankowski, 2004). What I didn't expect was for my own emotional difficulties and traumas to come to the surface at the same time. The nine months prior to data collection were very difficult for me on a personal level. I felt that I handled these life difficulties and stressors in stride and got through them all just fine. However, some of the lingering emotional 
effects of those experiences began to show themselves during the time period I was conducting the interviews. Further, interviewing youth about their experiences with the pandemic brought to mind some of my own difficult experiences. I found myself extremely depleted after each day of interviews and had to take a full day to re-group before I was able to continue any work, which was unexpected.

On the last day of interviews, I decided to end data collection early because I was feeling emotionally depleted. I didn't want to continue with interviews if I was not able to be fully present and engaged with youth. I also felt comfortable with the amount and variety of data I had collected, and I felt the need to go ahead and end the interviews and engage in self-care. While the impacts of the pandemic on me are minimal compared to many other groups, the impacts are still felt, are still stressful, and have still affected many aspects of my life. My tendency in difficult situations is to "power through" and do whatever I need to do, regardless of my current mental, emotional, spiritual, or physical well-being. In hindsight, I needed more time and space to take care of myself: I needed to do fewer interviews each day, to space them out more, and to take more time to debrief and process what was coming up for me throughout the research process, including during and after data collection.

I believe that I was a present and passionate as I could be as a witness (Laub, 1992) and that I took the stance of impassioned listener and human being (Stein \& Mankowski, 2004) throughout the interview process. However, I do think that more ideal circumstances or data collection timelines are possible that would have prevented the eventual emotional depletion I experienced. These more ideal circumstances or timelines 
would have allowed me to be more present and more capable of holding space for the experiences of my participants and my own emotional involvement in the research process and their lives.

\section{Limitations}

In addition to the reflections and challenges described in detail above, it is necessary to note a few additional limitations of this study. First, I originally intended to conduct both longer interviews with youth and also follow-up focus groups to consult with youth about my interpretations of the findings. Due to constraints on the service center and the youth who were visiting the service center, as well as concerns about the research being delayed or stopped due to COVID, the interviews were slightly shorter than anticipated. While all of the planned topics were covered in the interviews, some youth expressed hesitation before the interviews about how long they would take, and several stated that they would have spoken in more detail if they had more time than they did. In the future, I would aim to be more selective in recruitment in order to ensure that the youth who choose to participate are willing and able to spend the time and energy needed to fully respond to the questions I am asking.

Second, the range of experiences related to homelessness were quite varied among the small sample: some youth were in housing programs or shelters, while others were living out of their cars or in tents; the length of time and number of times youth were homeless varied from one day to over a decade; and youth's level of engagement with service centers and social networks also varied from minimal use to a high level of engagement. However, the sample was quite small, and only youth ages 18 and older 
were able to be interviewed. Thus, the perspectives of youth who are under 18 are missing, which limits our understanding of their well-being, community supports, goals, and experiences during the COVID-19 pandemic.

Furthermore, the youth who participated in this study were self-selected visitors of a local youth service center. In the interviews, these participants emphasized how much they like and appreciate this particular service center, which is probably why they choose to spend time there. However, despite informing youth that none of their answers will impact their access to services, the fact that the interviews occurred at this service center could have affected their responses. For example, youth may have been hesitant to speak poorly of the service center if they thought that staff may be able to identify them in any reports of the research. On the other hand, youth also discussed other local service centers positively, so this possible bias may not be a source of major concern.

Nevertheless, there is a chance that participants' responses might have been different had I recruited from multiple service centers.

Relatedly, there are youth experiencing homelessness who cannot or choose not to utilize service centers. Their experiences with the topics in this study may differ drastically from the youth who did participate, which should be considered carefully when interpreting the results. Other concerns about the potential limitations of where, how, and from whom data were collected are discussed in the section above on reflections about working with youth experiencing homelessness.

Finally, issues of trustworthiness, interpretation, and representation (Merrick, 1999) are always a concern in qualitative research. While I engaged in peer debriefing, 
reflexive journaling, and reporting rich quotes to help establish trustworthiness of the data, I was unable to complete other planned activities (e.g., follow-up focus groups with youth intended to be an opportunity for member checking) given the pandemic and the limitations that safety precautions put on the research.

\section{Future Directions}

Despite these limitations, the findings of the current investigation provide rich and nuanced information to service providers about how to best support the well-being and positive outcomes of the young people who walk through their doors. Findings also inform questions they may ask youth aimed at individualizing, or personalizing, the supports and resources they provide to them. For example, service centers could ask youth about their reasons for visiting the service center and how the service center might best support their specific needs or goals. More specifically related to the pandemic, the results suggest that many youth are missing important supports that they received from service centers prior to the pandemic, which likely negatively impacts their well-being. Service centers could use the findings from this study to advocate for increased philanthropic and government funding that allows them to better serve youth during the pandemic.

The findings from this study also inform future approaches to research among youth experiencing homelessness. Specifically, this research demonstrates the richness and nuance of understanding that can be gained from an in-depth conversation with a young person experiencing homelessness about their lives, and how this can inform our understandings of their needs, their well-being, their community experiences, and their 
goals - among many other things. Prior research using quantitative measures with this population could not provide the depth and nuance of qualitative research, and in many ways those quantitative measurements lacked applicability to the needs and experiences of this population. Future research with youth experiencing homelessness could focus on harnessing qualitative methods to expand our understandings of both the population and our theories of well-being, sense of community, and social support.

For example: the current research began an investigation into how youth define well-being for themselves. Future research should continue to explore this topic with more youth experiencing homelessness, testing alignment with current theories of wellbeing (e.g., Keyes, 2005, 2007) and potentially developing new theories that are more applicable to this population. Similarly, the findings in both the current study and prior research (e.g., Stewart \& Townley, 2020a; Taylor et al., 2004; Usborne, Lydon, \& Taylor, 2009) suggest certain kinds of social support may be more important to youth experiencing homelessness (e.g., peer support) than other domains of social support (e.g., familial support). Future research should investigate further how youth experiencing homelessness define and experience social support in their own lives, and then examine the extent of alignment with current theory and/or work toward development of social support theories that apply to the unique social context of this population.

Further, this research demonstrates complex interactions between youth's social supports and their well-being. Further investigation could aim to either apply or develop theories about well-being that takes such interactions into consideration. Relatedly, another approach could be to engage more deeply with each transcript as a case study 
analysis, which would help to elucidate both the bigger picture of youths' lives and the complex interactions occurring between youth's well-being and community experiences.

If quantitative measures are needed for use with this population (e.g., for longitudinal analysis demonstrating change over time), future research could utilize qualitative findings to help develop quantitative measures or mixed methods approaches to assess youth's well-being, community experiences, and social support that more accurately reflect the salient experiences of this population and their current needs. This could include adapting established measures of well-being, sense of community, or social support to more accurately reflect youth's definitions and experiences of these phenomena. It could also include creating new measures or employing mixed methods to assess these factors in this population.

For example: it is clear that youth understand their well-being quite holistically, and further that their experience of well-being is dynamic, where different well-being needs might be focused on at different times in an attempt to address all aspects of who they are as humans. Current measures of well-being (e.g., Diener et al., 1985; Keyes, 2002; Ryff \& Keyes, 1995) attempt to separate out different aspects of well-being, such as satisfaction with life, social well-being, and psychological well-being. The current research suggests, however, that researchers should look at multiple aspects of youth's lives (mental, emotional, physical, spiritual, etc.) as working together and interacting order to more thoroughly understand their well-being. 
Any new assessments utilized with youth experiencing homelessness should also consider an examination of the strengths and capacities that youth already possess as well as the areas in their lives that could benefit from additional attention or support.

Results can also inform participatory approaches to research that engage youth in collaborative program development at service centers, or that focus on strengths and capacity building among youth to bolster their tools for supporting their well-being and goal attainment. Participatory approaches and collaborative decision-making processes with youth could also inform service centers about how to direct their funding in order to provide programs and resources that will directly benefit and support youth's well-being and goal pursuits.

Further, findings may inform continued follow-up research aimed at collaborating with both youth experiencing homelessness and service providers to discover ways in which service centers might better and more directly support the well-being of youth and help them achieve their short- and long-term goals. For example, a collaborative endeavor between service centers and youth could include a participatory evaluation of how local service centers are collectively meeting youth's needs and where there are gaps in services. This would likely elucidate needs among youth that service centers might not have considered and could foster creative solutions for outreach and programming.

\section{Conclusion}

This study expanded on previous research and recommendations in the literature and suggested future directions for research based upon the findings and how they fit into the established body of literature. 
First, it built upon prior research examining the well-being of youth experiencing homelessness by asking youth to describe and define their own well-being for themselves - instead of the more common practice of having a researcher attempt to quantitatively measure youth's well-being with scales developed based on the experience of people with very different social contexts. Findings from this study indicate that youth's definitions of well-being focused on their physical health and basic needs; mindset or mental state; attitude toward self; and personal growth and fulfillment.

Second, it expanded on prior research by having youth directly and explicitly discuss how their community experiences and social supports relate to their well-being, whereas prior research made these connections with quantitative measures or researcherimposed theories and assumptions. This study also supported prior research (e.g., Stewart \& Townley, 2019, 2020a) by demonstrating the ways in which community experiences and social supports benefit the well-being of youth experiencing homelessness, and by providing concrete examples and narratives about how these community experiences and social supports directly impact the well-being of this population. Youth overwhelmingly described positive impacts of community experiences and social supports on both their well-being and goal pursuits.

However, community experiences (e.g., sense of community, social support) have generally been assumed to be a universally positive experience and to have a positive impact on well-being. These assumptions have not considered the ways in which communities and social supports can also be harmful (e.g., Brodsky, 1996) - even if they help to some extent. This study supported previous findings demonstrating varying levels 
of engagement with community and social supports among youth experiencing homelessness (e.g., Stewart \& Townley, 2019). It also expanded prior research by providing further evidence of the reasons that community and social supports might be harmful to youth. Further, it demonstrated the nuances and multiple considerations that youth make in deciding their level of engagement with community as they consider its impact on their well-being.

Third, while both well-being and community and social supports have been studied previously with youth experiencing homelessness (e.g., Barczyk, Thompson, \& Rew, 2014; Stewart \& Townley, 2019, 2020a; Usborne, Lydon, \& Taylor, 2009), this study expanded that research by tying these phenomena to youth's self-described shortand long-term goals. Much of the previous research with this population has made the assumption that youth's primary goals all revolve around not being homeless anymore. While this may indeed be a salient area of focus for youth, the study chose to remove this assumption about what youth's goals are and instead have them define their own goals, and how their community experiences, social supports, and well-being help them achieve these goals.

This study also expanded the prior research by weaving in the salient context of the COVID-19 pandemic. Participants described how the COVID-19 pandemic has negatively impacted their well-being and access to community supports. While minimal, preliminary research has been done to begin examining the impact of the pandemic on this population (e.g., Tucker et al., 2020), no research has examined how the pandemic has affected youth's well-being, community experiences, social supports, and goal 
pursuits. Hopefully, the current study is only the beginning of this area of research, as the needs of youth during this time are vast and urgent. More broadly, this research can help contribute to our understanding of how to better prepare for future large-scale societal challenges, including major threats to health, and also how to better support the wellbeing of our most vulnerable populations during those times. 


\section{Supplemental Material for Chapter IV: Semi-Structured Interview Questions}

1. Can you tell me a bit about yourself and what you've been up to today?

2. Next I'm going to ask you a bit of background and demographic information:

a. What is your age?

b. How do you identify your gender?

c. How do you identify your sexual orientation?

d. What is your racial background?

3. Can you please describe to me a bit about your trajectory of homelessness?

a. When were you first homeless?

b. How many times have you experienced homelessness?

c. How long have you been homeless?

d. How long have you been engaged with services like p:ear?

Now I'm going to ask you some questions about your well-being, your community experiences, your experiences at youth service centers, and your goals. These will be the main part of the interview. Please elaborate on each question as much as you feel comfortable -- we appreciate as much detail as you're willing to provide.

4. How do you describe your well-being?

a. What do you include in the idea of 'well-being' for yourself?

b. Can you provide examples of what this looks like in your daily life?

5. What kinds of community experiences or social supports do you benefit from regularly?

a. Do these include programs / services offered by different organizations?

b. Do these include your peers or other supportive people in your life?

c. Can you provide examples of what this looks like in your daily life?

6. What community experiences and social supports - such as service center offerings or social networks - impact your well-being on a day-to-day basis?

a. Can you describe how those supports impact your well-being?

b. Does this impact (on well-being) affect other parts of your life? How so?

c. What other community settings do you engage with frequently? What do you like about them? How do they support your well-being? 
d. What drew you to these communities or social supports, and what keeps you connected to them?

7. How has the COVID-19 pandemic impacted your community experiences and social supports?

8. How has the COVID-19 pandemic impacted your well-being?

9. What are some of your short-term goals? What are some of your long-term goals?

a. How might the community supports in your life impact your ability to achieve these goals you are striving toward?

b. How might an increased sense of well-being impact your ability to achieve these goals?

c. How might the organizations and service centers available to you better support your well-being so that you can continue to strive toward these goals?

d. How has the COVID-19 pandemic impacted your progress towards your goals?

[If youth describe being disengaged from community and social supports...]

10. What experiences did you have that encouraged you to disengage?

a. How did those experiences impact your well-being?

b. How would you describe your level of involvement or connection, if any?

c. Are you connected to other communities or social supports that provide you with a sense of well-being or help you in your daily life?

d. How has disengagement from community either supported or inhibited your ability to achieve the goals you have for yourself?

11. How has the COVID-19 pandemic impacted your engagement with the community?

Is there anything else that you would like to talk about that we didn't cover? 


\section{References}

Altheide, D. L., \& Johnson, J. M. (1994). Criteria for assessing interpretive validity in qualitative research. In N. K. Denzin \& Y. S. Lincoln (Eds.), Handbook of Qualitative Research (2nd ed., pp. 485-499). Newbury Park, CA: Sage.

Bender, K., Thompson, S. J., Mcmanus, H., Lantry, J., \& Flynn, P. M. (2007). Capacity for survival: Exploring strengths of homeless street youth. Child Youth Care Forum, 36(1), 25-42. https://doi.org/10.1007/s10566-006-9029-4

Brodsky, A. E. (1996). Resilient single mothers in risky neighborhoods: Negative psychological sense of community. Journal of Community Psychology, 24(4), 347363. https://doi.org/10.1002/(SICI)1520-6629(199610)24:4<347::AIDJCOP5>3.0.CO;2-R

Brodsky, A., \& Marx, C. (2001). Layers of identity: Multiple psychological sense of community within a community setting. Journal of Community Psychology, 29(2), $161-178$.

Bronfenbrenner, U. (1994). Ecological models of human development. In M.

Gauvain \& M. Cole (Eds.), Readings on the Development of Children. (2nd ed., Vol. 3, pp. 37-43). Oxford: Elsevier. https://doi.org/http://www.psy.cmu.edu/ siegler/35bronfebrenner94.pdf

Busen, N. H., \& Engebretson, J. C. (2008). Facilitating risk reduction among homeless and street-involved youth. Journal of American Academic Nursing Practice, 20, $567-575$. 
Cochran, B. N., Stewart, A. J., Ginzler, J. A., \& Cauce, A. M. (2002). Challenges faced by homeless sexual minorities: Comparison of gay, lesbian, bisexual, and transgender homeless adolescents with their heterosexual counterparts. American Journal of Public Health, 92(5), 73-777. doi:10.2105/ajph.92.5.773

Daniel, J. N. (2011). Sampling Essentials. Thousand Oaks, CA: Sage.

DeLyser, D., Herbert, S., Aitken, S., Crang, M., \& McDowell, L. (Eds.). (2010). The SAGE Handbook of Qualitative Geography. London: SAGE.

Diener, E., Emmons, R. A., Larsen, R. J., \& Griffin, S. (1985). The satisfaction with life scale. Journal of Personality Assessment, 49, 71-75.

Dumka, L. E., Gonzales, N. A., Wood, J. L., \& Formoso, D. (1998). Using qualitative methods to develop contextually relevant measures and preventive interventions: An illustration. American Journal of Community Psychology, 26, 605-638.

Ferguson, K. M., Kim, M. A., \& McCoy, S. (2011). Enhancing empowerment and leadership among homeless youth in agency and community settings: A grounded theory approach. Child and Adolescent Social Work Journal, 28(1), 1-22. https://doi.org/10.1007/s10560-010-0217-6

Grabbe, L., Nguy, S. T., \& Higgins, M. K. (2012). Spirituality Development for Homeless Youth: A Mindfulness Meditation Feasibility Pilot. Journal of Child and Family Studies, 21(6), 925-937. https://doi.org/10.1007/s10826-011-9552-2

Haleem, A., Javaid, M., \& Vaishya, R. (2020). Effects of COVID-19 pandemic in daily life. Current Medicine Research and Practice, 10(2), 78-79. https://doi.org/10.1016/j.cmrp.2020.03.011 
Hesse-Biber, S. N. (2017). The Practice of Qualitative Research: Engaging Students in the Research Process. (Third). Thousand Oaks, California: Sage Publications, Inc.

Hughes, D., \& DuMont, K. (1993). Using focus groups to facilitate culturally anchored research. American Journal of Community Psychology, 21(6), 775-806.

Johns, G. (2006). The essential impact of context on organizational behavior. Academy of Management Review, 31(2), 386-408. https://doi.org/10.1007/s10551-008-9983-x

Kelly, J. G., \& Hess, R. E. (Eds.). (1986). The ecology of prevention: Illustrating mental health consultation [Special issue]. Prevention in Human Services, 4 (no. 3/4).

Keyes, C. (2002). The mental health continuum: From languishing to flourishing in life. Journal of Health and Social Behavior, 43(2), 207-222.

Keyes, C. L. (2005). Mental illness and/or mental health? Investigating axioms of the complete state model of health. Journal of Consulting and Clinical Psychology, 73(3), 539.

Keyes, C. L. (2007). Promoting and protecting mental health as flourishing: A complementary strategy for improving national mental health. American Psychologist, 62(2), 95.

Kidd, S. A. (2003). Street youth: coping and intervention. Child and Adolescent Social Work Journal, 235-261.

Kidd, S. (2012). Invited Commentary: Seeking a Coherent Strategy in our Response to Homeless and Street-Involved Youth: A Historical Review and Suggested Future Directions. Journal of Youth and Adolescence, 41, 533-543.

https://doi.org/10.1007/s10964-012-9743-1 
Kidd, S. A., \& Carroll, M. R. (2007). Coping and suicidality among homeless youth. Journal of Adolescence, 30(2), 283-296. https://doi.org/10.1016/j.adolescence.2006.03.002

Kidd, S. A., \& Davidson, L. (2007). "You have to adapt because you have no other choice": The stories of strength and resilience of 208 homeless youth in New York City and Toronto. Journal of Community Psychology, 35(2), 219-238. https://doi.org/10.1002/jcop.20144

Kidd, S. A., \& Davidson, L. (2009). Homeless youth: The need to link research and policy. In J. D. Hulchanski, P. Campsie, S. Chau, S. W. Hwang, \& E. Paradis (Ed.), Finding Home: Policy Options for Addressing Homelessness in Canada (pp. 1-9). Toronto, ON: Cities Centre, University of Toronto.

Kidd, S., \& Shahar, G. (2008). Resilience in homeless youth: the key role of self-esteem. The American Journal of Orthopsychiatry, 78(2), 163-172. https://doi.org/10.1037/0002-9432.78.2.163

Kidder, L. H., \& Fine, M. (1997). Qualitative inquiry in psychology: A radical tradition. In D. Fox \& I. Prilleltensky (Eds.), Critical Psychology: An Introduction (pp. 34 50). Thousand Oaks, CA: Sage.

Laub, D. (1992). An Event Without a Witness: Truth, Testimony and Survival. New York: Routledge.

Levinson, J. (April 10, 2020). Portland to open 3 temporary emergency outdoor shelters. $O P B$. Retrieved from https://www.opb.org/news/article/portland-oregoncoronavirus-covid-19-temporary-emergency-outdoor-shelters/ 
Lincoln, Y. S., \& Guba, E. G. (1985). Designing a Naturalistic Inquiry. In Naturalistic Inquiry (pp. 221-249). Newbury Park, CA: Sage.

Lindsey, E. W., Kurtz, P. D., Jarvis, S., Williams, N.R., \& Nackerud, L. (2000) How runaway and homeless youth navigate troubled waters: Personal strengths and resources. Child and Adolescent Social Work Journal, 17(2), 115-141.

Mallett, S., Rosenthal, D., \& Keys, D. (2005). Young people, drug use and family conflict: Pathways into homelessness. Journal of Adolescence, 28, 185-199. https://doi.org/10.1016/j.adolescence.2005.02.002

Mann, S. A., \& Kelley, L. R. (1997). Standing at the crossroads of modernist thought. Gender \& Society, 11(4), 391-408.

Maton, K. I. (1993). A bridge between cultures: Linked ethnographic-empirical methodology for culture anchored research. American Journal of Community Psychology, 21, 747- 771. McMillan, D. W., \& Chavis, D. M. (1986). Sense of community: A definition and theory. Journal of Community Psychology, 14(1), 6-23.

Merrick, E. (1999). An Exploration of Quality in Qualitative Research: Are "Reliability" and "Validity" Relevant? In The Philosophical (pp. 25-36).

Multnomah County. (2015). 2015 Point-In-Time Report. Retrieved from: https://multco.us/housing-and-homelessness/2015-point-time-report Multnomah County. (2019). 2019 Point-In-Time Report. Retrieved from: https://multco.us/file/82568/download

O'Connell, J. J. (2004). Dying in the shadows: the challenge of providing health care for 
homeless people. Canadian Medical Association Journal, 170, 1251-1252.

Oppel, R. A. Jr, Gabeloff, R., Lai, K. K. R., Wright, W., \& Smith, M. (July 5, 2020). The fullest look yet at the racial inequality of coronavirus. New York Times. Retrieved from https://www.nytimes.com/interactive/2020/07/05/ us/coronavirus-latinosafrican-americans-cdc-data.html

Outside the Frame. (2019). About us. Retrieved from: http://otfpdx.org/ p:ear. (2018). Our philosophy. Retrieved from: https://www.pearmentor.org/about/ Parks, R.W., Stevens, R.J., \& Spence, S.A. (2007). A systematic review of cognition in homeless children and adolescents. Journal of the Royal Society of Medicine, 100, 46-50. Pedersen, E. R., Tucker, J. S., \& Kovalchik, S. A. (2016). Facilitators and Barriers of Drop-In Center Use Among Homeless Youth. Journal of Adolescent Health, 59(2), 144-153. https://doi.org/10.1016/j.jadohealth.2016.03.035

Robertson, M. J., \& Toro, P. A. (1999). Homeless youth: research, intervention, and policy. In L. B. Fosburg, \& D. B. Dennis (Eds.), Practical Lessons: The 1998 National Symposium on Homelessness Research. Washington, DC: U.S. Department of Housing and Urban Development (pp.1-32).

Ryff, C. D., \& Keyes, C. L. M. (1995). The structure of psychological well-being revisited. Journal of Personality and Social Psychology, 69(4), 719-727.

Salomonsen-Sautel, S., Van Leeuwen, J. M., Gilroy, C., Boyle, S., Malberg, D., \& Hopfer, C. (2008). Correlates of substance use among homeless youths in eight 
WELL-BEING AMONG YOUTH EXPERIENCING HOMELESSNESS

cities. American Journal on Addictions, 17(3), 224-234.

doi:10.1080/10550490802019964

Sarason, S. B. (1974). The Psychological Sense of Community: Prospects for a Community Psychology. San Francisco: Jossey-Bass.

Senn, C. Y. (2005). You can change the world-Action, participatory, and activist research. In Applied Social Psychology: Understanding and Addressing Social Problems (pp. 355-373).

Slesnick, N., \& Prestopnik, J. (2005). Dual and multiple diagnosis among substance using runaway youth. The American Journal of Drug and Alcohol Abuse, 31(1), 179-201. doi:10.1081/ADA-200047916

Smollar, J. (1999). Homeless youth in the United States: Description and development issues. New Directions for Child and Adolescent Development, 85, 47-58.

Stein, C. H., \& Mankowski, E. S. (2004). Asking, Witnessing, Interpreting, Knowing : Conducting Qualitative Research in Community Psychology. American Journal of Community Psychology, 33, 21-35.

Stewart, K., \& Townley, G. (2019). Intrapersonal and social-contextual factors related to the psychological well-being of youth experiencing homelessness. Journal of Community Psychology, 47(4), 772-789.

Stewart, K., \& Townley, G. (2020a). Community and well-being: a qualitative study of how youth experiencing homelessness define community and its relations to their well-being. Journal of Community Psychology, 48(3), 994-1009. 
Stewart, K., \& Townley, G. (2020b). How far have we come? An integrative review of the current literature on sense of community and well-being. American Journal of Community Psychology, 66(1-2), 166-189.

Strauss, A., \& Corbin, J. (1990). Basics of qualitative research. Newbury Park, CA: Sage.

Tay, L., \& Diener, E. (2011). Needs and subjective well-being around the world. Journal of Personality and Social Psychology, 101(2), 354-356.

Taylor, D. M., Lydon, J. E., Bougie, É., \& Johannsen, K. (2004). “Street Kids”: Towards an Understanding of their Motivational Context. Canadian Journal of Behavioural Science, 36(1), 1-16.

Townley, G., Pearson, L., Lehrwyn, J. M., Prophet, N. T., \& Trauernicht, M. (2016). Utilizing participatory mapping and GIS to examine the activity spaces of homeless youth. American Journal of Community Psychology, 404-414. https://doi.org/10.1002/ajcp.12060

Townley, G., Stewart, K., Greene, J., \& Petteni, M. (2020). Housing and Food Insecurity at Portland State University. Portland State University.

Trickett, E. J. (1984). Toward a distinctive community psychology: An ecological metaphor for the conduct of community research and the nature of training. American Journal of Community Psychology, 12, 261-279.

Trickett, E. J. (1996). A future for community psychology: The contexts of diversity and the diversity of contexts. American Journal of Community Psychology, 24, 209234. 
Trickett, E. J., Kelly, J. G., \& Vincent, T. A. (1985). The spirit of ecological inquiry in community research. In E. C. Susskind \& D. C. Klein (Eds.), Community Research: Methods, Paradigms, and Applications. New York: Praeger.

Trickett, E. J., \& Mitchell, R. E. (1991). An ecological metaphor for research and intervention in community psychology. In M. S. Gibbs, J. R. Lachenmeyer, \& J. Sigal (Eds.), Community Psychology: Theoretical and Empirical Approaches. New York: Gardner Press.

Tucker, J. S., D'Amico, E. J., Pedersen, E. R., Garvey, R., Rodriguez, A., \& Klein, D. J. (2020). Behavioral health and service usage during the COVID-19 pandemic among emerging adults currently or recently experiencing homelessness. Journal of Adolescent Health, 67(4), 603-605.

United States Interagency Council on Homelessness. (2018). Oregon Homelessness Statistics. Retrieved from: https://www.usich.gov/homelessness-statistics/or/ Usborne, E., Lydon, J. E., \& Taylor, D. M. (2009). Goals and social relationships: Windows into the motivation and well-being of "street kids." Journal of Applied Social Psychology, 39, 1057-1082.

Wrate, R. \& McLoughlin, P. (1997). Feeling bad: The troubled lives and health of single young homeless people in Edinburgh. Primary Care Services, Lothian Health, Edinburgh.

Zapata M.A., Liu, J., Everett, L., Hulseman, P., Potiowsky, T., \& Willingham, E. (2019). Governance, Costs, and Revenue Raising to Address and Prevent Homelessness in the Portland Tri-County Region. Portland State University. 


\section{Chapter V: Conclusion}

While the many risk factors that youth experiencing homelessness face can have numerous negative consequences for their lives, research has demonstrated resilience and protective factors among this population that support their chances of achieving positive outcomes. Practitioners and researchers alike have come to understand that solving youth homelessness requires a holistic approach and comprehensive interventions that go beyond addressing youth's day-to-day basic needs (Kidd, 2012). Many service organizations and researchers recognize the importance of supporting the well-being of youth in tandem with meeting more basic physical needs such as food and healthcare (e.g., Kidd \& Davidson, 2007; Outside the Frame, 2019; p:ear, 2019; Stewart \& Townley, 2019; Townley et al., 2016). However, prior research on well-being among homeless youth reported inconsistent findings (Taylor et al., 2004; Townley, Pearson, Lehrwyn, Prophet, \& Trauernicht, 2016), while understandings of how other experiences (e.g., social support, sense of community) impact youth's well-being were minimal (e.g., Taylor et al., 2004; Usborne, Lydon, \& Taylor, 2009).

The current body of research aimed to explore and develop a foundational understanding of the well-being and community experiences of youth experiencing homelessness. Taken together, these studies demonstrate that community experiences and social supports are an important contributor to the well-being of this population, but that other factors also impact their well-being-including unexpected societal changes, such as the policies and practices implemented to mitigate the spread of the COVID-19 
pandemic and how this impacted youth's access to services and changed their interactions with others in their social networks.

\section{Summary of Dissertation Studies}

\section{Study One}

Study One found that youth with greater levels of optimism, self-esteem, sense of community, social support, and empowerment, and lower levels of psychiatric distress, had greater levels of psychological well-being, while only self-esteem and psychological distress were significant predictors of psychological well-being when all six factors were considered. This confirmed prior exploratory research suggesting all of these factors as important to the well-being of youth experiencing homelessness.

Further, the finding that self-esteem and psychological distress were the strongest predictors of well-being among this population brought up questions surrounding the potential interactions between the factors as well as the limitations of quantitative measurement. For example, self-esteem, psychological distress, and psychological wellbeing are all intrapersonal variables that have some conceptual overlap, which is reflected in their measurement, and thus could explain their close statistical relationships.

Moreover, it could be that other unmeasured social-contextual factors influence the selfesteem or psychological distress of youth experiencing homelessness, which then impacts their well-being.

Thus, Study One suggested further research exploring the interpersonal factors (such as sense of community and social support) that support youth while homeless. A focus on interpersonal factors was suggested because focusing on intrapersonal factors 
(such as self-esteem) could wrongly place the full responsibility for well-being on the individual while ignoring the social context and ecological system (e.g., Kelly, 1966) that also influences their well-being. By studying interpersonal factors, researchers can better understand the context(s) that influences youth's well-being. This interpersonal focus can also help to build a foundation of research that can inform interventions and programs that support youth's well-being through changes to the social context, rather than only focusing on changes to the youth themselves.

A limitation of Study One was its underlying assumption that the ways in which researchers have defined and understood the phenomena being examined match the ways in which youth experience those phenomena. This assumption was challenged and addressed through the research questions asked and methodologies used in Studies Two and Three.

\section{Study Two}

Study Two presented the qualitative component of a mixed-methods study exploring what community means to youth experiencing homelessness and how it is important to them. The purpose of this was to explore why community might be important to youth and how it relates to their day-to-day well-being. Results demonstrated that youth experiencing homelessness define community in terms of: (1) commonality, (2) membership-acceptance, (3) social support, and (4) collaboration, reflecting the four dimensions of the primary theoretical framework for sense of community (McMillan \& Chavis, 1986). Results also demonstrated the ways in which youth draw upon their communities and community experiences for support while 
homeless, as well as counter-examples alluding to the notion that community is not always a supportive or positive experience for these youth.

Study Two also expanded the prior research by helping researchers understand how youth define community and why it is important to them, including how it impacts their day-to-day well-being. These results supported and expanded upon findings from Study 1 that community experiences (such as sense of community and social support) are important to youth's well-being, while also reflecting findings from previous research (e.g., Brodsky, 1996) suggesting that community is not always beneficial to well-being of every individual.

This study addressed a major limitation of Study One by removing the researcherimposed assumptions about how youth understand and define their community experiences. Similar to Study One, however, this study imposed theories and frameworks of well-being onto the day-to-day experiences that youth described, thus inherently assuming that youth define and experience well-being in the ways it has traditionally been defined in psychological research. Thus, limitations of Study Two suggested the need for further research that more explicitly engages youth in defining their well-being and describing their community experiences and social supports in order to remove (at least some) of the researcher's assumptions and instead seek to understand how youth experience these phenomena for themselves.

\section{Study Three}

Directly expanding on the research and recommendations from the first two studies, Study Three explicitly asked youth to define their well-being and describe how 
their community experiences and social supports impact their well-being. This helped to address the assumptions made in the first two studies by directly asking youth to connect these phenomena and describe how they experience interconnections between them in their daily lives, rather than leaving this entirely up to the researcher in the analysis and interpretation stage.

This study also engaged youth in a discussion of how these well-being and community supports relate to their goal pursuits as a way of understanding the impacts on youth's daily lives and eventual outcomes. Given the difficulty of conducting longitudinal studies with this population (Kidd, 2012), there is little research on the actual outcomes of youth experiencing homelessness, and none on how the factors focused on in this research (e.g., community experiences, well-being) impact those outcomes. Because of this gap in the literature, many researchers make assumptions about how certain factors or experiences might impact youth's outcomes, and they also make assumptions about what outcomes are important to youth, which is often limited to the outcome of no longer being homeless. A longitudinal study was not possible with the current research. However, instead of assuming what youth may desire for their own lives, the current research chose to instead ask youth about their own goals. Further, instead of connecting these goals to their experiences of social support and well-being after-the-fact, the research explicitly asked participants to describe those connections in the interviews. Thus, the current research removed several of the assumptions of prior research and expanded our current body of knowledge by having youth connect their experiences of 
community, social support, and well-being to their own goal pursuits as a proxy for understanding how these phenomena might impact youth's outcomes.

Finally, given the context of the COVID-19 pandemic, this study explored how the pandemic — and its direct and indirect impacts — affected youth's well-being, community experiences, and goal pursuits. This was an important topic to bring into the research given its salience in our country at this time and given the ways that it has impacted people in all facets of society, particularly those who are most vulnerable due to race, age, and socioeconomic status. Understanding the impacts of the pandemic on our most vulnerable populations is critical to better serving their needs during these profoundly difficult times.

Findings from this study indicate that youth's definitions of well-being clustered into the following themes: physical health and basic needs; mindset or mental state; attitude toward self; and personal growth and fulfillment. Further, youth overwhelmingly described positive impacts of community experiences and social supports on both their well-being and goal pursuits, as well as how their well-being impacts their goals pursuits. Participants described that these community experiences and social supports benefited their well-being through: emotional or mental health support; resources or practical support; and creating a sense of growth or purpose. These themes are reflective of the themes that emerged from youth's definitions of well-being (physical health and basic needs, mindset or mental state, attitudes towards themselves, and personal growth and fulfillment), with youth describing how those community experiences and/or social supports benefitted each of those parts of their well-being. 
However, some youth also described disengagement from community experiences, which supports counter-examples from prior research (e.g., Stewart \& Townley, 2020). The narratives from these youth reflected not wanting to rely on others and wanting to be independent. However, when this idea was probed by the researcher, some youth revealed or alluded to painful experiences that led them to distance themselves from others out of a fear of being hurt by or hurting those around them. While the number of youth who described themselves as hyper-independent was minimal, several youth described keeping their social circle small and/or only relying on one service center. These youth also described concerns and hesitations around how they might be treated by others, how others might perceive them, and a general notion of not having the energy to cope with having too many people in their lives.

Even with these different levels of engagement in community, all of the youth described how the community experiences and social supports in their lives positively impacted their goal pursuits, both directly and indirectly, through the impact on their well-being. Finally, participants explored how the COVID-19 pandemic impacted their well-being and access to community supports in a primarily negative way. Within these discussions, however, youth demonstrated high levels of resilience and adaptation, which has been demonstrated in prior research with this population (e.g., Kidd \& Davidson, 2007).

\section{Contributions to the Literature}

Overall, this series of research studies both supports and expands the existing literature on the well-being, community experiences, and social supports of youth 
experiencing homelessness. First, all three studies support prior findings suggesting that youth's communities and social supports are beneficial to their lives and well-being. Studies 2 and 3, however, also support previous research demonstrating that community experiences are not always beneficial to the well-being of marginalized populations.

Further, these studies expand the research literature by demonstrating that youth's community experiences and supports help them strive to attain their goals, both directly and through their positive impact on youth's well-being. While further research on youth's long-term outcomes is needed, this research suggests potential for harnessing the impacts of community and social supports in the lives of youth to help promote their health, wellness, and other outcomes - including their eventual transition out of homelessness or other outcomes they may desire.

More specifically, Study One helped to confirm that intrapersonal and socialcontextual factors which have been commonly examined among members of the general population were also significantly related to the well-being of youth experiencing homelessness. This study provided a foundation for future research examining how to support the well-being of youth experiencing homelessness, including ways that programs or activities intended to boost self-esteem may impact their well-being. Study One also has important implications for related areas of research (e.g., self-esteem, resilience, social support) and supports the needs for further exploration of the interactions between these factors among youth experiencing homelessness.

Study Two contributed to the research literature by exploring how youth define their community experiences and the impact of those experiences on their daily lives. 
While the results of prior research pointed to the importance of community experiences in the lives of youth experiencing homelessness, no prior qualitative research had directly addressed this topic with youth, nor had research asked youth to define what community means to them and describe the role it plays in their lives. This study found that youth define community very similarly to established theories (namely, sense of community theory), but that there are important differences that should be considered when studying community experiences among this population. This study also expanded the literature by connecting youth's definitions of community to their daily lived experiences and served as a foundation for research examining how community experiences directly impact youth's well-being.

The third study in this series expanded this area of research in multiple ways. First, it built upon prior research examining the well-being of youth experiencing homelessness by asking youth to describe and define their own well-being for themselves - instead of the more common practice of having a researcher attempt to quantitatively measure youth's well-being with scales developed based on the experience of people with very different social contexts.

Second, it expanded on prior research by having youth directly and explicitly discuss how their community experiences and social supports relate to their well-being, whereas prior research made these connections with quantitative measures or researcherimposed theories and assumptions. This study also supported prior research by demonstrating the ways in which community experiences and social supports benefit the well-being of youth experiencing homelessness, and by providing concrete examples and 
narratives about how these community experiences and social supports directly impact the well-being of this population.

Relatedly, community experiences (e.g., sense of community, social support) have generally been assumed to be a universally positive experience and to have a positive impact on well-being. However, these assumptions have not considered the ways in which communities and social supports can also be harmful - even if they help to some extent. This study supported previous findings demonstrating varying levels of engagement with community and social supports among youth experiencing homelessness. It also expanded prior research by providing further evidence of the reasons that community and social supports might be harmful to youth. Further, it demonstrated the nuances and multiple considerations that youth make in deciding their level of engagement with community as they consider its impact on their well-being.

Third, while both well-being and community and social supports have been studied previously with youth experiencing homelessness, this study expanded that research by tying these phenomena to youth's self-described short- and long-term goals. Much of the previous research with this population has made the assumption that youth's primary goals all revolve around not being homeless anymore. While this may indeed be a salient area of focus for youth, the study chose to remove this assumption about what youth's goals are and instead have them define their own goals, and how their community experiences, social supports, and well-being help them achieve these goals.

Study Three also expanded the prior research by weaving in the salient context of the COVID-19 pandemic. While minimal, preliminary research has been done to begin 
examining the impact of the pandemic on this population, no research has examined how the pandemic has affected youth's well-being, community experiences, social supports, and goal pursuits. Ideally the current study is only the beginning of this area of research, as the needs of youth during this time are vast and urgent. More broadly, this research can help contribute to our understanding of how to better prepare for future large-scale societal challenges, including major threats to health, and also how to better support the well-being of our most vulnerable populations during those times.

\section{Future Directions}

The knowledge gained from this research can inform both the broader research community and also service centers about the components of well-being that are most important to youth, the community and social factors that support their well-being, and the ways in which unexpected social changes impact their community experiences, wellbeing, and goals. The lessons learned from this program of research can help researchers and service providers develop and tailor programs and interventions that better serve the needs of this population.

For example: the final study found that the COVID-19 pandemic drastically altered youth's access to needed resources at service centers, which negatively impacted youth's well-being and hindered their goal pursuits. Researchers and service centers should continue exploring how the pandemic has impacted youth, what their immediate and long-term needs are related to the pandemic and the impacts it has had on them, and how service centers and others systems can better support youth both during and after the pandemic. Researchers and service providers should also critically examine the needs of 
youth and the capacity of service centers to serve them and develop contingency plans both for the ongoing pandemic and in preparation for major societal challenges in the future.

More broadly, the present investigation illustrates that youth may understand and define their community experiences, social supports, and well-being somewhat differently from how researchers or other populations define and experience these phenomena. Researchers should consider how to more accurately assess these factors within this population such that related research and interventions can be more precisely implemented and better serve the needs of youth experiencing homelessness. This could include the development of new quantitative measures or mixed methods approaches to examining these phenomena based on the ways that youth define and experience them.

For example, if youth's definitions of well-being emphasize having their basic needs met, then well-being measures with this population should include items related to youth's basic needs. Similarly, if a large part of their community experiences and social support is engagement with service centers, then measures of sense of community and social support should include the experiences that youth have with service centers. Alternatively, separate measures could be developed to assess youth's level of engagement with service centers and how they utilize those programs and offerings, as well as how that utilization (or lack thereof) impacts their well-being and goal pursuits. This would allow researchers and service centers to assess these phenomena with a broader sample and would lay the foundation for expanding or altering services and interventions accordingly. 
Further, the current research demonstrates that community experiences and social supports are, generally, beneficial to the well-being and goal pursuits of youth experiencing homelessness. However, both studies two and three present counterexamples to this general trend. The notion that community might be harmful or neutral to the well-being of youth should be explored further so that youth are not harmed through interventions that aim to bolster well-being through community or social supports that may actually be detrimental to youth. Ideally, and reflecting the above suggestions for measure development, researchers can find ways to more accurately assess all of these factors among this population — including whether youth view community and social supports as helpful or harmful — and tailor interventions and programs accordingly.

In conclusion, the current research presents a foundation from which to expand research aimed at understanding the well-being of youth experiencing homelessness, which can then inform programs and interventions that aim to support the well-being of this population. Despite the many hardships faced by these youth, they continually demonstrate resilience and a desire to move forward with their lives; and it is imperative that researchers, service providers, and communities find the best possible ways to support youth in doing so. 


\section{References}

Kelly, J. G. (1966). Ecological constraints on mental health services. American Psychologist, 21, 535-539.

Kidd, S. (2012). Invited Commentary: Seeking a Coherent Strategy in our Response to Homeless and Street-Involved Youth: A Historical Review and Suggested Future Directions. Journal of Youth and Adolescence, 41, 533-543. https://doi.org/10.1007/s10964-012-9743-1

Kidd, S. A., \& Davidson, L. (2007). "You have to adapt because you have no other choice": The stories of strength and resilience of 208 homeless youth in New York City and Toronto. Journal of Community Psychology, 35(2), 219-238. https://doi.org/10.1002/jcop.20144

McMillan, D. W., \& Chavis, D. M. (1986). Sense of community: A definition and theory. Journal of Community Psychology, 14(1), 6-23.

Outside the Frame. (2019). About us. Retrieved from: http://otfpdx.org/ p:ear. (2018). Our philosophy. Retrieved from: https://www.pearmentor.org/about/

Stewart, K., \& Townley, G. (2019). Intrapersonal and social-contextual factors related to the psychological well-being of youth experiencing homelessness. Journal of Community Psychology, 47(4), 772-789.

Stewart, K., \& Townley, G. (2020a). Community and well-being: a qualitative study of how youth experiencing homelessness define community and its relations to their well-being. Journal of Community Psychology, 48(3), 994-1009. 
Taylor, D. M., Lydon, J. E., Bougie, É., \& Johannesen, K. (2004). "Street Kids": Towards an Understanding of Their Motivational Context. Canadian Journal of Behavioural Science, 36, 1-16. http://dx.doi.org/10.1037/h0087211

Townley, G., Pearson, L., Lehrwyn, J. M., Prophet, N. T., \& Trauernicht, M. (2016). Using participatory mapping and GIS to examine the activity spaces of homeless youth. American Journal of Community Psychology, 57, 404-414. doi:

10.1002/ajcp. 12060

Usborne, E., Lydon, J. E., \& Taylor, D. M. (2009). Goals and social relationships: Windows into the motivation and well-being of "street kids." Journal of Applied Social Psychology, 39, 1057-1082. doi: 10.1111/j.1559-1816.2009.00472.x 